\title{
AN INVESTIGATION OF NAVIGATION PROCESSES IN HUMAN LOCOMOTOR BEHAVIOR
}

\author{
by \\ Christi J. Adams \\ Thesis submitted to the Faculty of the \\ Virginia Polytechnic Institute and State University \\ in partial fulfillment of the requirements of the degree of \\ MASTER OF SCIENCE \\ in \\ Industrial and Systems Engineering
}

APPROVED:

R. J. Beaton, Chairman
A. M. Prestrude
T. A. Dingus

Keywords: Locomotion, Visually Moderated Behavior, Navigation 


\title{
AN INVESTIGATION OF NAVIGATION PROCESSES \\ IN HUMAN LOCOMOTOR BEHAVIOR
}

\author{
by \\ Christi J. Adams \\ Committee Chairman: Robert J. Beaton \\ Industrial and Systems Engineering
}

\section{(ABSTRACT)}

For humans, walking is the principle means of locomotion, or moving from one point to another. While upright locomotion is a human characteristic, the way humans direct their locomotion has not been studied extensively. Prior to the late 1940's, little research or scholarly thought was published regarding locomotion. In 1950, J. J. Gibson published one of the first texts on visual perception, which included theories and research on how humans interpret and react to a world of movement, even as they move within that world. Published research on the topic has been sporadic since then, especially when compared to the volume of work on eye-hand coordination and other eyebrain perception issues. Very little work has been documented on humans moving in a "real world" setting, not laboratory settings or under very specific timing requirements.

This study begins by proposing a heuristic framework of human navigation, a description of how humans move from point to point, navigating over and across navigation hazards in the walking path. The heuristic model provides an engineering perspective for the safe design of pedestrian areas, allowing sufficient area for visual recognition of hazards. 
Two observational studies were performed, one with four different navigation hazards humans come in contact with and the other one with two different hazards that humans pass without contacting. These two classes of hazards involve different perceptual principles. The studies examined the effects of ambient lighting available affected the time required for high attention, fine navigation when approaching a navigation hazard. Specific comparisons between types of navigation hazards were not contemplated, since the perceptual and motor requirements varied considerably among the hazards.

Low ambient light levels, representing twilight and night conditions, increase the amount of time required for fine navigation. Analysis of variance (ANOVA) showed a statistically significant difference in the fine navigation time to contact a navigation hazard for stairs travelling down, a $90^{\circ}$ turn in the path, and walking downhill with a step midway. ANOVA also showed a significant difference in the fine navigation time to pass a navigation hazard for two different hazards. Under all conditions, post hoc analysis showed Night lighting levels were different from Day lighting levels.

Practical applications of this research are in the facilities planning and safety design fields. The individual's locomotion speed combined with the fine navigation time required determines the distance needed for visual recognition of the hazard and preparatory locomotor changes. With extensive research, formalized guidelines and standards can be developed for the safe planning, design and redesign of pedestrian walkways. The human factors engineer could interact knowledgeably with other professional designers to assure that walking paths are designed to meet the human's requirements for safe locomotion. 


\section{ACKNOWLEDGMENTS}

I would like to thank all those who have assisted and supported me in my thesis work. I am thankful for the guidance, indulgence and encouragement of my committee members, Drs. Robert Beaton, Al Prestrude, and Tom Dingus. Your willingness to journey down a relatively obscure and underappreciated path is appreciated deeply.

Sincere thanks to Dr. Robert Beaton, who asked me "why do people trip and fall?" and thus began the journey.

Tony Benger was my prodder, pusher, and cheerleader throughout my return to the university. Thank you for believing I could succeed, even when I had serious doubts.

My deepest gratitude to friends, near and far, who patiently listened.

Special (and somewhat bewildered) thanks to Sebastian and Amy Fry, my great-grandparents, who somehow created a visually/optically aware gene pool. After a practical visual psychologist/consultant, a research visual psychologist/ optometrics professor and a practicing optometrist, I am the fourth member of the family to study a visually related field. What an unusual legacy! 


\section{TABLE OF CONTENTS}

TABLE OF CONTENTS.

LIST OF TABLES viii

LIST OF FIGURES

$\ldots \mathbf{X}$

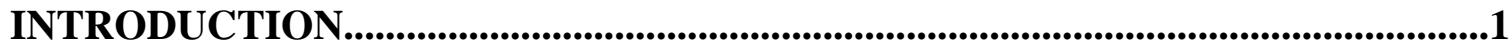

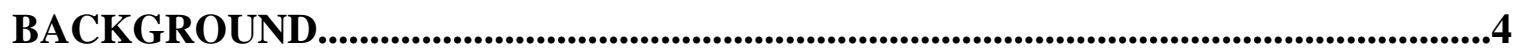

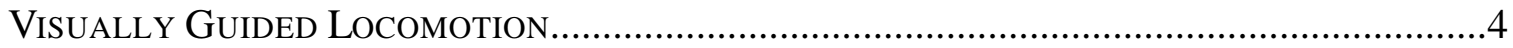

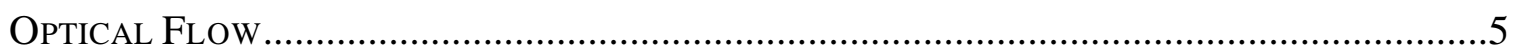

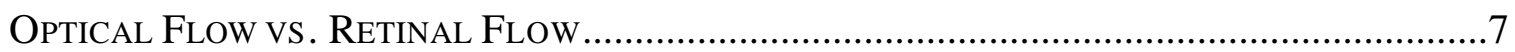

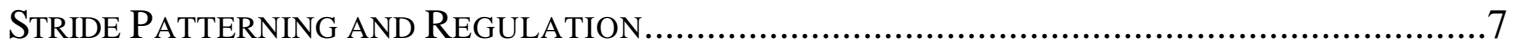

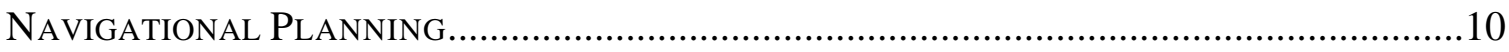

GENDER AND LOCOMOTOR BEHAVIOR....................................................................... 11

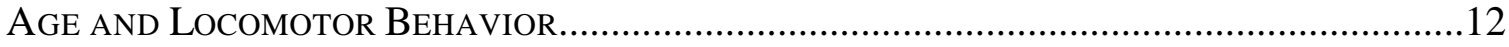

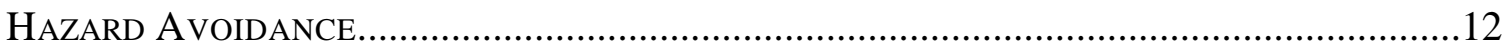

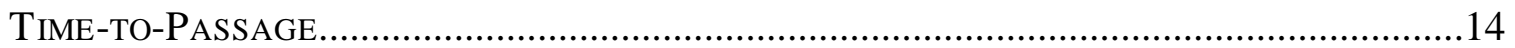

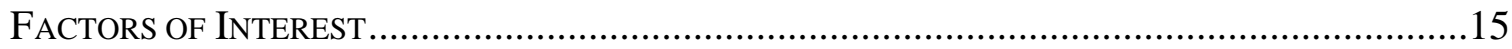

HEURISTIC OF WALKING BEHAVIOR..................................................................17

Heuristic M Odel of Human Locomotion.................................................................19

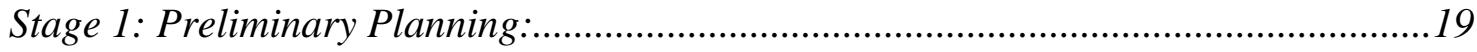

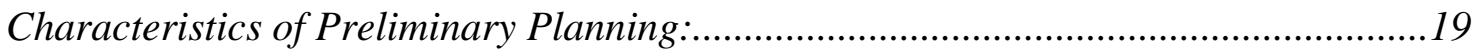

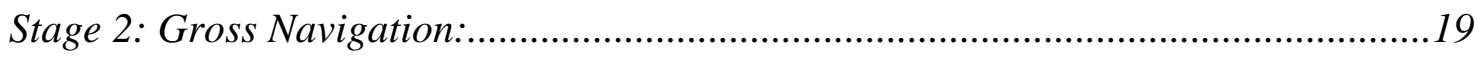

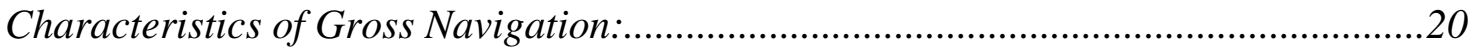

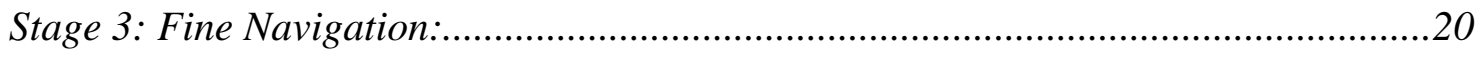

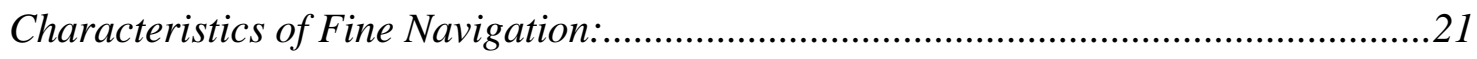


Model in Action.

SCOPE AND PURPOSE OF STUDY

METHODS. .25

DESIGN OF EXPERIMENT. .25

PARTICIPANTS .26

LOCATIONS .27

EQUIPMENT .42

Procedure - DAy AND Twilight Conditions. .44

Procedure - Night Condition .45

RESULTS. 47

ObSERVATIONAL StUdy VERSUS LABORATORY STUdy .47

Use of ONE-WAy ANOVA AnAlyses. .47

ANALYSIS. .48

Experiment 1 - Fine Navigation Time-to-Contact, TC. .49

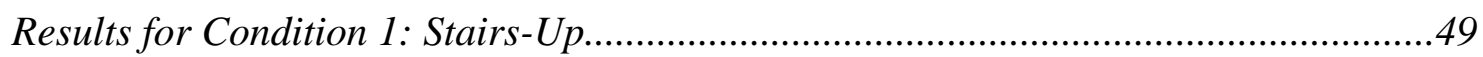

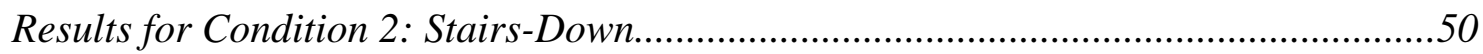

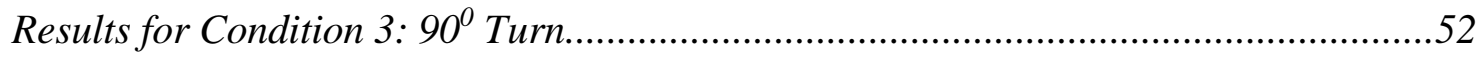

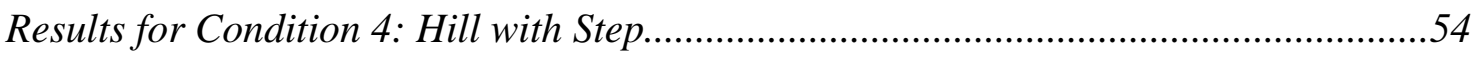

EXPERIMENT 2: Fine NAVigation Time-To-PASSAGE, TP...........................................58

Results for Condition 1: Safety Bucket Hazard........................................................58

Results for Condition 2: Road Triangle Hazard.....................................................60

ExAMINING DisPERsion of MeAns ACross Conditions ...........................................63

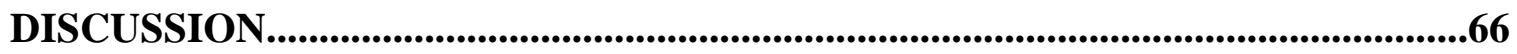

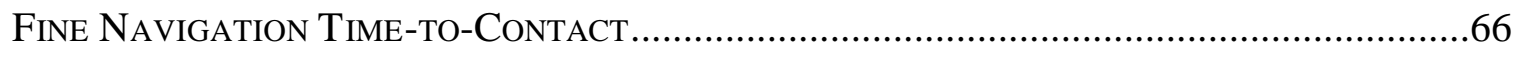

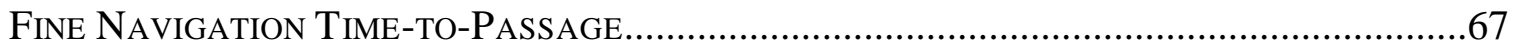

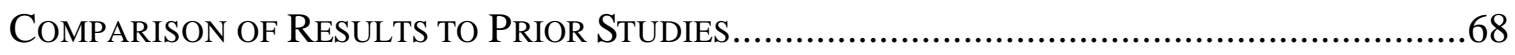


AGE-RELATED ISSUES ............................................................................................69

ENGINEERING APPLICATIONS AND GuIDELINE DeVELOPMENT...........................................69

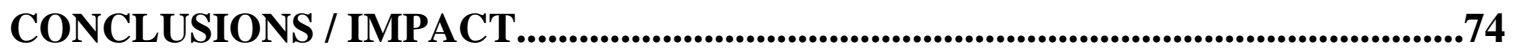

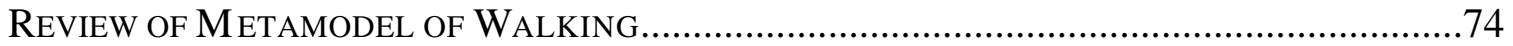

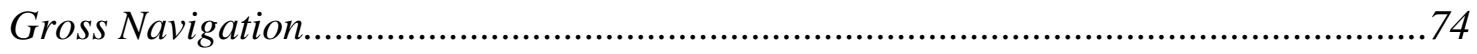

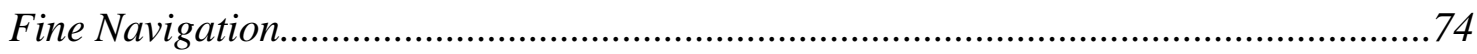

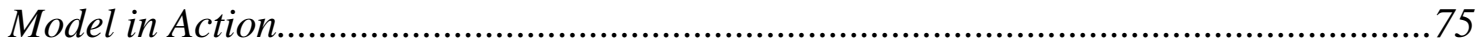

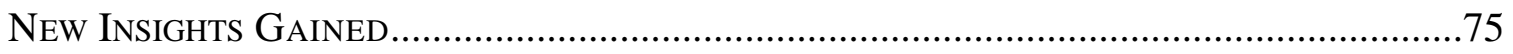

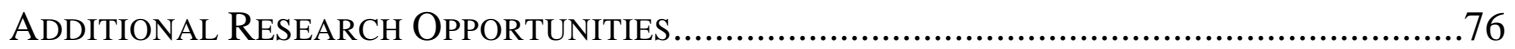

Human FACTORS ENGINEERING AND DeSIGN IMPACT .....................................................77

REFERENCES..............................................................................................................................79

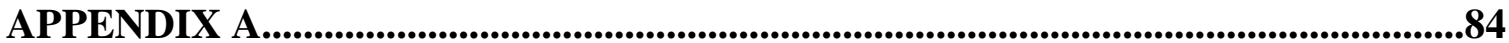

IRB APPROVAL- EXEMPTION..............................................................................................84

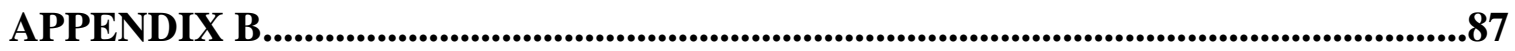

LOCATION SPECIFIC DATASHEETS.............................................................................87

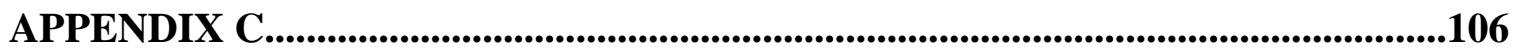

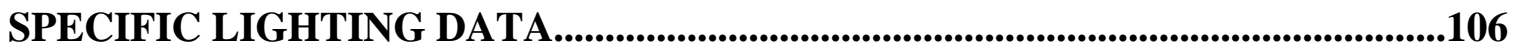

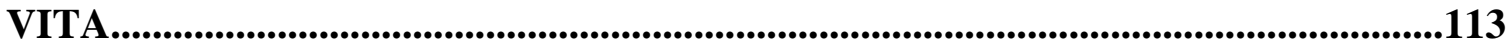




\section{LIST OF TABLES}

Table 1: ANOVA Summary Table for Fine Navigation Time-to-Contact for StairsUp Condition

Table 2: ANOVA Summary Table for Fine Navigation Time-to-Contact for StairsDown Condition.

Table 3: Newman-Keuls Results for Fine Navigation Time-to-Contact for StairsDown Condition.

Table 4: ANOVA Summary Table for Fine Navigation Time-to-Contact for 90

Degree Turn Condition.

Table 5: Newman-Keuls Results for Fine Navigation Time-to-Contact for $90^{\circ}$

Turn Condition.

Table 6: ANOVA Summary Table for Fine Navigation Time-to-Contact for Hill with Step Condition.

Table 7: Newman-Keuls Results for Fine Navigation Time-to-Contact for Hill with Step Condition.

Table 8: Basic Statistics for Experiment 1: Fine Navigation Time-to-Contact, Tc.57

Table 9: ANOVA Summary Table for Fine Navigation Time-to-Passage for

Safety Bucket Condition.

Table 10: Newman-Keuls Results for Fine Navigation Time-to-Passage for

Safety Bucket Condition.

Table 11: ANOVA Summary Table for Fine Navigation Time-to-Passage for

Road Triangle Condition

Table 12: Newman-Keuls Results for Fine Navigation Time-to-Passage for

Road Triangle Condition.

Table 13: Basic Statistics for Experiment 2: Fine Navigation Time-to-Passage,

Tp.

Table 14: Sample Design Guidelines for Safe Pedestrian Navigation of Contact

Type Hazards for a Variety of Locomotor Speeds. 
Table 15: Sample Design Guidelines for Safe Pedestrian Navigation of Passage Type Hazards for a Variety of Locomotor Speeds. 73

Table 16: Raw Data: Stairs-Up Hazard, Day Condition 88

Table 17: Raw Data: Stairs-Up Hazard, Twilight Condition 89

Table 18: Raw Data: Stairs-Up Hazard, Night Condition 90

Table 19: Raw Data: Stairs-Down Hazard, Day Condition 91

Table 20: Raw Data: Stairs-Down Hazard, Twilight Condition. 92

Table 21: Raw Data: Stairs-Down Hazard, Night Condition. 93

Table 22: Raw Data: $90^{\circ}$ Turn Hazard, Day Condition. 94

Table 23: Raw Data: $90^{\circ}$ Turn Hazard, Twilight Condition. 95

Table 24: Raw Data: $90^{\circ}$ Turn Hazard, Night Condition 96

Table 25: Raw Data: Hill with Step Hazard, Day Condition 97

Table 26: Raw Data: Hill with Step Hazard, Twilight Condition 98

Table 27: Raw Data: Hill with Step Hazard, Night Condition 99

Table 28: Raw Data: Safety Bucket Hazard, Day Condition 100

Table 29: Raw Data: Safety Bucket Hazard, Twilight Condition 101

Table 30: Raw Data: Safety Bucket Hazard, Night Condition 102

Table 31: Raw Data: Road Triangle Hazard, Day Condition 103

Table 32: Raw Data: Road Triangle Hazard, Twilight Condition 104

Table 33: Raw Data: Road Triangle Hazard, Night Condition 105

Table 34: Specific Lighting During Data Recording - Stairs-Down Location. 107

Table 35: Specific Lighting During Data Recording - Stairs-Up Location. 108

Table 36: Specific Lighting During Data Recording - 90 Turn Location 109

Table 37: Specific Lighting During Data Recording - Hill with Step Location 110

Table 38: Specific Lighting During Data Recording-Safety Bucket Condition 111

Table 39: Specific Lighting During Data Recording-Road Triangle Condition112 


\section{LIST OF FIGURES}

Figure 1: Rasche Staircase. Both Stairs-Down and Stairs-Up conditions were filmed at this location.

Figure 2: Rasche Staircase, viewed from the videocamera's location for filming the Stairs-Up condition.

Figure 3: Cowgill Plaza: $90^{\circ}$ Turn was made at the point where the staircase intersects the main plaza.

Figure 4: North Main Plaza. Hill with Step Location. Also details variance in slopes from upper to lower walkways.

Figure 5: North Main Plaza. Participants' Point of View. Note lack of contrast for detailing edge of step.

Figure 6: Snyder Lane. Safety Bucket Location. Participants' view from sidewalk; participants walking to the north-northeast.

Figure 7: Snyder Lane. Safety Bucket Location. Participants' view from sidewalk; participants walking to the west-southwest.

Figure 8: Detail of Safety Bucket Hazard.

Figure 9: Giles Street. Road Triangle Hazard Location. Participants' view of sidewalk and road triangle hazard. Camera location was the passenger seat of the car in frame.

Figure 10: Detail of Road Triangle Hazard.

Figure 11: Main Effect of Ambient Illumination on Fine Navigation Time-to-

Contact for Stairs-Up Condition. Error bars are $+/-1$ standard error of the mean.

Figure 12: Main Effect of Ambient Illumination on Fine Navigation Time-to-

Contact for Stairs-Down Condition. Error bars are +/- 1 standard error of the mean.

Figure 13: Main Effect of Ambient Illumination on Fine Navigation Time-to-

Contact for $90^{\circ}$ Turn Condition. Error bars are $+/-1$ standard error of the mean. 
Figure 14: Main Effect of Ambient Illumination on Fine Navigation Time-toContact for Hill with Step Condition. Error bars are +/- 1 standard error of the mean.

Figure 15: Main Effect of Ambient Illumination on Fine Navigation Time-to-

Passage for Safety Bucket Condition. Error bars are $+/-1$ standard error of the mean.

Figure 16: Main Effect of Ambient Illumination on Fine Navigation Time-to-

Passage for Road Triangle Condition. Error bars are +/- 1 standard error of the mean.

Figure 17: Dispersion of means across Tc conditions. Three curves in each color represent Day, Twilight, and Night Lighting conditions, respectively. 63

Figure 18: Dispersion of means across Stairs-Up and Stairs-Down conditions.

Three curves in each color represent Day, Twilight, and Night Lighting conditions, respectively.

Figure 19: Dispersion of means across Safety Bucket Hazard and Road Triangle Hazard conditions. Three curves in each color represent Day, Twilight, and Night lighting conditions, respectively. 


\section{INTRODUCTION}

For humans, walking is the principle means of locomotion, or moving from one point to another. Anthropologists consider upright locomotion to be the hallmark distinction between ancestral pre-humans and the other primate species. Even though upright locomotion is a distinct human characteristic, the way humans direct their locomotion has not been studied extensively. This fact is unusual since locomotion, and, specifically, walking, is such a large part of human life.

Prior to the late 1940's, little research or scholarly thought was published regarding locomotion. In 1950, J. J. Gibson published one of the first texts on visual perception, which included theories and research on how humans interpret and react to a world of movement, even as they move within that world. From this research, a large amount of initial work was done on analyzing eye-hand coordination of movement. No large amount of substantive work was done on eye-foot coordination, or human locomotion, until the mid1970's, when Lee (1974) led one of the first teams since the 1950's to put Gibson's theories about visual perception to work in examining locomotion. Published research on the topic has been sporadic since then, especially when compared to the volume of work on eye-hand coordination and other eyebrain perception issues. Nearly all of the research published until now has involved observing humans walking, running, or moving under laboratory conditions. This information represents a good start in understanding human locomotion, but it does not account for the "real world" situations humans face daily when moving from point to point.

It is ironic that relatively little research has been performed into understanding how humans navigate, especially since most humans walk every day. In 1993, in the United States alone, falls on the same level (as 
opposed to falls from heights) accounted for 520 fatalities and 1,374,000 emergency room visits(National Safety Council, 1996). The National Safety Council (1996) also reports that falls on the same level are the third largest cause (13.2\%) of nonfatal occupational injuries involving days away from work

Considering this evidence of what happens when there are miscues in human locomotion, why does current fall research focus principally on coefficients of friction (Cohen and Cohen, 1994; Tisserand, 1985; Strandberg and Lanshammar, 1981), perception of how "walk-on-able" a surface is (Swensen, Purswell, and Schlegel, 1992; Cohen, Templer, and Archea, 1985), or human attention span (Cohen and Cohen, 1992; Flach, 1995), when researchers do not fully comprehend how we navigate from point to point in the first place? While these topics have relevance in and of themselves, any theories generated regarding fall prevention do not necessarily take into account the "real world" way that humans navigate through an area.

Before researchers can draw defining conclusions about how to prevent falls, work needs to be performed in analyzing how humans navigate in their environment, outside of the laboratory. When a thorough examination of real world navigation is performed and combined with results from the ongoing laboratory work, new guidelines for designing and engineering the constructed environment can be developed. These principles should help reduce the likelihood of navigational miscues, thus reducing the probability of human injury from basic locomotion.

The purpose of the present research is to provide a starting point for the "real world" environmental research. This thesis begins with a review of the laboratory research into human locomotion, specifically walking and running. It is followed by a discussion of the conditions examined in those studies. An observational experiment is described in which several environmental factors 
were examined in terms of their effects on the time to engage fine motor adjustment prior to crossing a navigational hazard. 


\section{BACKGROUND}

\section{Visually Guided Locomotion}

Locomotion must be understood as a visually guided behavior. For humans, vision is the dominant sense. If a human is presented with visual cues and other sensory cues simultaneously, the human normally interprets the visual cues as correct, even if they are not. The phenomenon has been referred to as visual capture (Smyth and Wing, 1984) or visual dominance (Wickens, 1984). An example of this phenomenon is visual-tactile conflict. When an object is viewed as one shape (i.e. oval) and is felt to be another shape (i.e. round) the visual perception is favored (Smyth et al., 1984). Human locomotion, whether it is walking, running, or some other means, is visually dependent. If deprived of sight, humans drastically alter their locomotor behavior. Individuals who are blind undergo extensive training and confidence building so that they will move "normally", meaning similarly to sighted individuals.

In 1954, even before the initial publication of references to the theory of optical flow, Gibson theorized how the brain perceives movement and how the brain interprets what movement comes from an object versus movement of the body itself (Gibson, 1994). Gibson divided the perception of motion, and therefore locomotion, into three distinct, but related problems: "How do we see the motion of an object? How do we see the stability of the environment? How do we perceive ourselves as moving in a stable environment?" Questions like these are important, considering that at the same time that an individual is locomotoring through an environment, other objects also may be moving in the environment. For safe locomotion, the human must be able to distinguish selfmotion from object motion against a background. At the same time, the eyes themselves are moving within the head, which adds yet another motion to be deciphered or screened by the brain (Gibson, 1994). 


\section{Optical Flow.}

Until Lee's concerted studies began in 1980, not much research took place regarding optical flow and locomotion, even though the initial work on the principles of optical flow was reported by Gibson (1958). Before 1980, much of the study of locomotion was rooted in kinematic evaluation of the human stride, not in the cognitive functions behind stride regulation. Meanwhile, optical flow studies focused more on examining reach and grasping characteristics, not locomotion (Lee and Thomson, 1982).

When researchers began to connect the study of optical flow with the study of locomotion, and how the brain interprets what it sees when the entire body is in motion, experimental psychologists and ergonomists discovered a new direction. Researchers began to look at the "why" questions regarding human locomotion, rather than the "how" questions.

The examination of locomotion as an interactive, visual-locomotor system is relatively new. Initial studies were performed in animals and reported by Gibson in the late 1950's and early 1960's (Laurent and Thomson, 1991). Gibson (1958) initially reported on the principle of time-to-contact (Tc), the calculation within the brain of the amount of time between the present locomotor position and contact with a target. This was in opposition to other views that the brain calculates only distance to contact. Tc is critical in locomotion, since velocity and acceleration of the body are time-dependent variables.

To provide a framework for the brain's calculation of Tc, Lee proposed his $\tau$-theory of optical flow (Lee, 1974). This theory argues that locomotion is controlled through temporal resources in the brain, rather than spatial concepts. The brain analyzes images from the eye to determine how quickly an object is getting larger on the retina. This leads to an estimation of how quickly 
the body is moving toward the focus object, or vice versa. Optical flow information is represented by the variable $-\tau$. Lee argues that visual control of locomotion is naturally "prospective," or anticipatory (Lee and Thomson, 1982). The body acts upon optical flow information to make alterations in locomotion, such as stride length, braking, turning, and targeting (Lee, Lishman and Thomson, 1982; Bardy and Laurent, 1989; Bardy and Laurent, 1991; Patla, Prentice, Robinson, and Neufield, 1991).

Optical flow has such a large proportional impact on gait regulation that manipulation of the optical flow can force changes in gait. Konczak (1994) manipulated the movement of walls in a room in a manner that was independent of the locomotor speed of the subject. The subjects' selfperception of forward velocity was impacted by the movement speed of the surroundings. By changing the speed of the entire room or just the peripheral walls moving past the subject, Konczak could impose a change of walking speed on the subject.. For instance, when the walls moved backward in relation to the subject, 45 percent of subjects increased locomotor velocity, ostensibly to attempt to repeat their normal walking speed (the speed of the optical flow seen when the walls were not moving). Opposite results were seen when the optical flow moved forward (Konczak, 1994).

Bardy and Laurent (1989) show how locomotor decision making is altered as the optical flow is altered, specifically when peripheral vision is restricted. The study shows that interruption of peripheral vision in the overall optical flow has a significant effect on the Tc calculation ability of the brain. When peripheral vision is unrestricted, braking time allocated to avoid hitting a navigation hazard is less than braking time allocated for limited peripheral vision or for foveal-only vision conditions (Bardy, et al., 1989). 


\section{Optical Flow vs. Retinal Flow.}

At the present time, there is substantial debate within the experimental psychology field as to whether optical flow is the key to visually guided behavior (Kim, Turvey, and Growney, 1996) or whether retinal flow [which includes rotational information] is the key (Cutting, 1996; Cutting, Springer, Braren, and Johnson, 1992). From an engineering perspective, this is a philosophical exercise, and is not related to how the physical environment should be designed. Therefore, this background investigation will not discuss the debate in detail. From an engineering perspective, it is sufficient to understand that the human is able, somehow, to filter out the fact that the eyeballs are moving inside the head while the body is moving. The human interprets itself as a whole body, not a series of independently moving components (Gibson, 1979).

\section{Stride Patterning and Regulation.}

If given a long travel distance to a target, one would anticipate the human visual system to continually regulate locomotor patterns (such as stride length and frequency) in the most effective manner. This would require less change in gait and less overall error in targeting. However, studies by Lee, Lishman and Thomson (1982), Bardy and Laurent (1989, 1991), and Warren, Young and Lee (1986) among others show that this assumption is not valid. Overall, the human does not make targeting changes in locomotion until shortly before contact. On average, this is less than 6 strides before contact with the target (Laurent, et al., 1991).

The Lee, et al. (1982) long jump studies represent some early work in the study of gait regulation as a function of optical flow. This study examined the approach of long jumpers as they run toward the take-off board. Ideal long jump conditions are possible when the jumper strikes the $20 \mathrm{~cm}$ wide board with their toes within $2 \mathrm{~cm}$ of the front edge. This maximizes jump distance. The long jumper normally sprints 30 to $40 \mathrm{~m}$ before jumping. While the sprint aspect of the jump exhibited some consistency in stride length and cycle time, 
the jumpers all had to make corrections to their stride length in order to accurately strike the board. Lee, et al. determined, through a series of videotaped jump attempts, that the athletes exhibited a change in stride length and a rapid decrease in footfall error when they were three to four strides away from the board. This was consistent within subject trials and between subjects (Lee, et al., 1982). Lee, et al. hypothesized that the athletes switched approach patterns in those last strides from "a stereotyped stride pattern to regulating their strides...[based on a] visually perceived relationship to the board, in order to hit it" (Lee, et al., 1982). This observation suggests a change from a gross adjustment system of movement to a fine adjustment system.

In a continuation of the long jump studies, Hay (1988) examined the long jump approaches of 28 Olympic and world-class athletes (male and female) over two studies. While every jumper attempted to achieve the stereotypical long jumpers' stride pattern during the sprint phase, Hay found that all jumpers adopted a visual control strategy at an average of five strides before striking the board. While this study reported the results in terms of number of strides, there are some significant findings that help point to a temporal regulation of locomotion. First, the point at which a visual control strategy was adopted "...was apparently unrelated to the error in accuracy of striding up to that point. (Hay, 1988)" Additionally, the average distance from the board where females adopted visual control strategies was approximately 3 meters closer than the distance for males. Hay concludes that this has "...much more to do with differences in stature and speed than with differences in strategy (Hay, 1988)." While there were no specific Tc's generated as a part of this study, differences in speed and stature would induce differences in the optical flow field, which is temporal in nature.

While Warren, et al. (1986) were primarily examining the kinematics of stride adjustment in their cross country running studies, they concluded that the kinetic impulses needed for stride adjustment are regulated and modulated by 
optical flow $(\tau)$ information. They examined the elements of the stride to look for modifications. These elements are commonly described as heelstrike, stance, toe-off, and swing. Heelstrike is when the heel touches the ground. Stance is when the foot is flat on the ground, and when the propulsion forces are added to the stride (Warren, et al., 1986). Toe-off is when the toe leaves the ground. Swing is when the leg travels through the air, aligning for the next heelstrike. Their conclusion is that the runner monitors the $\tau$-gap to the next target footplant and modifies the vertical impulse of the stride so that the next step is equal in timing to that $\tau$-gap (Warren, et al., 1986). Vertical impulse is the "magnitude of the force exerted on the ground during contact, and/or the time over which the force is applied" during the stance phase (Warren, et al., 1986). Warren, et al. propose a control function equation that shows vertical impulse as a function of mass, gravity and $\tau$ : "I $=m g \Delta \tau$. (Warren, et al., 1986)."

Bardy's and Laurent's (1991) study of visual cues in locomotor positioning added a new methodology for looking at locomotor behavior. They utilized a dual task methodology to assess attention demand in walking. The study's aim was to examine the ways optical flow processing affected overall cognitive load. Their results show that reaction time to the secondary task was steady until the subject was within 1.5 seconds of the target. At that time, the secondary task reaction time became longer, indicating that locomotion was presenting a higher cognitive load on the subject (Bardy, et al., 1991). Bardy, et al. also found that there was no statistical difference in Tc when approaching a small target as opposed to a large target under single task conditions. Walking speed was relatively constant throughout the study, at $1.5 \mathrm{~m} / \mathrm{s}$, which corresponds to a moderately brisk walking pace. Tc held steady, regardless of the size of the target (Bardy, et al., 1991). Since the subjects were to touch the target with their noses, there would naturally be safety issues for the subject, as the target was at face height. With Tc holding steady regardless of the target 
size under the single task condition, there is the possibility that the study was showing a safety-related Tc.

Laurent and Thomson (1991) propose examining regulation of stride in terms of motor action units instead of distance. The principle of motor action units is used to account for individual differences in the number of strides or overall distance of locomotor regulation. A long-jump study by Hay (1988) shows that the regulation phase can vary from one to eight strides when running. Another study by Laurent (1982, as cited in Laurent, et al., 1991) showed some regulation of stride occurring within six walking strides of a target with final adjustments within three strides.

\section{Navigational Planning.}

Step length regulation is only one form of adaptation that humans make in order to navigate in the environment. In a paper that makes some general observations on visual control of locomotion, Patla (1989) refers to some navigational planning adaptations he feels are important to consider when examining locomotion. Humans will stop and select a different path that is easier to negotiate. Humans also will change direction or select a different path without stopping. They also will alter limb trajectory to clear a navigation hazard (step over or around it) without changing stride pattern (Patla, 1989). All of these strategies show that humans are adept at changing navigational strategies in the environment.

Patla, Prentice, Robinson, and Neufeld (1991) studied visual control and strategies for changing locomotor direction, showing that any walking direction change plans must be initiated prior to step initiation. Changes in direction cannot be initiated effectively once the leg has begun the step sequence. Overall, the fastest that direction can be changed is when cued during the step prior to the step where the direction change must take place. Neither the distance to be traversed in the step nor the angle (from forward) of the direction 
change is a factor in human ability to change direction. The study concludes that some level of locomotor planning must be done before motion takes place (Patla, et al., 1991).

Even though Patla, et al. found that direction change cannot be effectively changed once the leg begins the step sequence, Hollands, Marple-Horvat, Henkes, and Rowan (1995) found that a subject's gaze remained on a target until just after the foot made contact with that target. The subject's gaze moves away "...only when they were confidant that the current footfall was either just about to occur or had already occurred (Hollands, et al., 1995)." Hollands, et al. hypothesize that direct vision is required to "fine-tune" the footfall. While locomotor planning may begin before the leg motion ever takes place, the human is continually monitoring the success of the navigation through the completion of the footfall.

\section{Gender and Locomotor Behavior.}

In a number of studies of different aspects of locomotor behavior, researchers have consistently found little or no difference between the reactions of male and female subjects. Hay (1988) found "...little difference between elite male and female athletes with respect to adoption of a visual control strategy." Any differences in the actual results between male and female subjects were attributed to small sample size, rather than real differences between men and women. In an examination of Tc when approaching a vertical hazard, Wann, Edgar, and Blair (1993) found no differences between men and women in deceleration curve slopes, time, velocity at the deceleration switch point, distance from the hazard, or relative kinetic energy at the point of contact. In situations involving passing a hazard safely, as opposed to contacting a hazard, McFayden, Magnan, and Boucher (1993) found "...no differences...between males and females" in their anticipatory navigation strategies. 


\section{Age and Locomotor Behavior.}

Konczak's (1994) set of studies included a study to determine if older adults (all over 70 years old) show an increase reliance on visual information when walking as compared to younger adults. Konczak found that $92 \%$ of the subjects showed changes in step velocity; the effect was similar regardless of the age of the subject. He also found that changes in optical flow patterns do not dramatically change balance when an individual is walking, regardless of age. Therefore, older adults are not more dependent on visual information for locomotor guidance than younger adults (Konczak, 1994). As long as an individual is capable of unassisted walking at a reasonable speed, age should not be a discriminating factor in subject selection.

\section{Hazard Avoidance.}

An interesting note coordinating Tc and stride regulation is the findings of an unpublished 1987 study by Laurent quoted in Laurent and Thomson (1991). Laurent examined locomotor braking distance, braking duration, and Tc for a variety of speeds. He found that, while braking distance and duration were highly correlated with subject's speed, the Tc was independent of the speed. Laurent suggests that Tc calculation provides a very economical locomotor strategy because basing action upon Tc provides a "consistent temporal safety zone irrespective of the speed of the subject's movement" (Laurent, et al., 1991). If the human seeks a consistent safety zone, it is reasonable to expect that Tc has a direct influence on the switch between gross and fine locomotor adjustment phases. Therefore, Tc, stride length, stride regulation and switch to fine locomotor adjustment are all interrelated and are all time dependent.

If the brain is using optical flow information to continually calculate Tc as a safety margin or zone when the body is in motion, why do humans bump into things? Zohar (1978) examined human optical flow characteristics as a part of researching this question. He examined aspects of peripheral versus foveal 
optic field, as well as familiar versus unfamiliar environments. The study concluded that eye fixations are directed forward and at a vertical angle that corresponds to environmental knowledge factors, such as general familiarity with the location, lighting levels, and floor conditions. To analyze the results of the studies, Zohar developed a "bumping profile" (Zohar, 1978). The bumping profile shows the probability of bumping into objects at varying heights and on varying sides of the body under a particular visibility condition. The visibility field could be open or could be partially obstructed (e.g., walking around a curve or through a doorway). If one is moving in a familiar environment, with no detected or anticipated hazards, Zohar noted that the line of sight can be presumed to be only slightly below horizontal eye level. The bumping profiles show that the described conditions support a higher probability of bumping into something at or below hip level. If one is in an unfamiliar area, or there are unusual factors noted in a familiar environment, the visual angle is shifted downward and the bumping probability becomes higher for hazards above hip level. The probability increases most dramatically for hazards above mid-torso level (Zohar, 1978). These results indicate that the concept of a safety zone also is dependent on familiarity with the locomotion environment.

McFayden, et al. (1993) also examined locomotion around fixed hazards, and found that safe locomotion "...requires anticipation on the part of the motor control system." This study examined human walking behavior when the subjects were presented with fixed hazards at varying distances from their starting points, with the subject not having seen the layout of hazards before they began walking (laboratory experiment). McFayden, et al. hypothesize that the brain incorporates past experience with current perception of both the body's motion and the environment to prepare for future interaction with the environment. Thus, if the human sees a hazard far enough in advance, the body can take appropriate measures to avoid or safely navigate through the hazard. If sufficient time or viewing distance is not available to process all of the required information, McFayden, et al. (1993) observed "...seemingly 
unnecessary patterns during walking...extra cautious behaviour was noticeable during near hazard walking." They noted that near hazards present a decreased observation time, which led subjects to behave cautiously, as exhibited by slowed and/or erratic walking behavior. The researchers theorize that caution is exhibited because "...safety is paramount and will override any desire to minimize energy cost increases due to extra or augmented movement (McFayden, et al., 1993)."

\section{Time-to-Passage.}

Time-to-passage (Tp) is a different concept than time-to-contact, which has been discussed up until this point. In a Tc situation, the human actually comes in contact with the hazard or target presented. This differs from the Tp situation, where the human passes by the target without physically coming in contact with it. Most visual research has involved Tc situations, yet Tp situations occur in everyday navigation. Tp situations have been most prevalent in vehicular research. Only within the past decade has Tp research begun in the human locomotion realm (Kaiser and Hecht, 1995).

Cutting, et al., (1992) performed a series of experiments on human navigation. One of these experiments involved participants walking past a hazard, as opposed to touching it in some way. Their "...act of hazard avoidance..." follows the Tp concept:"...the reaction time necessary to recognize that an object is in one's path, the time necessary to adjust footfall, and the time necessary to negotiate a turn and avoid an object (Cutting, et al., 1992)." This experiment yielded a longer reaction time than for Tc type experiments. For a forward velocity of $1.9 \mathrm{~m} / \mathrm{s}$, Cutting, et al. (1992) observed a reaction time of 3.08 seconds. This is substantially longer than the common Tc's observed as less than 1.5 seconds for similar speeds (Bardy, et al., 1991; Wann, et al., 1993). 


\section{Factors of Interest.}

Some of the factors of interest used in prior studies cannot be controlled sufficiently in observational studies. The factors that can be controlled in observational studies are the amount of ambient lighting available, the navigation hazard, and the use of Tc or Tp hazards.

In the case of the internal timing factor, Tc and Tp were contemplated. However, the locomotor behaviors behind these factors are very different. It is not reasonable to compare Tc results with $\mathrm{Tp}$ results, because the way the human approaches the navigation hazard is completely different. For Tc, the individual comes directly in contact with the obstacle, reducing instantaneous forward velocity to near zero at the point of contact. For Tp, the individual adjusts angle and gait in advance of the hazard. Thus the individual walks past the hazard without ever touching it and without a change in forward velocity. The individual's navigational approach to the Tc hazard is substantially different from the Tp hazard. For this reason, Tc and Tp must be evaluated separately.

Regarding the navigation hazard type, all prior reported research, except for the long jump studies (Lee, et al., 1982; Hay, 1988), has been under controlled laboratory conditions. While the long jump studies do not have laboratory conditions, they do not represent normal, casual locomotion either. Long jumpers have very specific stride patterns that are seen only in long jump competition (Lee, et al., 1982). Because no "normal" locomotor patterns have been described, location selection is not discussed here.

For the ambient lighting available, three general lighting conditions were defined: Day, Twilight, and Night. Only for Night were there any clear, specific definitions found in the literature. The Illuminating Engineering Society (IES) defines "night" in two ways. Night occurs when "...the center of the sun's disk is six degrees below the horizon...(Kaufman and Christensen, 1984)." Darkness is defined as a condition with 5 lux or less ambient illumination (Kaufman and 
Christensen, 1972). IES has not published distinct definitions for twilight or day. 


\section{HEURISTIC OF WALKING BEHAVIOR}

Most current research on walking as a visually guided behavior has been reported in the experimental psychology and sports psychology literature. Examination of walking in human factors engineering has been directed to fall avoidance through coefficient of friction or attentional focusing. There are a few individuals who have put forth theories on the overall strategies of locomotion.

In his 1979 book on visual perception, Gibson proposed a number of "rules for the visual control of locomotion," but these are guidelines for manipulation of optical flow instead of a proposal of how humans navigate from point to point. As an example, Gibson includes rules of:

1. Standing. Keeping the feet in contact with the supporting surface.

2. Starting, Stopping, Going Back. All involve manipulation of the optical flow. Starting means making the array flow, stopping means canceling the flow, etc.

3. Steering. Shifting the center of the outflow for one area to another. Gibson (1979) continues these visual control rules for approaching, entering enclosures, keeping a safe distance, and flight. These rules are meant to demonstrate how any animal manipulates the optical flow fields, not just how humans manipulate it. None of these rules provide a framework for how the human plans the locomotor activity. One key concept that Gibson discusses is "affordances of support." Affordances are simply what the environment provides the individual for bodily support. In term of locomotion, this is the walking surface. For effective locomotion, the ideal surface should be nearly horizontal, flat, rigid enough to provide support, and sufficiently extended to provide for safe travel from point to point (Gibson, 1979). 
In his discussion of optical versus retinal flow, Cutting (1996) proposes an overall strategy for "wayfinding." He divides wayfinding into four general subtasks:

1. Plot a course through the environment.

2. On the basis of visual (and perhaps vestibular and kinesthetic information), periodically check one's success in following that course.

3. On the basis of visual information, avoid fixed and moving hazards.

4. If returning along an unfamiliar path, recognize landmarks from the reverse side, and guide oneself home accordingly (Cutting, 1996). This is perhaps the closest to a planning strategy for locomotion that has been proposed.

From a human engineering perspective, the designer should fully understands the task that will be performed in a space. This permits the designer to fit the surroundings to the human's needs. As an example, there are many human factors guidelines and principles for the layout of an office computer workstation or for the layout of an aircraft cockpit. All of these guidelines were derived with an understanding of the activity set going on in the workspace.

The same perspective needs to be applied when designing an area, indoors or out, where humans will be walking. For this reason, this work proposes a heuristic model of human locomotion. This model was derived from observing videotape of humans walking in outdoor environments, as well as personal experience. The model consists of three stages of human locomotion: preliminary planning, gross navigation, and fine navigation.

The model can be applied to goal directed type walking behavior (destination in mind) as well as to wandering type behavior (no specific destination in mind). Both types of behavior require visual moderation of 
locomotion to keep the individual safe. This is regardless of making a decision to go to a specific place well in advance, like walking from the office to the parking lot, or on the spur of the moment, like wandering through a shopping mall.

\section{Heuristic Model of Human Locomotion}

\section{Stage 1: Preliminary Planning:}

Preliminary Planning is the phase when an individual decide where they are going and what is the "best" way to get there. The "best" way is determined by many factors, like distance, available time, and others that may be personally important.

\section{Characteristics of Preliminary Planning:}

1. During stage 1, the individual determines the locomotor goal or destination.

2. Determining the "best" path takes into account known hazards and impediments (e.g., traffic intersections, dangerous areas, location relevant information (like mean, unleashed dogs).

3. Determining the "best" path also accounts for affordances of environment (what kind of environmental conditions will be encountered, like dirt paths versus paved sidewalks (Gibson, 1979)), but this is limited to initial path planning.

4. Effective Preliminary Planning is dependent on individual knowledge of existing hazards between current location and destination.

\section{Stage 2: Gross Navigation:}

Gross navigation takes place when an individual moves from one navigational landmark to another. Navigational landmarks are those waypoints that form hazards to locomotion (e.g., staircases, curbs) or indicate that 
direction must be changed (e.g., intersections). Navigational landmarks are not necessarily anticipated during the Preliminary Planning stage. As an example, sidewalk construction may not be anticipated when an individual plans the journey, but it must be handled.

\section{Characteristics of Gross Navigation:}

1. During stage 2 , the individual determines shorter range/ intermediate strategies for getting to the goal/destination.

2. Gross navigation takes into account observed gross impediments (construction, obstructions, safety issues observed during locomotion).

3. Guides you from a navigational landmark to the next landmark, where changes in locomotion are required.

4. Changes in optical flow characteristics are not necessarily noticeable to the observer. There is no observable recognition of limb movement.

5. Affordances of support (Gibson, 1979) are taken into consideration.

6. Secondary tasks are observed to have little or no effect on ability to perform gross navigation (Bardy, et al., 1991).

\section{Stage 3: Fine Navigation:}

Fine navigation takes place when an individual maneuvers around or across those hazards to navigation encountered in the environment. Fine navigation requires more attention than gross navigation, because the individual is moving through an area that has potential safety hazards or areas that, if not recognized, could lead to navigational mistakes. As examples, fine navigation is used when approaching a staircase to assure that the foot will land squarely on the first step, so that a change from horizontal walking to stairclimbing is accomplished safely. Fine navigation also is used to turn corners, assuring that the individual stays on course, so that the final destination can be reached. 


\section{Characteristics of Fine Navigation:}

1. Fine Navigation guides the individual through transitions in locomotor strategy or methodology.

2. It is more focused and requires more attention than gross navigation.

3. Observed on videotapes: most people who are with other people stop talking/minimize extraneous responses during this phase, especially if there is a change in surface height involved.

4. Fine Navigation usually is limited to areas where there are Gibson's (1979) "preventers of locomotion:...obstacles, barriers, water margins, and brinks."

5. Changes in optical flow are more important. Limb movements must be more precise in order to prevent injury. Proprioceptive responses are more in play in an observable manner.

6. Affordances of support (Gibson, 1979) are under continual reevaluation. See: characteristics 4 and 5 .

\section{Model in Action.}

In practice, the model is not a strictly throughput model. Normally, an individual would start at stage 1 and plan the path. Stage 2 is entered when walking begins. When the individual reaches the first navigational landmark, navigation strategy switches to stage 3 until the landmark is safely negotiated. Then the individual switches back to stage 2. Stages 2 and 3 can switch in rapid succession if there is a series of landmarks in close proximity. Under normal circumstances, the walker cycles between stages 2 and 3 continually until the walker reaches the destination. The walker normally is not aware of the switches in navigation strategy. If the individual encounters some unexpected major hazard or impediment, the walker may have to go back to stage 1 and evaluate the chosen path, determining a new "best" path. 
This model is a rapid response model. A navigation stage switch occurs for planned landmark contacts and unanticipated obstacle encounters. Changes in navigation stages are automatic and are responsive to unexpected circumstances. Anything less than a rapid response and navigation switch would leave the individual more vulnerable to injury than is currently seen. The heuristic model covers behavior observed over a wide variety of lighting levels and navigation hazard types. It allows for immediate response to emergency situations. If immediate response were not a part of human locomotion, unexpected hazards would be more likely to injure humans, and injury statistics would be higher than they already are. 


\section{SCOPE AND PURPOSE OF STUDY}

Visibility of hazards and navigational landmarks plays a critical role in the safe movement from a point of origin to the point of destination. Many accidents and injuries that occur while locomotoring (walking, jogging, and running) take place because the individual does not see the hazard or does not see it in time to adjust the travel path. From a safety perspective, the design of walkways, staircases, fitness trails, indoor walking paths and other places of locomotion need to afford the human as much visibility as possible, in order to detect hazards. From an engineering perspective, the design of walkways needs to maximize human safety while meeting the constraints of facility design.

In order to optimize walkway design, it is important to examine the point at which humans switch from Gross Navigation to Fine Navigation. This switch point is important because it represents the human brain's safety margin requirement for a safe transition from one phase of locomotion to another. Times should be specified instead of distances because the brain's temporal safety margin does not normally vary with approach speed (refer to the discussion of the various long jump studies for additional information, for example: Lee, et al., 1982; Hay, 1988). Once the minimum time requirements can be determined, normal approach speeds can be estimated. This is helpful when trying to optimize the safe design of walkways, especially in crowded areas or areas with limited visibility.

The study presented here consists of two experiments. The first experiment represents time-to-contact conditions with no unanticipated obstacles. The locations selected were unaltered by the experimenter, and represent the normal navigational landmarks that the individual expects on the path of choice. The second experiment represents time-to-passage conditions 
where an unanticipated hazard is present. The experimenter placed a small, highly visible obstacle on the pathway, forcing the individual to evaluate it as an unexpected navigational landmark that must be passed safely. These two experiments represent a sampling of the navigational conditions humans encounter in everyday locomotion.

The study focused on the point of transition between gross and fine navigation. Its purpose is to refine understanding of this critical switch, so that guidelines for the safe design of walkways can be developed. The study does not seek to verify the metamodel previously described in this document at this time. 


\section{METHODS}

In these experiments, participants walked along existing, outdoor walkways to their own destination. Participants were discretely video recorded as they walked. The observer did not interfere with the participant's locomotion.

\section{Design of Experiment.}

This body of research consisted of two factorial experiments. The research was divided into two experiments because two differing psychophysical principles were involved in the selected tasks: a time-to-contact task (Tc) and a time-to-passage task (Tp).

Experiment 1: Fine Navigation Time-to-Contact, Tc, was a 3 x 4 factorial, between subjects design with 15 observations per cell. Independent Variables were Lighting Condition and Navigation Hazard. Lighting Condition was a three level variable denoting general lighting conditions: "Day", "Twilight", and "Night." Since there were no specific definitions available, the experimenter had to make assumptions based primarily upon observations performed outdoors. In the evening, the sun is setting or has already crossed the horizon, and shadows are lengthening when the ambient horizontal illumination is about 100 lux. If night is defined at 5 lux or less, there should be a definite break between data collection under night conditions and data collection under twilight conditions. For that reason, a level of 10 lux was selected as the lowest lighting level under twilight conditions. In order to provide another lighting breakpoint between day and twilight, a level of 200 lux was selected. Day was defined as 200 lux or more. Horizontal illumination conditions were measured at the general location and level of the hazard, which was ground level. Specific illumination readings were taken at the time that data recording began and ended. Navigation Hazard was a four level variable denoting a navigation hazard or change in the individual's direct walking path: "Staircase - Down", "Staircase - Up", " $90^{\circ}$ Turn Required", and "Downhill with Steps." These 
hazards were selected because they represent types of frequently encountered navigation hazards in outdoors environments. The staircase and $90^{\circ}$ turn also represent conditions frequently encountered indoors. The experimental dependent measure was "Fine Navigation Time-to-Contact."

Experiment 2: Fine Navigation Time-to-Passage, Tp, was a $3 \times 2$ factorial, between subjects design with 15 observations per cell. Independent Variables were Lighting Condition and Navigation Hazard. Lighting Condition was the same as for Experiment 1. Horizontal illumination conditions were measured at the general location and level of the hazard, which was ground level. Specific illumination readings were taken at the time that data recording began and ended. Navigation Hazard was a two level variable denoting the type of navigation hazard that was placed in or alongside the walking path: "Safety Bucket" and "Road Triangle". These specific obstacles were selected because they were of sufficient height and color to be highly visible, would not be likely to injure anyone passing by, and posed simple, yet unexpected, navigation hazards that would not fully block the walkway. The heights of the Safety Bucket and the Road Triangle are both under $50 \mathrm{~cm}$. These heights fit the objects in the range of height corresponding to Zohar's (1978) region of highest probability of bumping. Zohar's bumping profile indicates objects less than $50 \mathrm{~cm}$ high present a probability of bumping of greater than 0.20 for objects presented on the left side and 0.12 for the right side. The color schemes (yellow and black stripes, orange and red reflective) are normally associated with areas where extra caution is required, thus reinforcing the idea that the individual should walk around the navigation hazard and not move it or step over it. The experimental dependent measure was "Fine Navigation Timeto-Passage."

\section{Participants.}

Because these studies utilized video images only, the image recording is considered to be surveillance work. So long as no audio was utilized, no 
participant consent was required. This is similar to newsgathering organizations' videotaping without expressed consent from the individuals passing through the camera's field of view.

A total of 270 individuals, 15 per experiment cell, was used. Participants were all adults. They exhibited no indications of inhibited locomotor ability or obvious vision defects. Gender was not recorded. Participants were all observed in Blacksburg, VA, either at locations in the town or on the campus of Virginia Polytechnic Institute and State University.

\section{Locations.}

Six locations in the town of Blacksburg and on the campus of Virginia Polytechnic Institute and State University were used to represent the six conditions outlined for the two experiments. Selection was made through discussions regarding typical types of hazards encountered. Once general types of hazards were decided, specific locations were scouted. Scouting involved looking for conformity with the hazard type desired, pedestrian traffic flow levels, and lighting available at each location, especially at night. Locations are as follows:

1. Staircase near the main entrance to Rasche Hall, used for Stairs-Up and Stairs-Down conditions for Tc experiment. Pictured in Figures 1 and 2, this location has six poured concrete stair treads, all of the same color and of the same color as the sidewalk surfaces leading to and from the staircase. The location was selected for two reasons: it has a heavy traffic pattern and there are areas immediately adjacent to the landings where the videocamera could be placed. At night, the area has pathway lighting, but the lights are not immediately near the staircase. In addition, tree and vegetation growth blocks much of the light to the area. This area consistently had illumination levels of less than 1 lux on the staircase at night. 
The staircase itself is $3.66 \mathrm{~m}$ wide, $0.66 \mathrm{~m}$ high, and $1.83 \mathrm{~m}$ deep. Rise/run ratio is $5 / 12$. In the Stairs-Down direction, view of the staircase is unobstructed from the sidewalk. There are $20.34 \mathrm{~m}$ of sidewalk leading to the staircase from the last turn in the walkway. In the Stairs-Up direction, view of the staircase is unobstructed from the sidewalk. This particular staircase is at the top of another flight of stairs that leads up a hill. At the top of the main hill stairs is a landing that forks left and right. The staircase under observation is the staircase at the right side of the fork. There is also a staircase on the left side of the fork, which was not under observation for this study. There are $12.2 \mathrm{~m}$ of sidewalk leading from the top of the main staircase, around a slight curve and to the bottom of the observed staircase. 


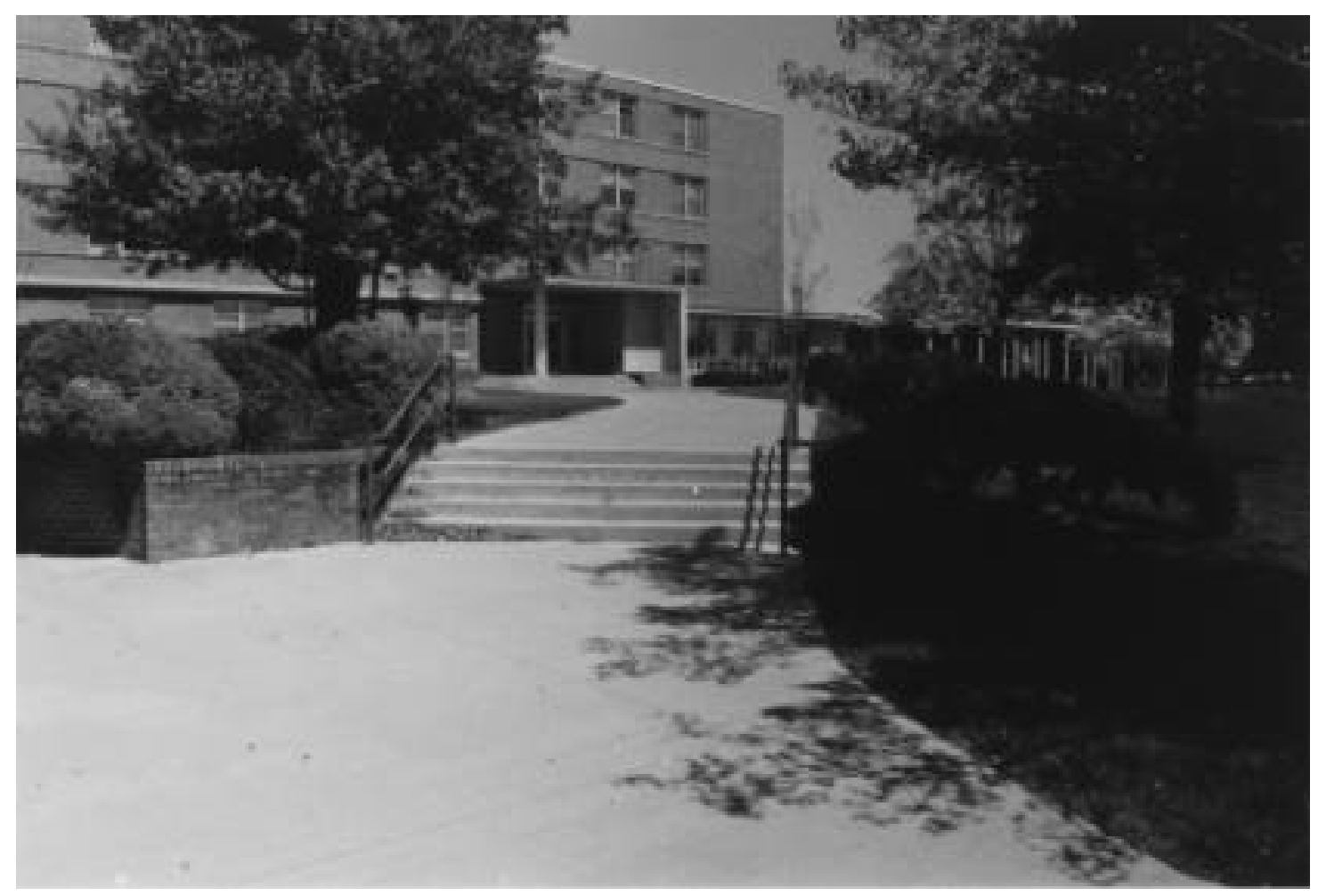

Figure 1: Rasche Staircase. Both Stairs-Down and Stairs-Up conditions were filmed at this location. 


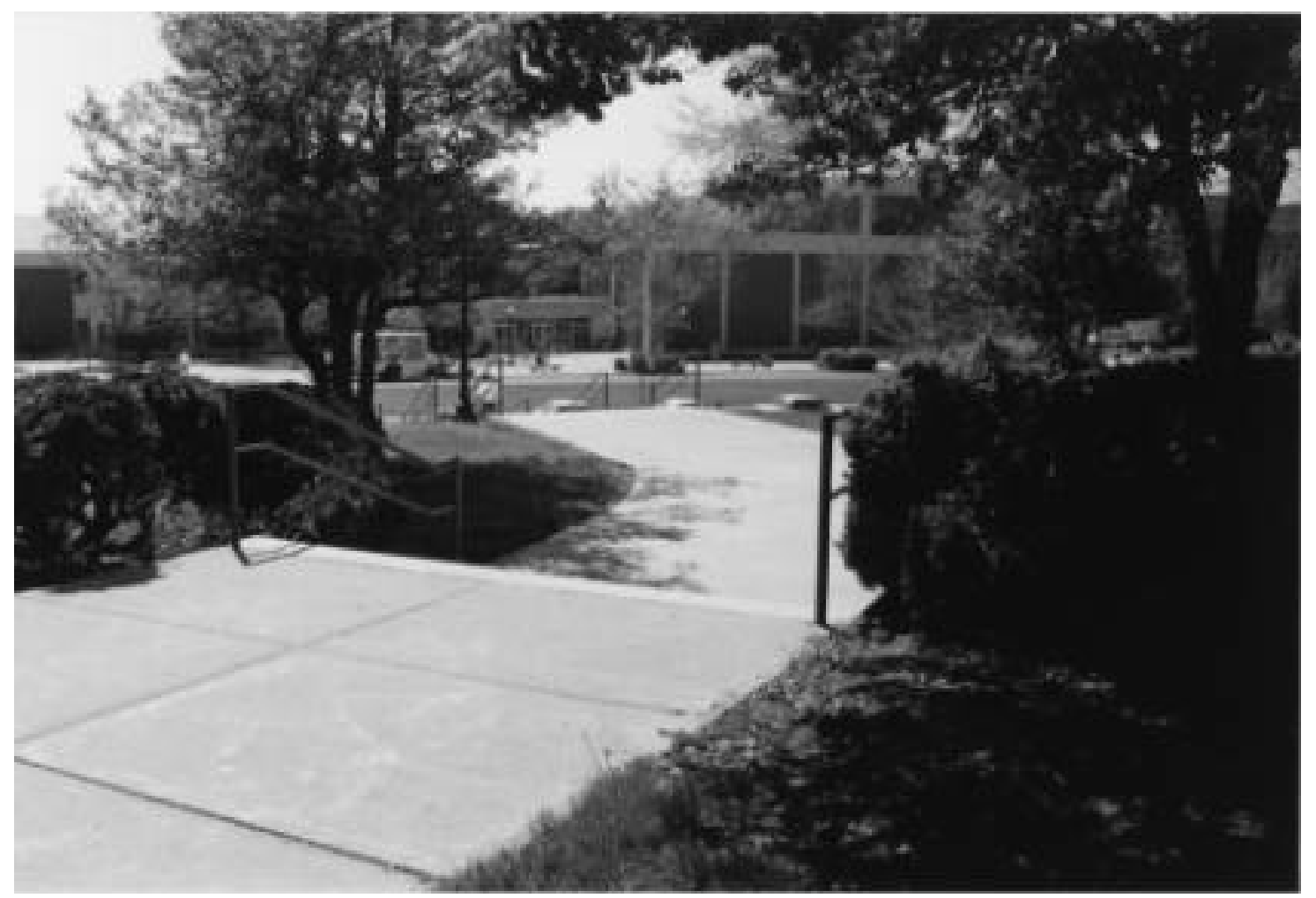

Figure 2: Rasche Staircase, viewed from the videocamera's location for filming the Stairs-Up condition. 
2. Plaza walkway leading from the west entrance of Cowgill Hall to the north staircase of G. Burke Johnson Student Center, used for the $90^{\circ}$ turn condition for Tc experiment. The plaza's walking surface is poured concrete, with no noticeable differences in coloration or texture across the entire plaza surface. Pictured in Figure 3, this location was selected because it involves a relatively sharp turn that changes walking direction. Across the plaza is an unobtrusive area where the videocamera was positioned. At night, the plaza has general lighting. The ambient night illumination was consistently below 3 lux. The portion of the plaza under observation is $13.5 \mathrm{~m}$ long and $3.66 \mathrm{~m}$ wide, which affords a large area for the turn to be made. Of the $13.5 \mathrm{~m}$ length of plaza section, $4.9 \mathrm{~m}$ at one end is in front of the staircase. The individual's view of the area where the turn must be negotiated and the bottom of the staircase is unobstructed. 


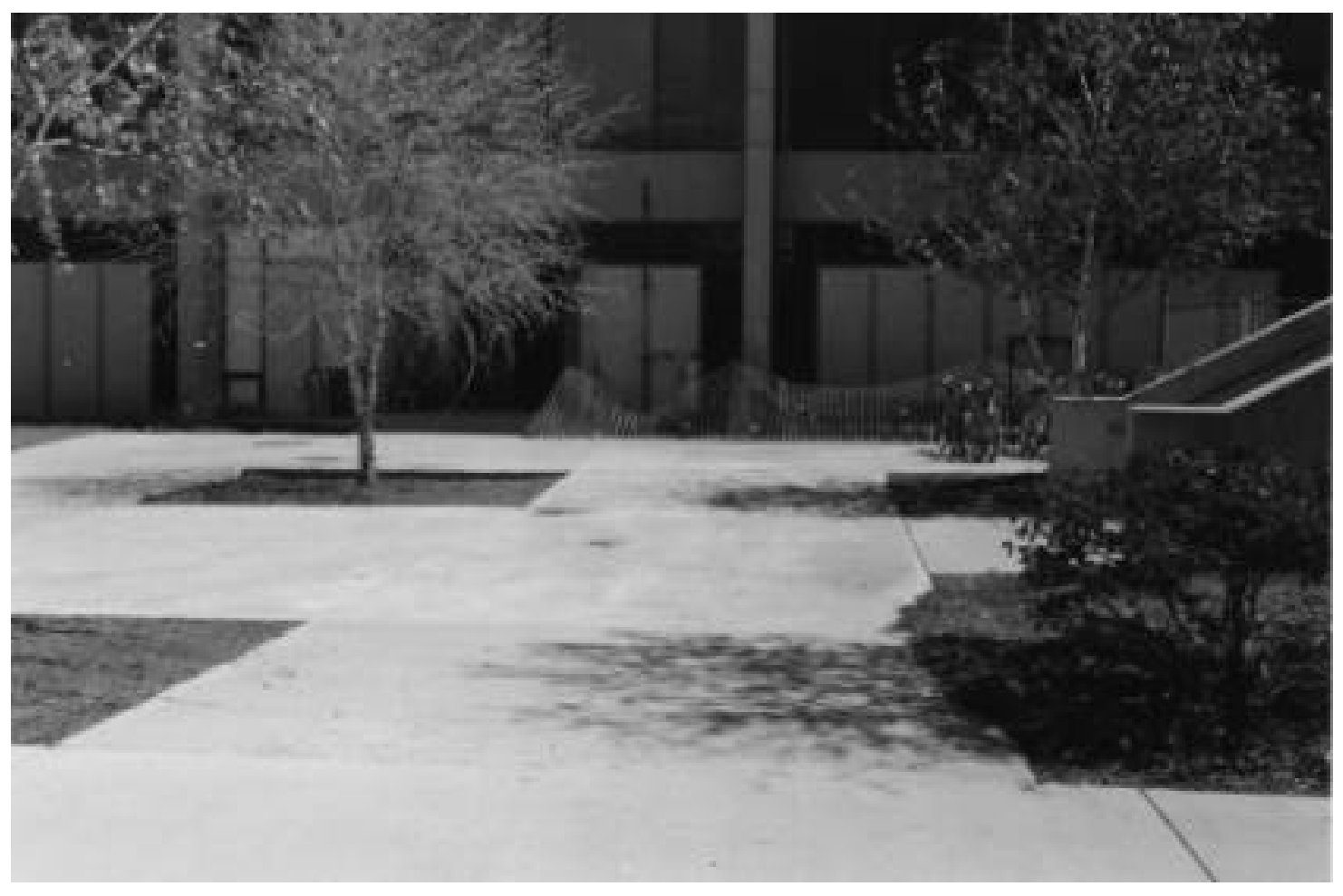

Figure 3: Cowgill Plaza: $90^{\circ}$ Turn was made at the point where the staircase intersects the main plaza. 
3. Downhill sloping sidewalk with a step incorporated in it located behind the North Main Plaza Shopping Complex. Both sections of sidewalk and the step between are of poured concrete with no noticeable differences in coloration or texture across the surfaces. The upper sidewalk has a $5^{0}$ slope. The lower sidewalk has a $8.7^{0}$ slope. Slope angle measurements were performed using a $1.22 \mathrm{~m}$ carpenters level, a tape measure (Sears, Model 939446) and geometric calculations. This location was used in the Tc experiment. Pictured in Figures 4 and 5 , this location was selected because it challenges individuals with a complex condition set that must be successfully negotiated, with two different slopes and a step in the center. The videocamera was placed in the experimenter's automobile, which was parked at the bottom of the sidewalk, where it T-intersects another sidewalk.

The $5^{0}$ sidewalk section is $16.5 \mathrm{~m}$ long and $1.52 \mathrm{~m}$ wide. The step is $0.18 \mathrm{~m}$ high, $1.52 \mathrm{~m}$ wide and $0.61 \mathrm{~m}$ deep. The $8.7^{0}$ sidewalk section is $4.76 \mathrm{~m}$ long and $1.52 \mathrm{~m}$ wide. There is another step at the end of that section, which was not under observation. The individual's view of the sidewalks and step is unobstructed. There is a tree located near the step, which has low hanging branches, but not low enough as to obstruct the overall view. At night, this location receives illumination from two streetlights. The trees immediately around the sidewalk area keep night illumination levels consistently below 1 lux. 


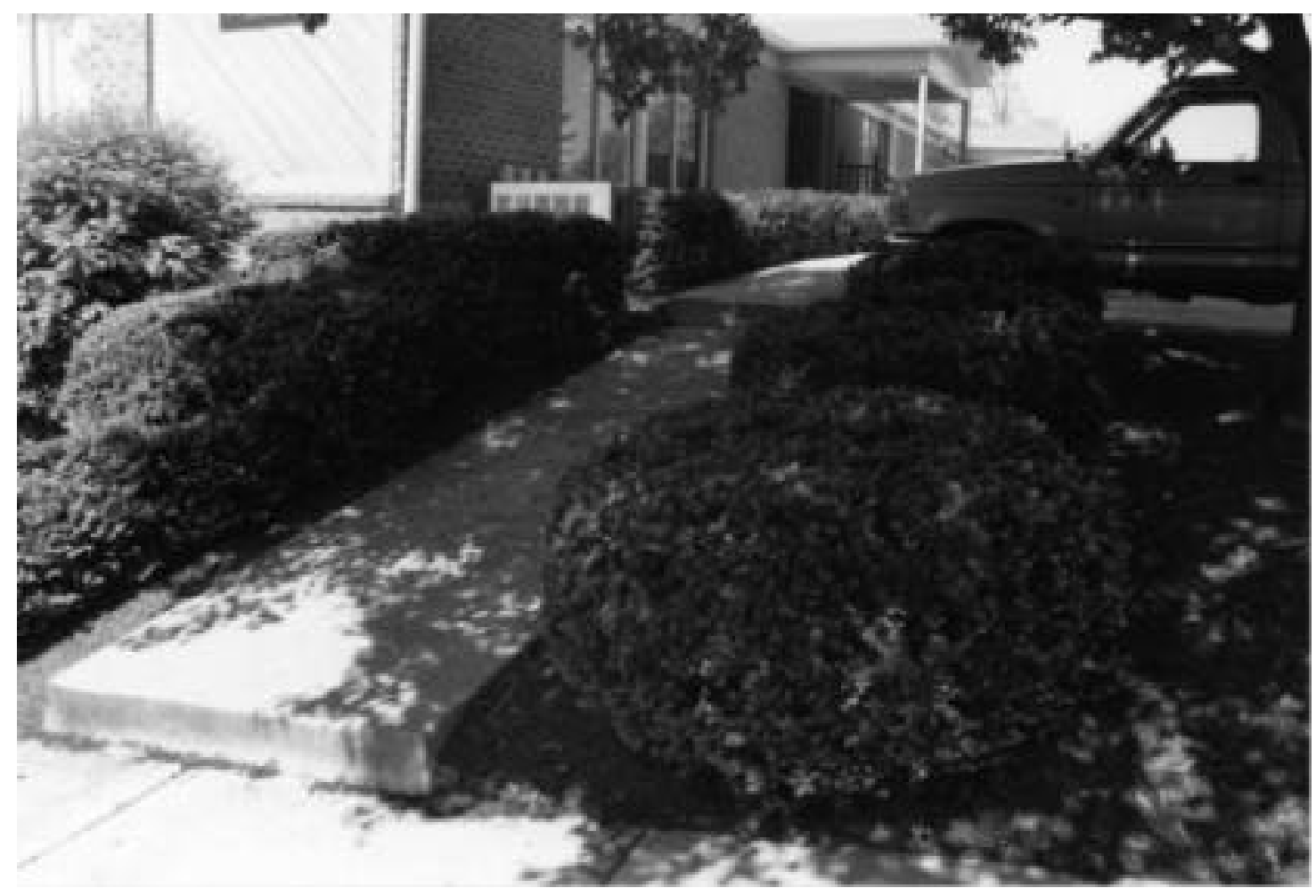

Figure 4: North Main Plaza. Hill with Step Location. Also details variance in slopes from upper to lower walkways. 


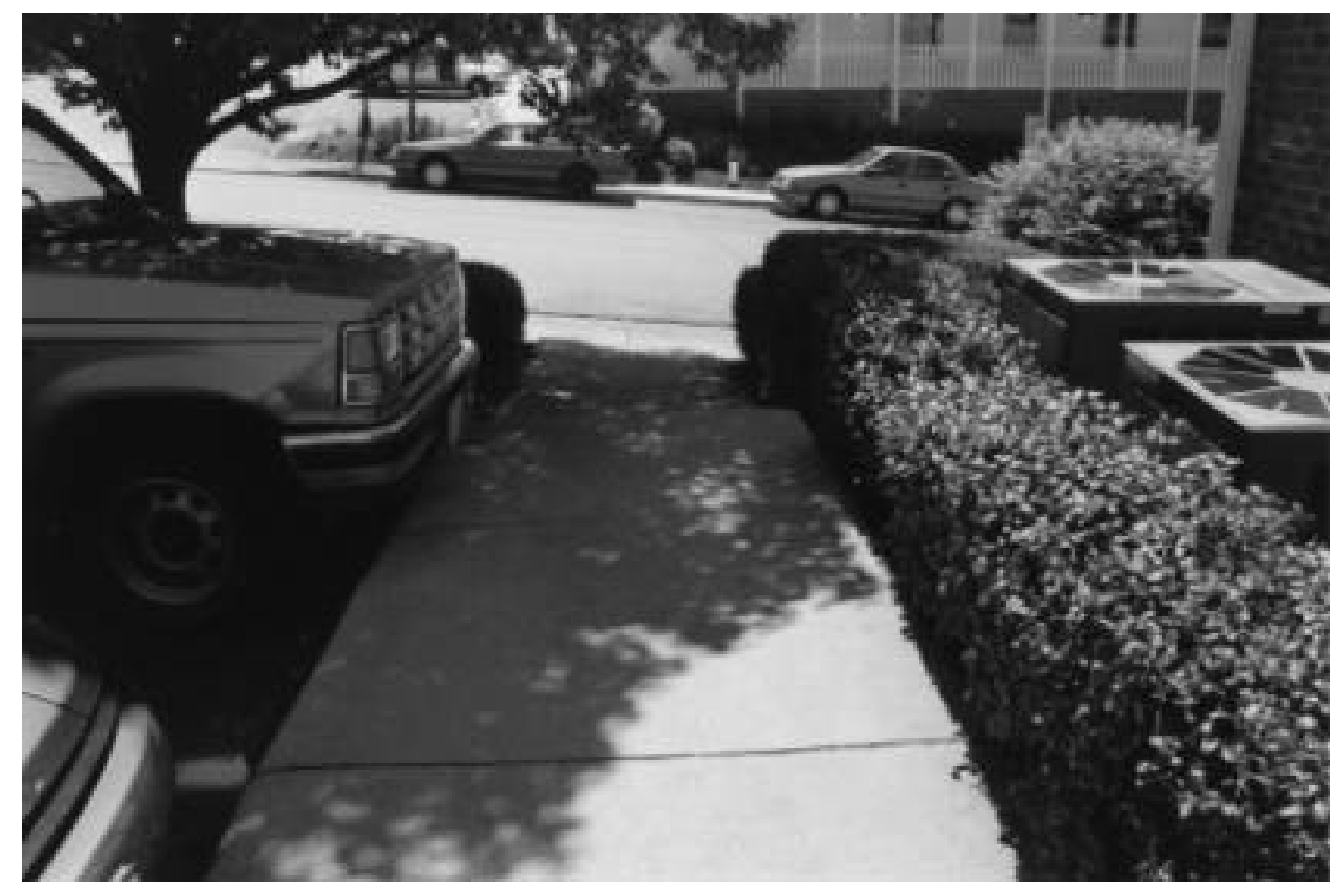

Figure 5: North Main Plaza. Participants' Point of View. Note lack of contrast for detailing edge of step. 
4. Sidewalk fronting the Snyder Pavilion Clubhouse, Snyder Lane, in the Terrace View Apartment complex, used for the Safety Bucket condition in the Tp experiment. The sidewalk is constructed of poured concrete with no noticeable differences in coloration or texture across the surface. Pictured in Figures 6 and 7, this location was selected because it afforded a nearly horizontal walking surface and a wide sidewalk, allowing individuals to walk around the navigation hazard without endangering the individual. The videocamera was placed in a lawn area near the sidewalk approximately $10 \mathrm{~m}$ away from the safety bucket.

The sidewalk area offered an unobstructed view of the safety bucket. The sidewalk was nearly level and straight. There were no trees or large shrubs along the area. The sidewalk is $1.52 \mathrm{~m}$ wide and offers more than $20 \mathrm{~m}$ of unobstructed length in either direction from the bucket. At night, there is a streetlight in the general area, located $11.75 \mathrm{~m}$ distant to the location of the bucket. The safety bucket was placed at a distance from the streetlight so that the ambient illumination was consistently less than 2 lux. It was placed in the middle of the sidewalk, offering the pedestrian a choice of passing it on the left or the right. The safety bucket is pictured in Figure 8. 


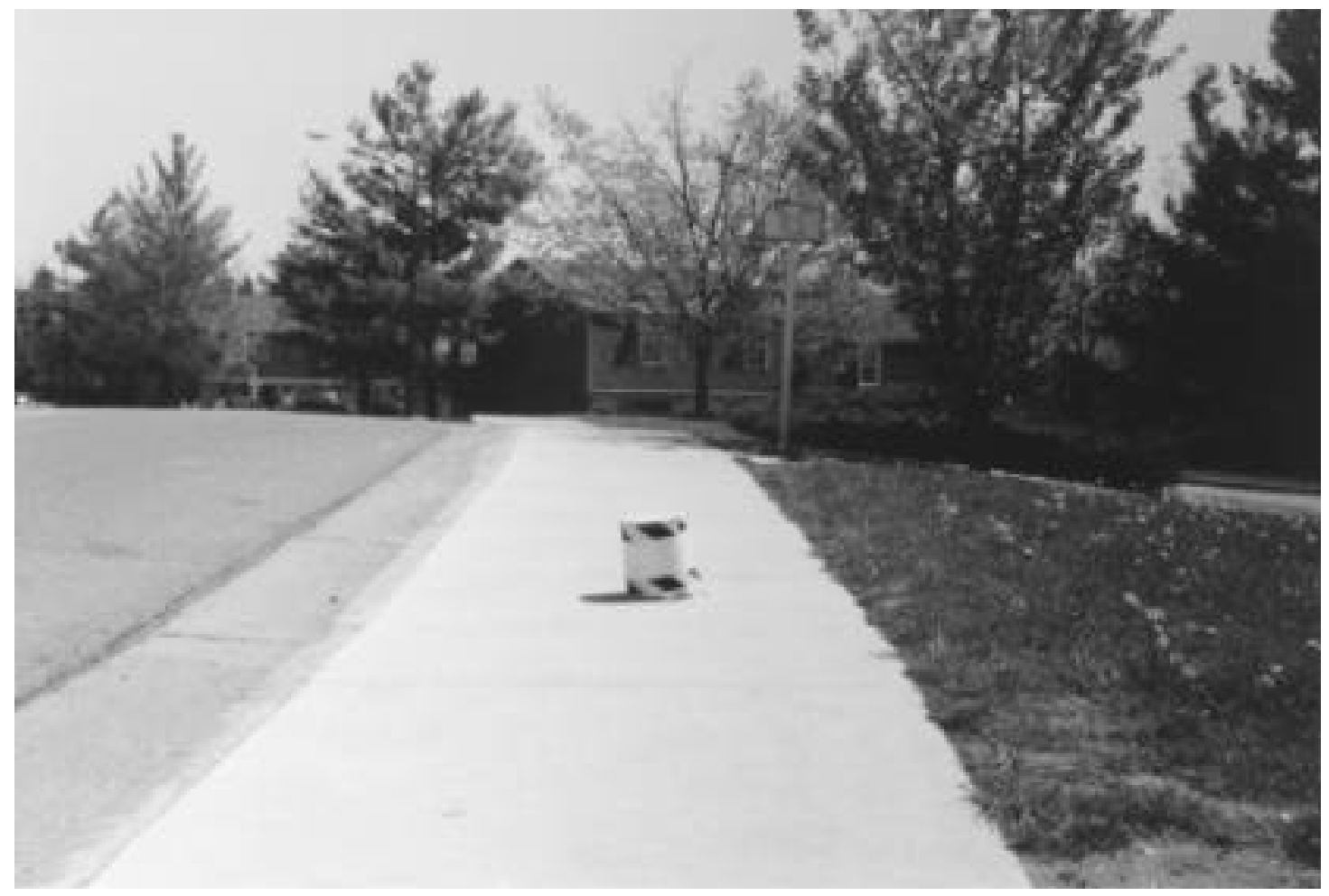

Figure 6: Snyder Lane. Safety Bucket Location. Participants' view from sidewalk; participants walking to the north-northeast. 


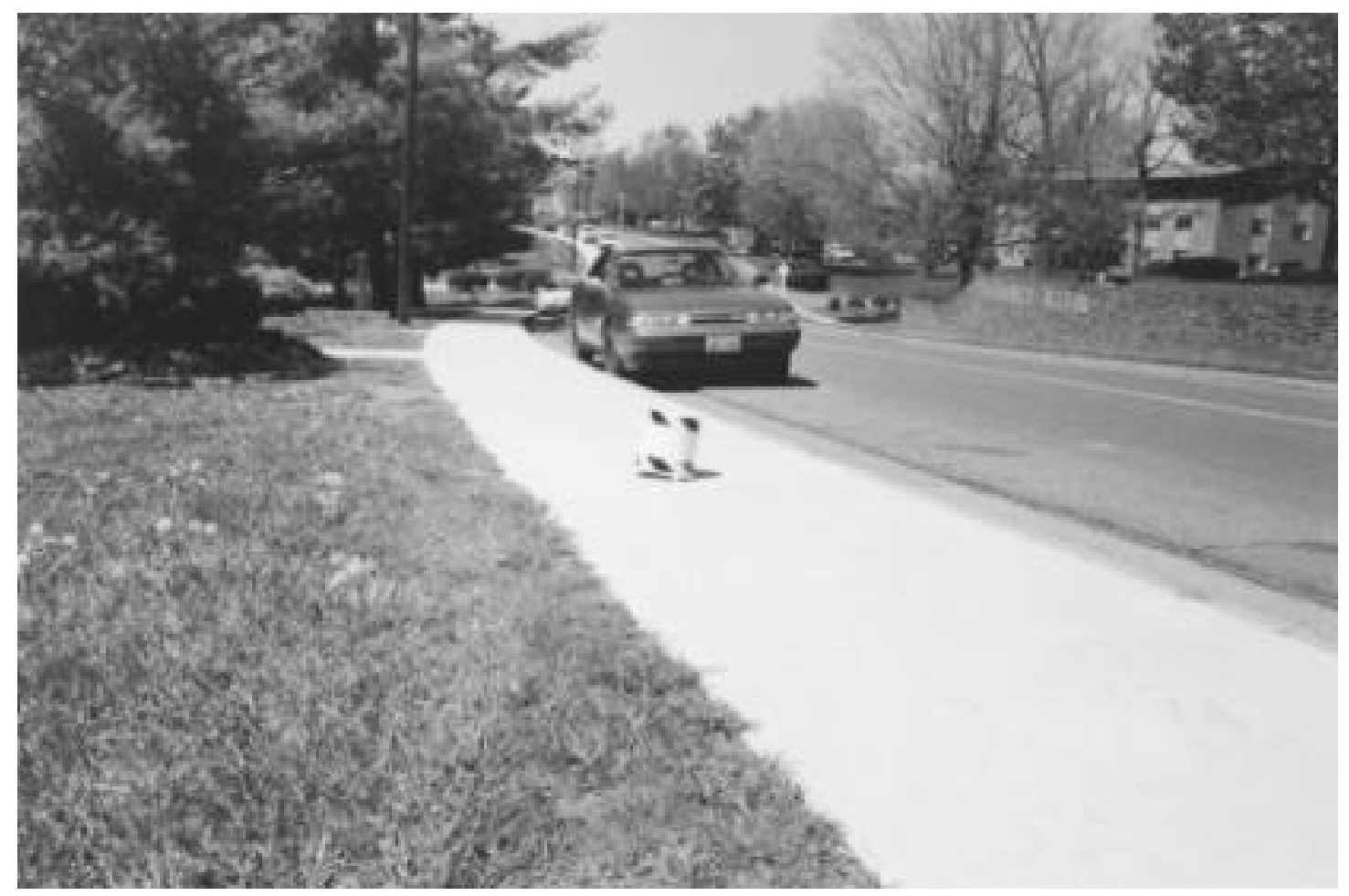

Figure 7: Snyder Lane. Safety Bucket Location. Participants' view from sidewalk; participants walking to the west-southwest. 


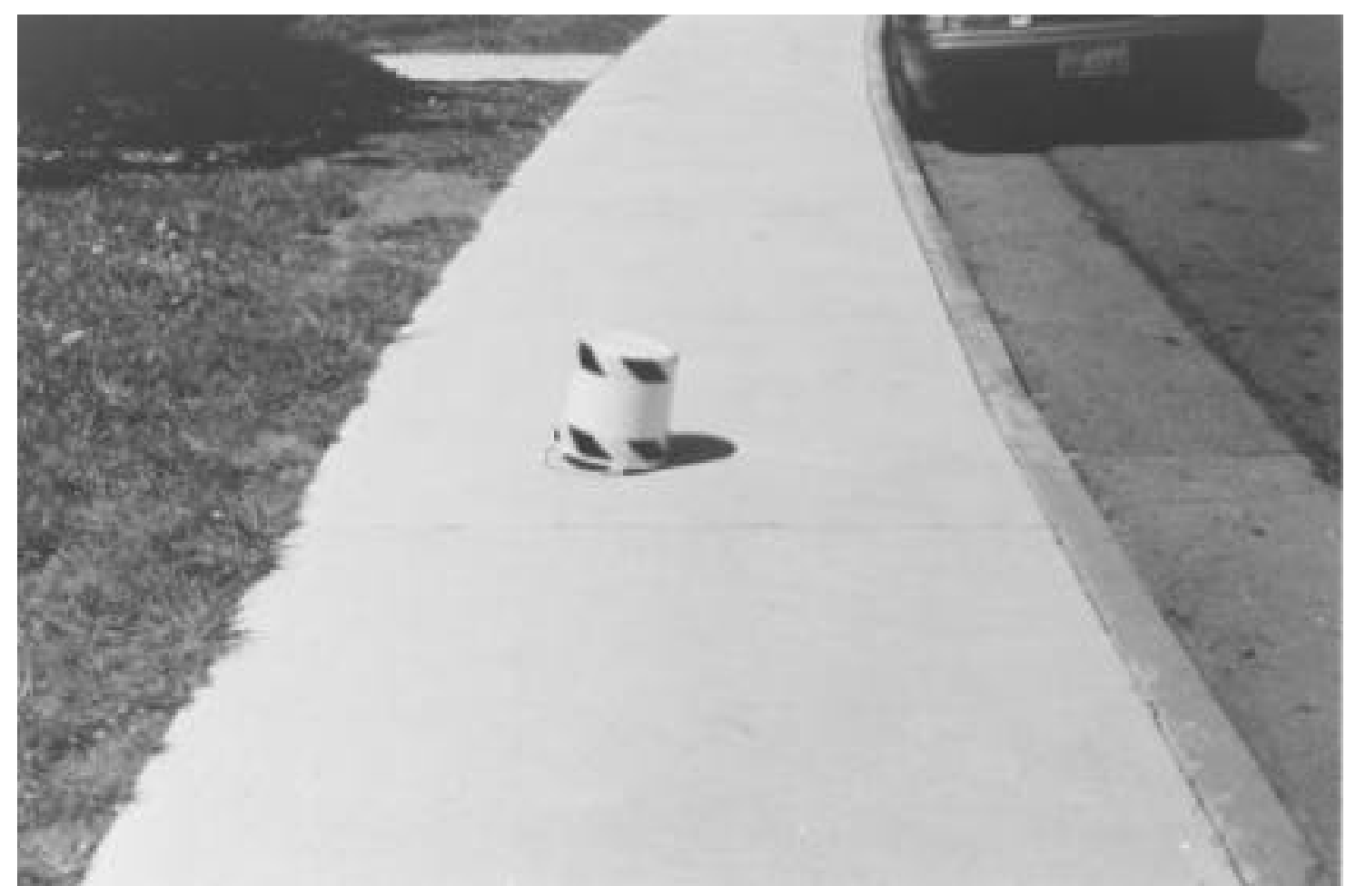

Figure 8: Detail of Safety Bucket Hazard. 
5. Sidewalk on Giles St. in front of the Mill Mountain Coffee Shop, used for the Road Triangle condition in the Tp experiment. The sidewalk is constructed of poured concrete with no noticeable differences in coloration or texture across the surface. This location was selected because it includes a slightly inclined (less than $5^{\circ}$ slope) walking surface and a wide sidewalk, allowing individuals to walk around the navigation hazard without endangering the individual. The videocamera was placed in the experimenter's automobile, which was parked at the top of the rise, approximately $10 \mathrm{~m}$ away. The camera was placed in the automobile because there was no convenient and discrete place beside the sidewalk where the tripod could be set. The sidewalk area offered an unobstructed view of the road triangle. The sidewalk was slightly inclined and straight. There were no trees or large shrubs along the area. The sidewalk is $1.52 \mathrm{~m}$ wide and offers more than $17 \mathrm{~m}$ of unobstructed length in either direction from the triangle. At night, there is a streetlight in the general area. The road triangle was placed at a distance from the streetlight so that the ambient illumination was consistently less than 2 lux. The triangle was placed to the pedestrian's left side at the edge of the sidewalk, so that only part of the triangle obstructed the sidewalk. Location is pictured in Figures 9 and 10. 


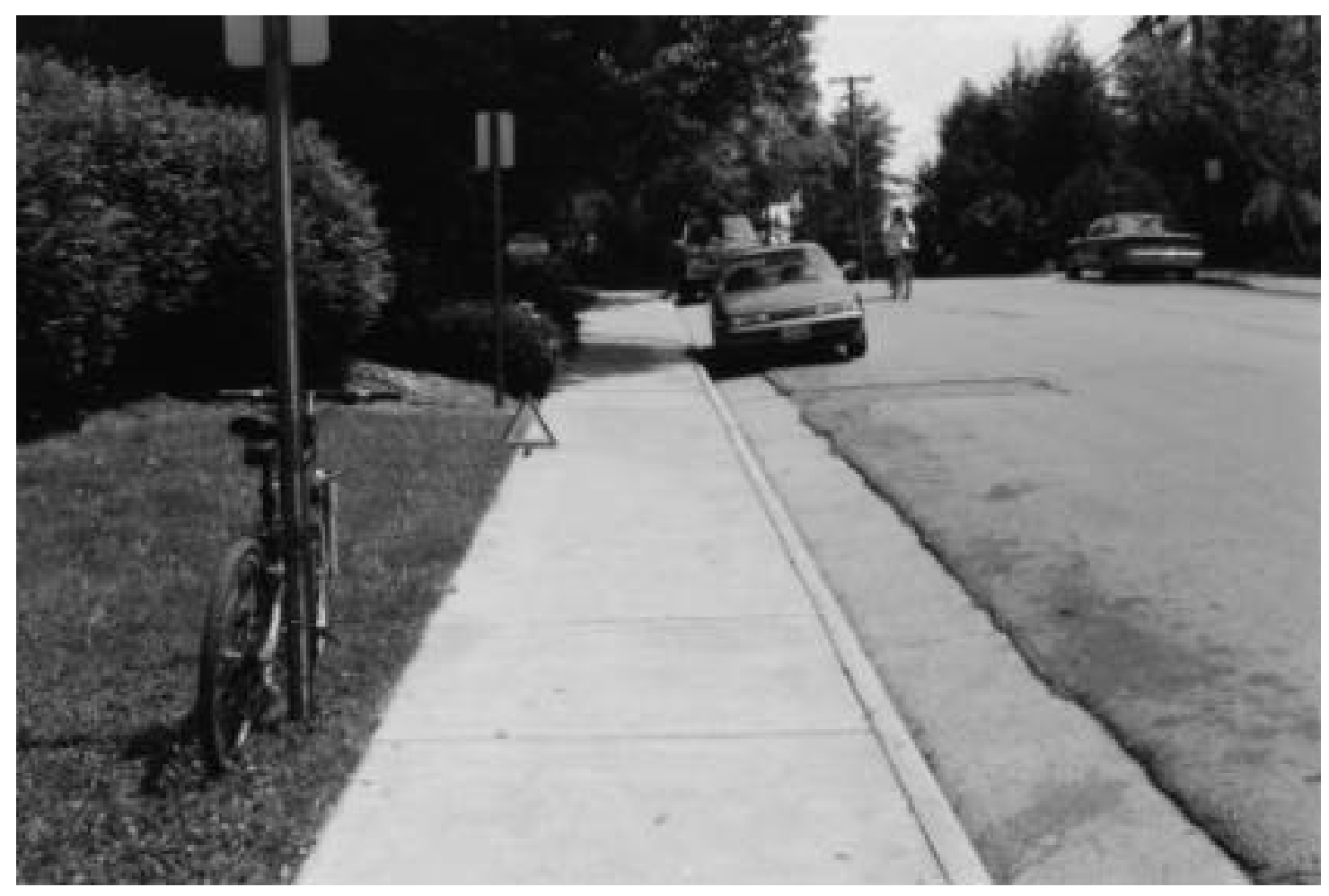

Figure 9: Giles Street. Road Triangle Hazard Location. Participants' view of sidewalk and road triangle hazard. Camera location was the passenger seat of the car in frame. 


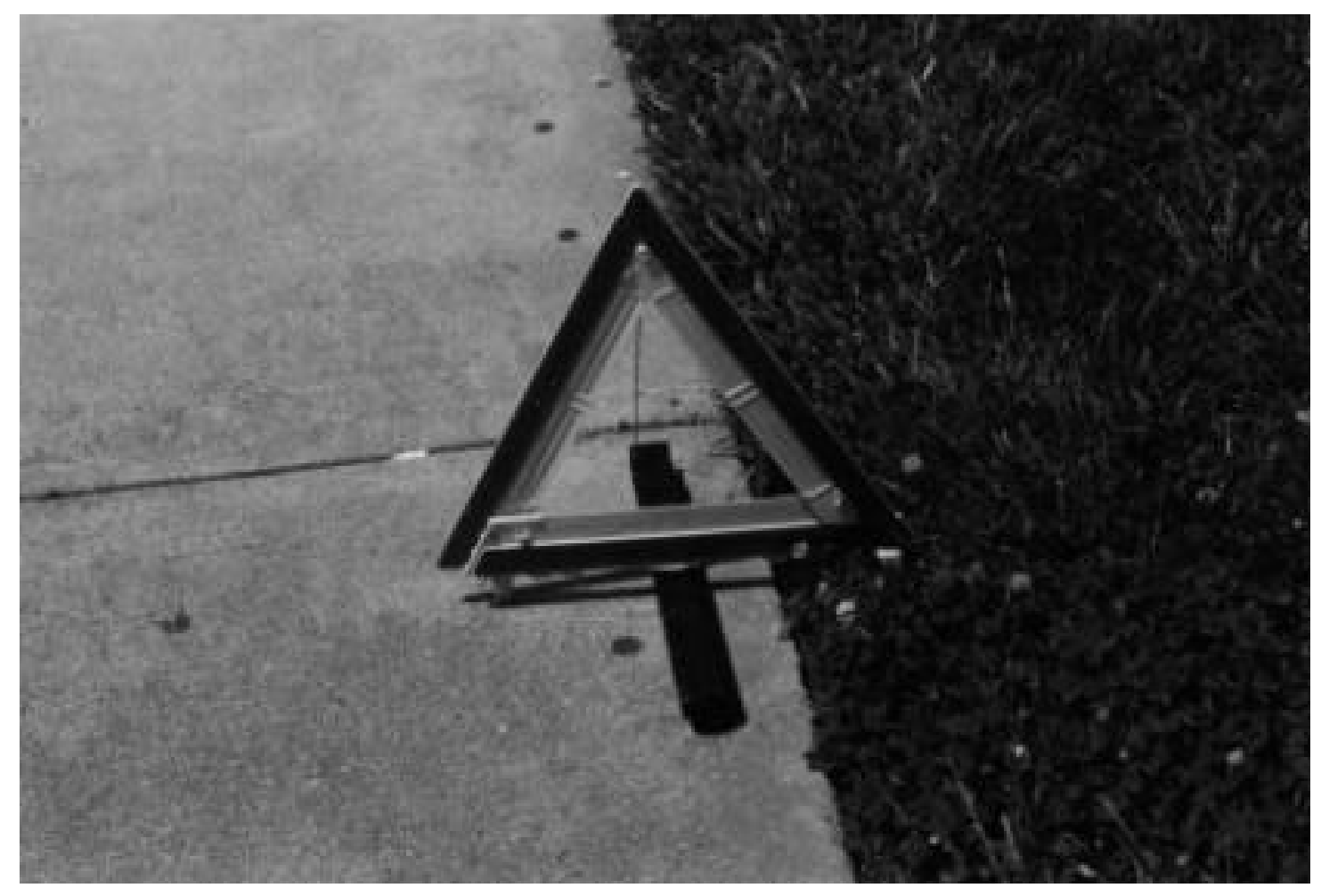

Figure 10: Detail of Road Triangle Hazard.

At all locations, observations were performed only if the weather was clear (no precipitation) and if the walking surfaces were dry and free of debris. This procedure eliminated the likelihood of observations being distorted by the perception of slippery walking surfaces.

\section{Equipment}

An illuminanace meter (Minolta, Model T-1), and a chromoluminance meter (Minolta, Model CS-100), were used to record ambient lighting levels.

Two video cameras were used over the course of the experiments (but not simultaneously): a Panasonic XJ-12, utilizing VHS-C recording cassettes and a Sears 934.53802391, utilizing standard VHS recording cassettes. Both 
cameras have Macro (within $1 \mathrm{~m}$ ) to infinite zoom capability. When recording, the video camera was mounted on a Velbon professional tripod.

A color television (Sony, Model KV-32S10) and a video cassette player (Mitsubishi, Model Diamond Pro BV-2000) were used to play back videotape for analysis.

For the Tp experiments, two hazards were used. The navigation hazards were selected so that they would be readily visible to passersby. They were also lightweight with no sharp edges, so that if a person struck the object they would not be injured. The "safety bucket" was a $23.8 \mathrm{~cm}$ high, $26 \mathrm{~cm}$ diameter, yellowish-almond colored, matte finish, plastic bucket. The outside of the bucket was wrapped in yellow and black striped, matte finish, safety tape at the top and bottom. Neither the bucket nor the safety tape were of reflective material. At night, there was not much observable distinction between the yellow of the safety tape and the almond of the bucket The bucket contained approximately $3.5 \mathrm{~kg}$ of fill material to prevent it from blowing under wind conditions. At the location, the bucket was inverted and placed on the sidewalk, so it formed a solid hazard. The "road triangle" was an ANSI-approved roadside safety/warning triangle, normally used when an automobile or truck breaks down along the highway. The triangle was $43.18 \mathrm{~cm}$ high and $42 \mathrm{~cm}$ wide. It was bright orange with red reflectors, and was designed to be visible under a variety of lighting conditions, especially at night.

Once original video footage was recorded, the videotapes were professionally dubbed to include frame numbers. Dubbing was performed by Virginia Tech Video Broadcast Services under contract Q-1895.

During Night conditions, a Micronata digital stopwatch, model 63-5021, was used to record observed Fine Navigation Tc or Tp. This stopwatch is capable of measuring hundredths of seconds. 


\section{Procedure - Day and Twilight Conditions.}

At each location, the video recording equipment was positioned so that individuals approaching the Navigation Hazard were recorded as they approached, traversed, or passed the navigation hazard. The camera was placed in a location to minimize any distraction the camera would impose on the individuals being recorded. While the camera was not completely hidden from view, it was placed a discrete distance from the navigation hazard. This was normally more than $10 \mathrm{~m}$ distant from the navigation hazard.

Prior to recording and at the end of each recording session, ambient illumination and luminance levels were measured and recorded. Illumination was checked to assure the proper lighting condition (day, twilight or night) was met prior to any recording.

Video recordings were made of individuals as they traversed the navigation hazard under the specified lighting conditions. These individuals were passersby who happened to walk along the path of interest in the direction of interest. No feedback regarding individuals' walking ability or success in navigating was provided.

Video recordings from each location were analyzed, looking for individuals who exhibited a physical manifestation of the switch from gross adjustment of trajectory to fine adjustment of trajectory. This was determined by observing changes primarily in head posture, eye posture, and walking rhythm. Specific changes observed include tilting the head downward, squaring of the head or shoulders, alteration of length or angle of stride, rapidly scanning eye movement, and ceasing any extraneous movement (e.g., talking, shifting things in totebags, expressive talking with the hands). The type of observed change was noted for each subject videotaped. This specific frame number was noted as the "start" frame. 
The "stop" frame was determined as the location where the participant first encountered the navigation hazard. For the stairs, this was the point at which the participant first placed foot on a stairtread. For the $90^{\circ}$ turn, this was the point where the turn had been at least halfway completed. At the Hill with Step location, this was the point at which the participant placed foot on the step. Under the Tp conditions, the "stop" frame was the frame where the participant's foot was next to or immediately past the hazard. The measurement was taken when the participant's foot was fully planted on the ground. This is the same criterion that was used in the various long jump studies (Lee, et al., 1982; Hay, 1988). It also corresponds to research which indicates that humans remain fixed on a footfall target until just after (mean of $51 \mathrm{~ms}$ ) footfall is made, so that "...landing on the target may be fine-tuned (Hollands, et al., 1995)."

Once the precise change was observed and the specific frame number was recorded, the fine navigation time-to-contact (Tc) or time-to-passage (Tp) was calculated and used for analysis. Tc and Tp were calculated by counting the number of frames between the "start" and "stop" frame numbers, then multiplying the number of video frames by a time standard of one video frame equals 33.333 milliseconds.

\section{Procedure - Night Condition}

Under the night lighting level, video recording was not possible. There was insufficient ambient light for frame-by-frame video analysis to be possible. An attempt to use a U.S. Army ANVIS-6 night vision ocular, affixed to the video equipment, was not successful, mainly due to "light blooms" from point sources of light in the camera's field of view.

During night conditions, the experimenter positioned herself in a location that afforded an unobstructed view of the observed location. This location was near to where the tripod mounted camera would have been placed for day or twilight conditions. The experimenter observed individuals as they navigated to 
and through the navigation hazards presented. When the experimenter observed the body indicators that signaled a change in navigation strategy, she depressed the start button on the stopwatch. When the participant reached the cue point to stop timing, the stop button was pushed. The experimenter then recorded the observed fine navigation Tc or Tp.

While this method is not as precise as the video analysis, it is a reasonable, scientifically valid method, utilizing the principles of methods engineering (Niebel, 1988). This method does assume that the biological signal processing delay of the human is equal for the observed start point as for the observed stop point. 


\section{RESULTS}

\section{Observational Study versus Laboratory Study.}

It is important to remember that the study outlined herein is an observational study, as opposed to a rigidly controlled, laboratory study. Participants were not given instructions. They were observed as they walked from one point to another, encountering a navigational hazard along the way. While participants who were recorded for this study were all walking at a "normal" pace, they were not necessarily all walking at the same pace. Some were walking with other people; others walked alone. Some realized they were being observed while others did not. The experimenter did not know if all participants were familiar with the areas they were traversing.

\section{Use of One-Way ANOVA Analyses.}

One-way ANOVAs were used for the analysis of data collected, even though $3 \times 4$ and $3 \times 2$ full factorial designs were used to structure the data collection. The one-way ANOVA examined the effects of lighting levels within navigation hazard type on fine navigation time-to-contact or time-to-passage.

The two-way ANOVA was not practical to use for these navigation hazard types because the locations selected were not of the same width and had varying depth of field. This means that one location may offer a different viewing distance leading up to the navigation hazard, and the participant may have more or less room to execute the navigational change, than at another navigation hazard location. The types of maneuvers varied as well. For example, making a wide $90^{\circ}$ turn is a different process from changing gait to safely go down a flight of stairs. 
If considered from an engineering perspective, it does not make much sense to directly compare the time going around a corner at night to going up stairs during daylight conditions. An engineer would be much more interested in how the human's perception of one particular navigation hazard changes over different lighting conditions. For this reason, and the reasons outlined above, one-way ANOVAs were used in data analysis.

\section{Analysis.}

For statistical analyses, the participants' recorded fine navigation timesto-contact or times-to-passage were subjected to an Analysis of Variance (ANOVA). Separate ANOVAs were performed for each navigation hazard, as the navigation hazards were sufficiently dissimilar to prevent meaningful analysis among the various hazards (Minitab, Minitab program release 10Xtra, Windows).

While multiple replications were made within each experiment, each replication represented an independent condition with no overlapping subjects. For this reason, no experiment wide $\alpha$ corrections were made. Experimental Type I error levels of significance were set at $\alpha=0.05$, which is common in human factors research and represents a conservative approach to statistical analysis. For all post-hoc tests, experimental Type I error levels of significance were also set at $\alpha=0.05$. 


\section{Experiment 1 - Fine Navigation Time-to-Contact, Tc.}

The fine navigation Tc data obtained in the experiment were subjected to navigation hazard specific, one-way ANOVAs (Subjects nested within Lighting Level). Results of these ANOVAs are shown in Tables 2, 4, 6, and 8. Graphical diagrams of the mean Tc values are shown in Figures 11 through 14. These provide a visual representation of how mean Tc's trended at each hazard across lighting levels. The ANOVAs results indicate that the main effect of lighting level is statistically significant across three of four navigation hazards. Lighting Level is significant in the stairs-down condition $[F(2,42)=11.01, p=$ 0.000 ], $90^{\circ}$ turn condition $[F(2,42)=7.08, p=0.002]$, and the hill with step condition $[F(2,42)=4.51, p=0.017]$.

\section{Results for Condition 1: Stairs-Up.}

The Stairs-Up condition did not generate significant results across the Lighting Level variable. ANOVA results for the Stairs-Up Condition are reported in Table 1.

Table 1: ANOVA Summary Table for Fine Navigation Time-to-Contact for StairsUp Condition

\begin{tabular}{llllll}
\hline Source & $d f$ & $S S$ & $M S$ & $F$ & $p$ \\
\hline Lighting Level (L) & 2 & 542938 & 271469 & 1.83 & 0.172 \\
Subjects (S/L) & 42 & 621733 & 148032 & & \\
& & 7 & & & \\
\hline Total & 44 & 676027 & & & \\
& & 5 & & & \\
\hline
\end{tabular}




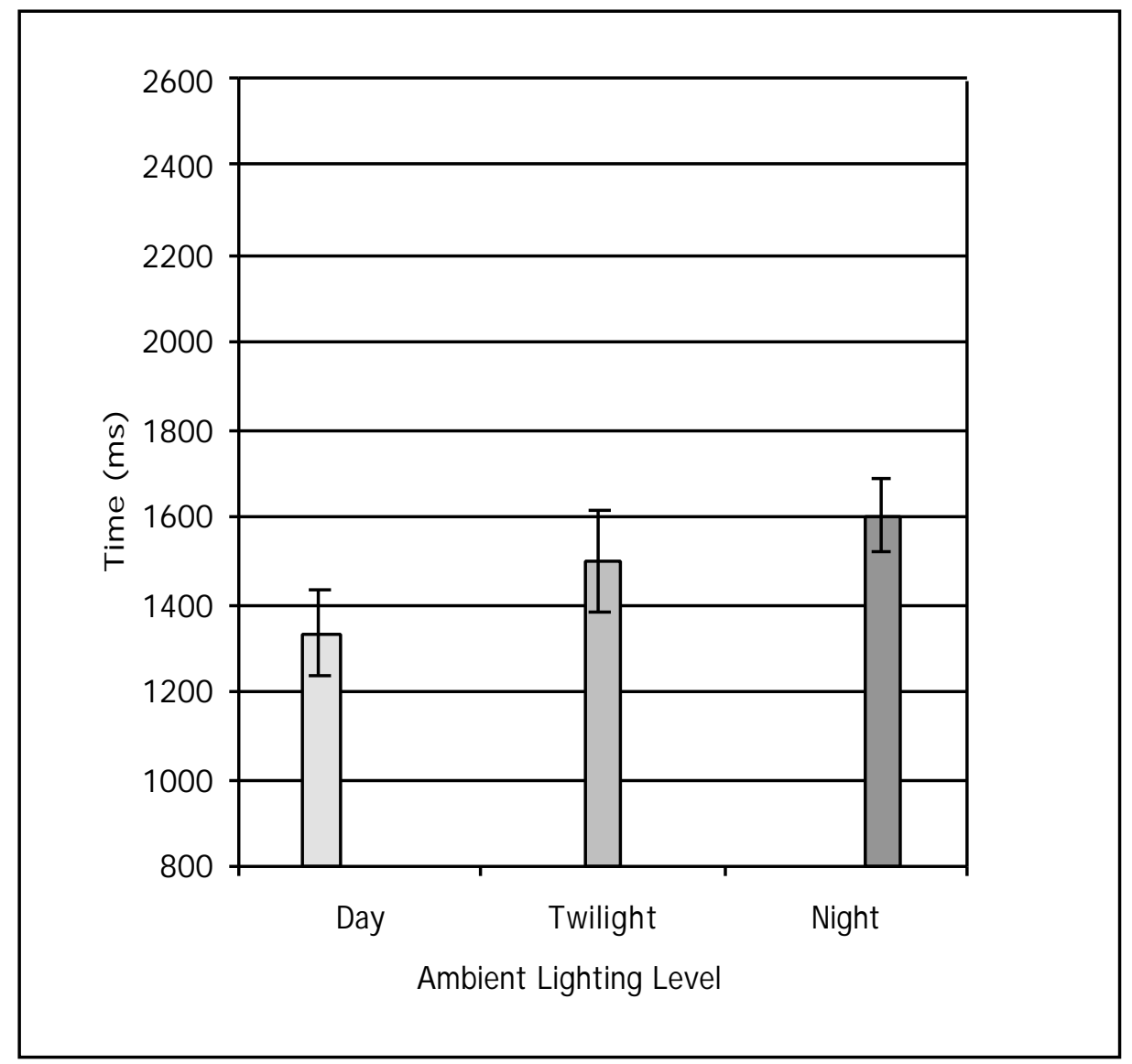

Figure 11: Main Effect of Ambient Illumination on Fine Navigation Time-toContact for Stairs-Up Condition. Error bars are +/- 1 standard error of the mean.

\section{Results for Condition 2: Stairs-Down.}

The Stairs-Down condition generated significant results across the Lighting Level variable. ANOVA results for the Stairs-Down Condition are reported in Table 2. 
Table 2: ANOVA Summary Table for Fine Navigation Time-to-Contact for StairsDown Condition.

\begin{tabular}{llllll}
\hline Source & $d f$ & $S S$ & $M S$ & $F$ & $p$ \\
\hline Lighting Level (L) & 2 & 4379457 & 218972 & 11.01 & $\mathbf{0 . 0 0 0}$ \\
& & & 9 & & \\
Subjects (S/L) & 42 & 8355208 & 198934 & & \\
\hline Total & 44 & 1273466 & & & \\
& & 5 & & & \\
\hline
\end{tabular}

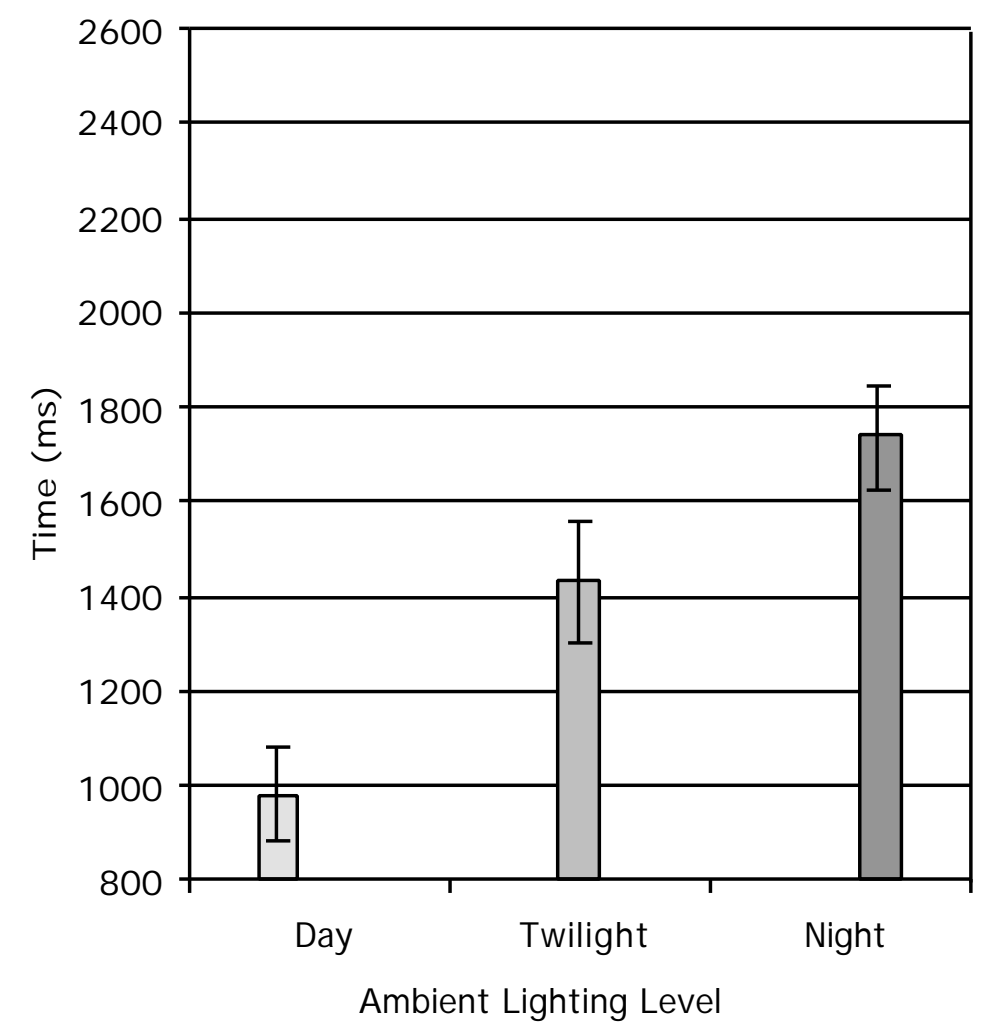


Figure 12: Main Effect of Ambient Illumination on Fine Navigation Time-toContact for Stairs-Down Condition. Error bars are +/- 1 standard error of the mean.

On a post-hoc basis, a Newman-Keuls range test was performed for the Stairs-Down navigational hazard to determine, through pairwise comparisons, which lighting levels were significantly different from other levels. Results are shown in Table 3. For the Stairs-Down hazard, the night lighting level is statistically different from the day lighting level. In addition, the twilight lighting level was statistically different from the day lighting level.

Table 3: Newman-Keuls Results for Fine Navigation Time-to-Contact for StairsDown Condition.

\begin{tabular}{|c|c|c|c|}
\hline Navigation Hazard & Lighting Level & $\overline{\mathrm{x}}-\mathrm{Tc}(\mathrm{ms})$ & Group \\
\hline \multirow[t]{3}{*}{ Stairs-Down } & Day & 977.8 & $\bar{A}$ \\
\hline & Twilight & 1426.7 & $\mathrm{E}$ \\
\hline & Night & 1737.8 & $\mathrm{E}$ \\
\hline
\end{tabular}

Groups with the same letter are not statistically different, $p>0.10$.

\section{Results for Condition 3: $90^{\circ}$ Turn.}

The $90^{\circ}$ Turn condition generated significant results across the Lighting Level variable. ANOVA results for the $90^{\circ}$ Turn Condition are reported in Table 4.

Table 4: ANOVA Summary Table for Fine Navigation Time-to-Contact for 90 Degree Turn Condition.

\begin{tabular}{llllll}
\hline Source & $d f$ & $S S$ & $M S$ & $F$ & $p$ \\
\hline
\end{tabular}




\begin{tabular}{llllll} 
Lighting Level (L) & 2 & 6982463 & 349123 & 7.08 & $\mathbf{0 . 0 0 2}$ \\
& & & 1 & & \\
Subjects $(\mathrm{S} / \mathrm{L})$ & 42 & 2069906 & 492835 & & \\
& & 8 & & & \\
\hline Total & 44 & 2768153 & & \\
& 2 & & \\
& & & & \\
\hline
\end{tabular}

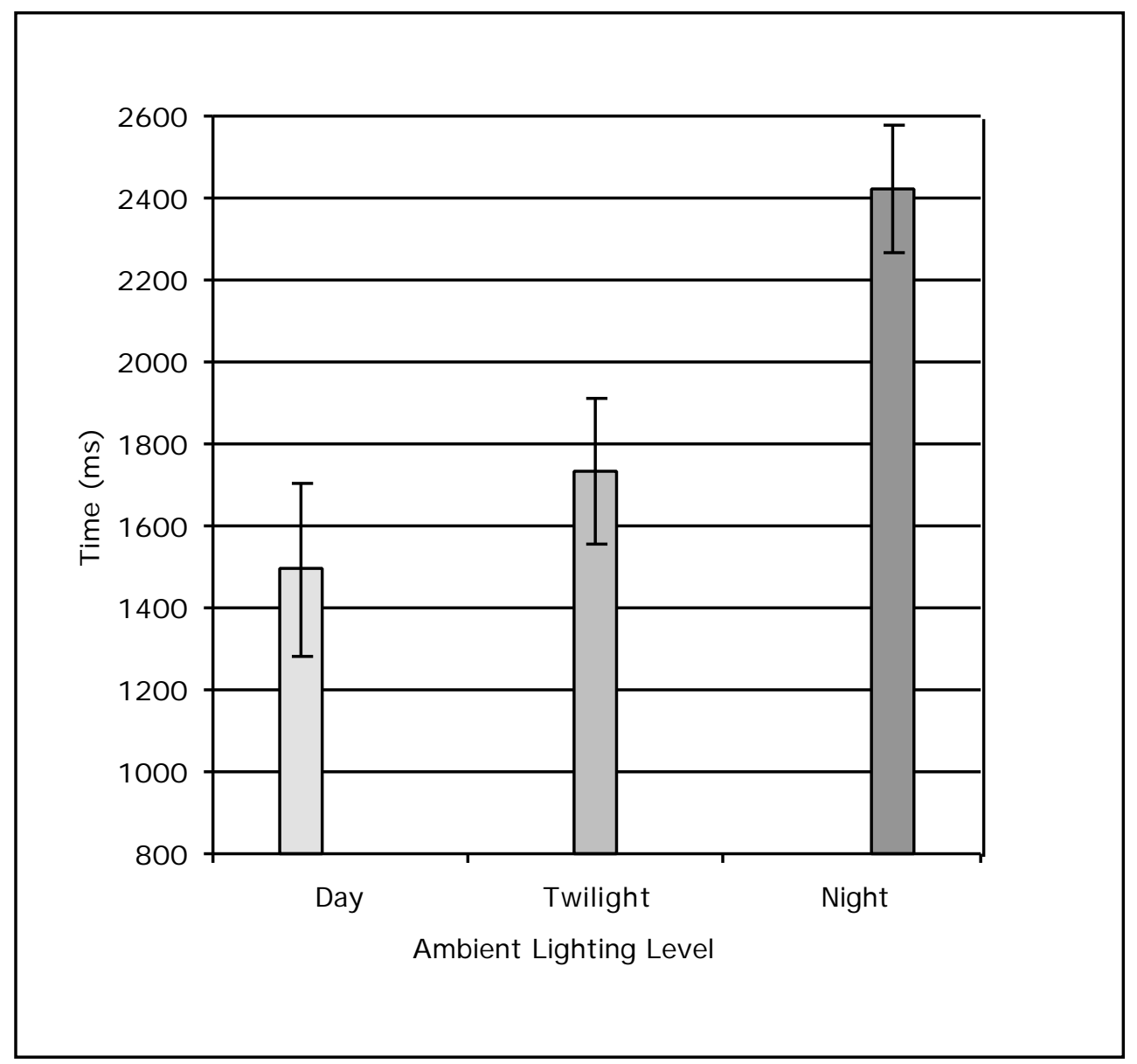

Figure 13: Main Effect of Ambient Illumination on Fine Navigation Time-toContact for $90^{\circ}$ Turn Condition. Error bars are $+/-1$ standard error of the mean. 
On a post-hoc basis, a Newman-Keuls range test was performed for the $90^{\circ}$ Turn navigational hazard to determine, through pairwise comparisons, which lighting levels were significantly different from other levels. Results are shown in Table 5. For this hazard, the night lighting level was statistically different from the day lighting level and the twilight lighting level.

Table 5: Newman-Keuls Results for Fine Navigation Time-to-Contact for $90^{\circ}$ Turn Condition.

\begin{tabular}{ccclc}
\hline Navigation Hazard & Lighting Level & $\mathrm{x}-\mathrm{Tc}(\mathrm{ms})$ & \multicolumn{2}{c}{ Group } \\
\hline $90^{\circ}$ Turn & Day & 1493.3 & $\mathrm{C}$ & \\
& Twilight & 1733.3 & $\mathrm{C}$ & \\
& Night & 2422.7 & & $\mathrm{D}$ \\
\hline
\end{tabular}

Groups with the same letter are not statistically different, $p>0.10$.

Results for Condition 4: Hill with Step.

The Hill with Step condition generated significant results across the Lighting Level variable. ANOVA results for the Hill with Step Condition are reported in Table 6.

Table 6: ANOVA Summary Table for Fine Navigation Time-to-Contact for Hill with Step Condition.

\begin{tabular}{llllll}
\hline Source & $d f$ & $S S$ & $M S$ & $F$ & $p$ \\
\hline Lighting Level (L) & 2 & 3781927 & 189096 & 4.51 & $\mathbf{0 . 0 1 7}$ \\
& & & 4 & & \\
Subjects (S/L) & 42 & 1760521 & 419172 & &
\end{tabular}


shown in Table 7. For this hazards, the night lighting level is statistically different from the day lighting level and from the twilight lighting level.

Table 7: Newman-Keuls Results for Fine Navigation Time-to-Contact for Hill with Step Condition.

\begin{tabular}{ccclc}
\hline Navigation Hazard & Lighting Level & x -Tc (ms) & \multicolumn{2}{c}{ Group } \\
\hline Hill with Step & Day & 1282.2 & E & \\
& Twilight & 1408.9 & E & \\
& Night & 1950.7 & & F \\
\hline
\end{tabular}

Groups with the same letter are not statistically different, $p>0.10$. 
Basic statistics for each navigation hazard type and each lighting level are reported in Table 8.

Table 8: Basic Statistics for Experiment 1: Fine Navigation Time-to-Contact, Tc.

\begin{tabular}{cccc}
\hline Navigation Hazard & Lighting Level & $\bar{x}$-Tc $(\mathrm{ms})$ & S-Tc $(\mathrm{ms})$ \\
\hline 1. Stairs-Up & Day & 1333.3 & 383.8 \\
& Twilight & 1493.3 & 437.4 \\
& Night & 1600.7 & 324.8 \\
2. Stairs-Down & Day & 977.8 & 387.0 \\
& Twilight & 1426.7 & 506.3 \\
& Night & 1737.8 & 436.6 \\
3. 90 ${ }^{0}$ Turn & Day & 1493.3 & 810.5 \\
& Twilight & 1733.3 & 683.9 \\
& Night & 2422.7 & 594.9 \\
& & & \\
4. Hill with Step & Day & 1282.2 & 491.8 \\
& Twilight & 1408.9 & 634.3 \\
& Night & 1950.7 & 783.2 \\
\hline
\end{tabular}




\section{Experiment 2: Fine Navigation Time-to-Passage, Tp.}

The fine navigation Tp data obtained in the experiment were subjected to navigation hazard specific, one-way ANOVAs (Subjects nested within Lighting Level). Results of these ANOVAs are shown in Tables 9 and 11. Graphical diagrams of the mean Tp values are shown in Figures 15 and 16. These provide a visual representation of how mean Tp's trended at each hazard across lighting levels. The ANOVA results indicate that the main effect of lighting level is statistically significant across both navigation hazards. Lighting Level is significant in the safety bucket condition $[F(2,42)=8.53, p=0.001]$ and the road triangle condition $[F(2,42)=10.71, p=0.000]$.

\section{Results for Condition 1: Safety Bucket Hazard.}

The Safety Bucket Hazard generated significant results across the Lighting Level variable. ANOVA results for the Safety Bucket Hazard are reported in Table 9.

Table 9: ANOVA Summary Table for Fine Navigation Time-to-Passage for Safety Bucket Condition.

\begin{tabular}{llllll}
\hline Source & $d f$ & SS & $M S$ & $F$ & $p$ \\
\hline Lighting Level (L) & 2 & 19105498 & 9552749 & 8.53 & $\mathbf{0 . 0 0 1}$ \\
Subjects (S/L) & 42 & 47013584 & 1119371 & & \\
\hline Total & 44 & 66119084 & & & \\
\hline
\end{tabular}




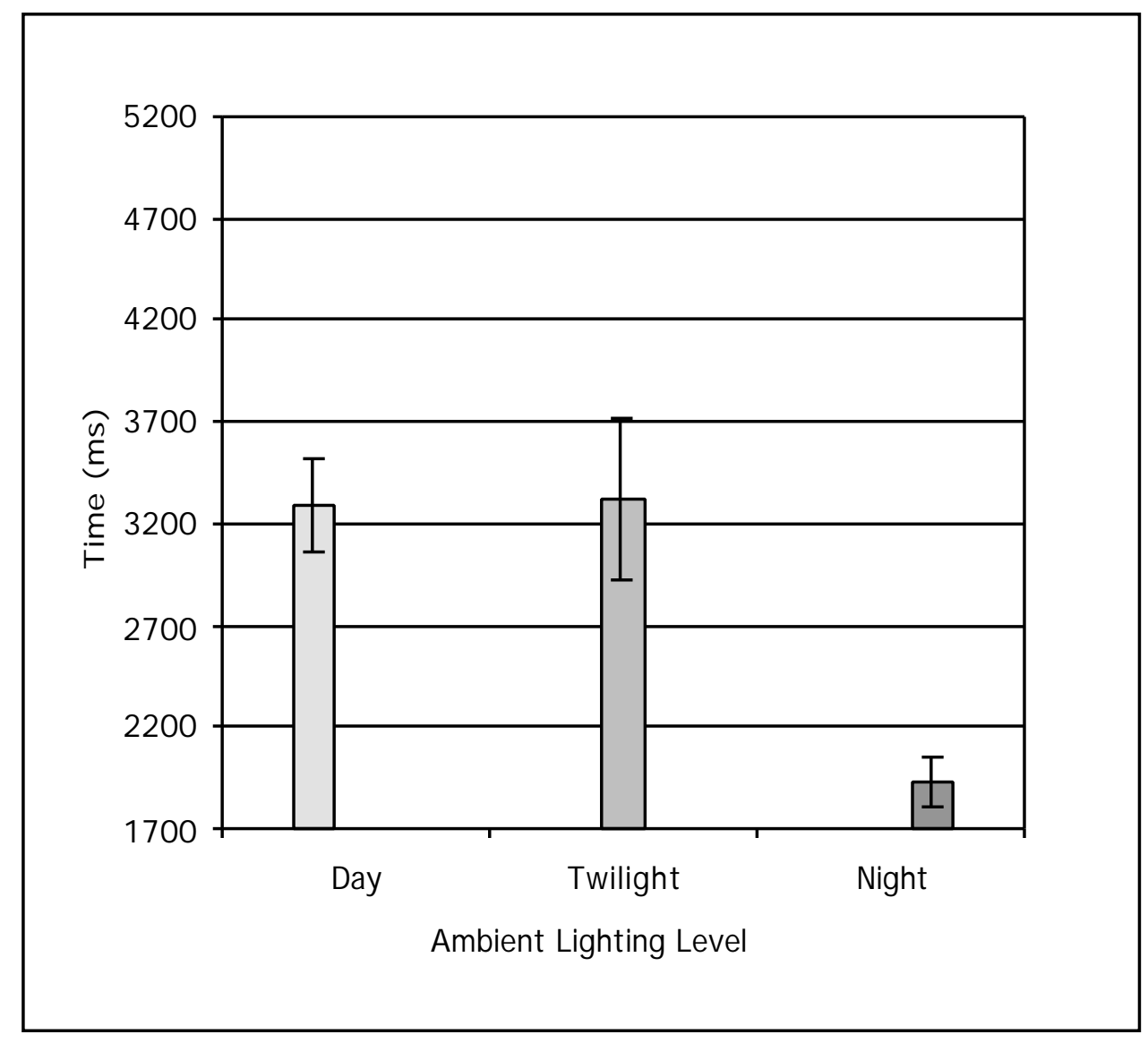

Figure 15: Main Effect of Ambient Illumination on Fine Navigation Time-toPassage for Safety Bucket Condition. Error bars are $+/-1$ standard error of the mean.

On a post-hoc basis, a Newman-Keuls range test was performed for the safety bucket hazard to determine, through pairwise comparisons, which lighting levels were significantly different from other levels. Results for the safety bucket condition are shown in Table 10. The night lighting level is statistically different from the day lighting level and from twilight lighting level. Twilight lighting levels and day lighting levels were not statistically different. 
Table 10: Newman-Keuls Results for Fine Navigation Time-to-Passage for Safety Bucket Condition.

\begin{tabular}{ccclc}
\hline Navigation Hazard & Lighting Level & $\bar{x}-\mathrm{Tp}(\mathrm{ms})$ & \multicolumn{2}{c}{ Group } \\
\hline Safety Bucket & Day & 3289 & $\mathrm{G}$ & \\
& Twilight & 3318 & $\mathrm{G}$ & \\
& Night & 1921 & & $\mathrm{H}$ \\
\hline
\end{tabular}

Groups with the same letter are not statistically different, $p>0.10$.

Results for Condition 2: Road Triangle Hazard.

The Road Triangle Hazard generated significant results across the Lighting Level variable. ANOVA results for the Road Triangle Hazard are reported in Table 11.

Table 11: ANOVA Summary Table for Fine Navigation Time-to-Passage for Road Triangle Condition

\begin{tabular}{llllll}
\hline Source & $d f$ & $S S$ & $M S$ & $F$ & $p$ \\
\hline Lighting Level (L) & 2 & 25957286 & 12978643 & 10.71 & $\mathbf{0 . 0 0 1}$ \\
Subjects (S/L) & 42 & 50889260 & 1211649 & & \\
\hline Total & 44 & 76846544 & & & \\
\hline
\end{tabular}




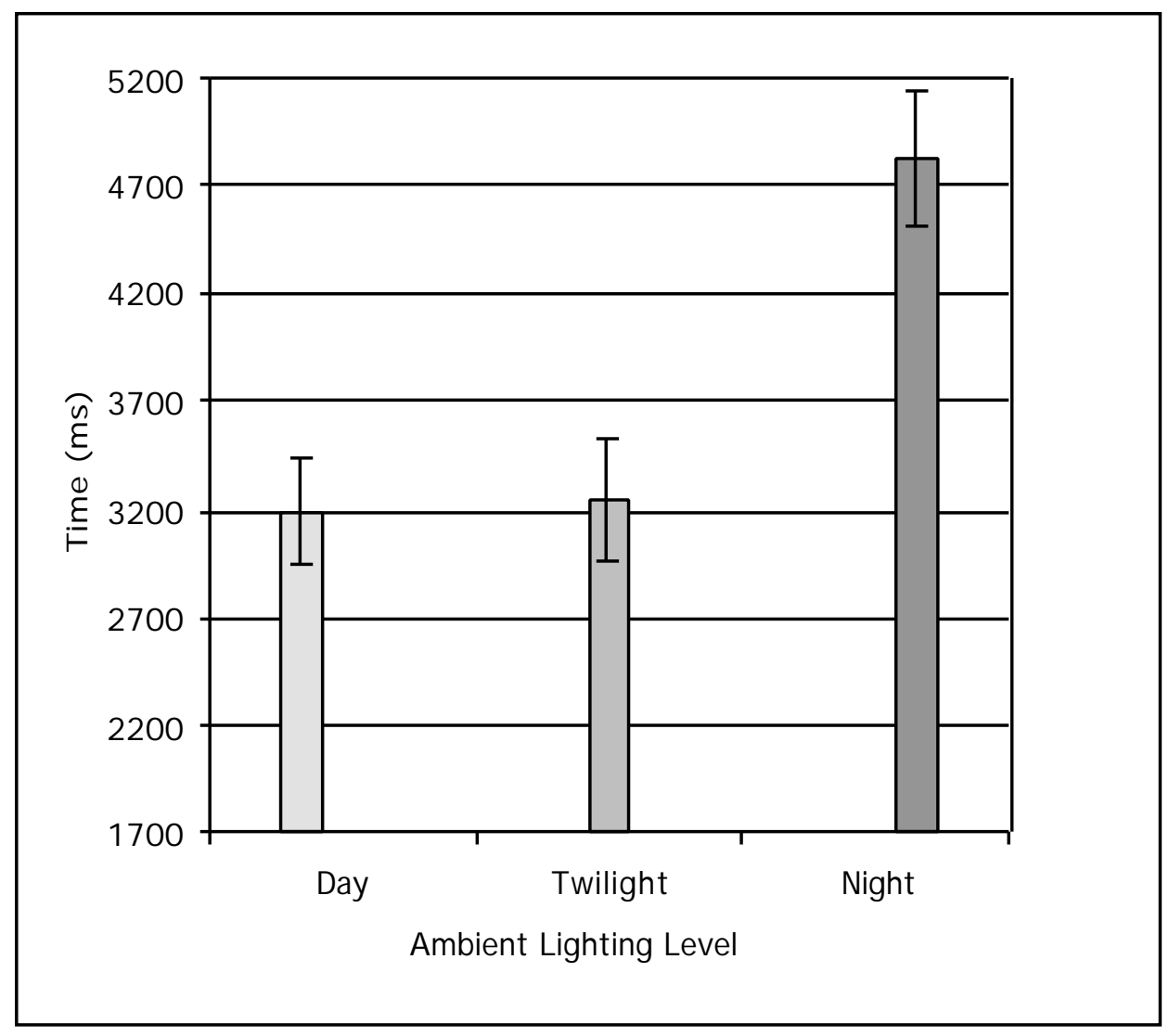

Figure 16: Main Effect of Ambient Illumination on Fine Navigation Time-to-

Passage for Road Triangle Condition. Error bars are $+/-1$ standard error of the mean.

On a post-hoc basis, a Newman-Keuls range test was performed for the Road Triangle Hazard to determine, through pairwise comparisons, which lighting levels were significantly different from other levels. Results are shown in Table 12. For the Road Triangle navigation hazard, the night lighting level is statistically different from the day lighting level and from twilight lighting level. Twilight lighting levels and day lighting levels were not statistically different. 
Table 12: Newman-Keuls Results for Fine Navigation Time-to-Passage for Road Triangle Condition.

\begin{tabular}{ccccc}
\hline Navigation Hazard & Lighting Level & $\bar{x}-\mathrm{Tp}(\mathrm{ms})$ & \multicolumn{2}{c}{ Group } \\
\hline Road Triangle & Day & 3198 & $\mathrm{I}$ & \\
& Twilight & 3242 & $\mathrm{I}$ & \\
& Night & 4831 & & $\mathrm{~J}$ \\
\hline
\end{tabular}

Groups with the same letter are not statistically different, $p>0.10$.

Basic statistics for each navigation hazard type and each lighting level are reported in Table 13.

Table 13: Basic Statistics for Experiment 2: Fine Navigation Time-to-Passage, Tp.

\begin{tabular}{cccc}
\hline Navigation Hazard & Lighting Level & $\overline{\mathrm{x}} \mathrm{Tp}(\mathrm{ms})$ & $\mathrm{S}-\mathrm{Tp}(\mathrm{ms})$ \\
\hline 1. Safety Bucket & Day & 3289 & 882 \\
& Twilight & 3318 & 1537 \\
& Night & 1921 & 467 \\
& & & \\
2. Road Triangle & Day & 3198 & 953 \\
& Twilight & 3242 & 1102 \\
& Night & 4831 & 1230 \\
\hline
\end{tabular}




\section{Examining Dispersion of Means Across Conditions}

While specific locations should not be compared directly to each other due to differences in physical geometry and transitions in types of locomotion, it is interesting to briefly examine the dispersion of the means for each location and lighting level as compared to other, similar location. The graphs presented here are not designed for analytical purposes. The curves roughly represent normal curves. $P(T c)$ is the probability that a $T c$ is at that value. $A$ $\mathrm{P}(\mathrm{Tc})$ of 0.5 represents the mean value for that condition. Figure 17 compares all Tc locations under all lighting conditions. Figure 18 looks specifically at the Stairs-Up and Stairs-Down locations, as they used the same staircase. Figure 19 compares the two passage-type hazards, as they were both placed on relatively comparable sidewalks.

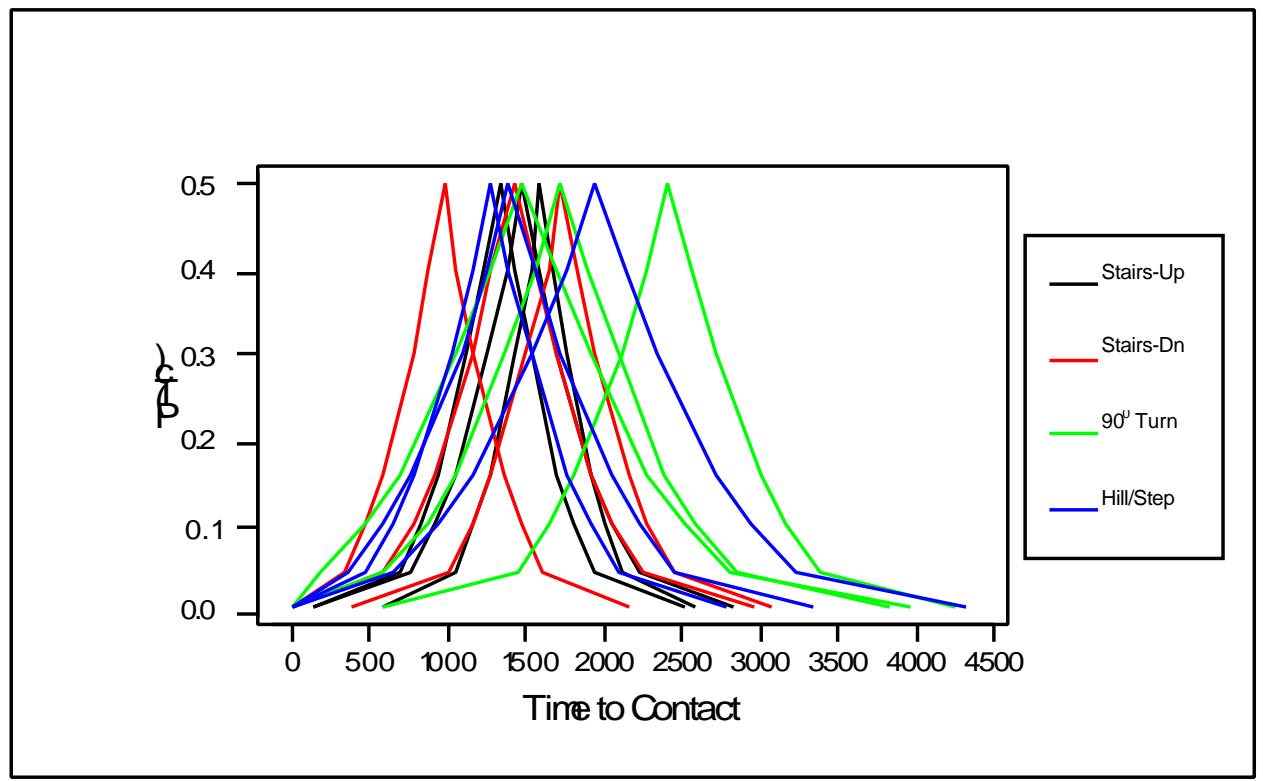

Figure 17: Dispersion of means across Tc conditions. Three curves in each color represent Day, Twilight, and Night Lighting conditions, respectively.

The large cluster of dispersions covers a wide band, ranging from peaks at about $1000 \mathrm{~ms}$ to just under $2000 \mathrm{~ms}$. 


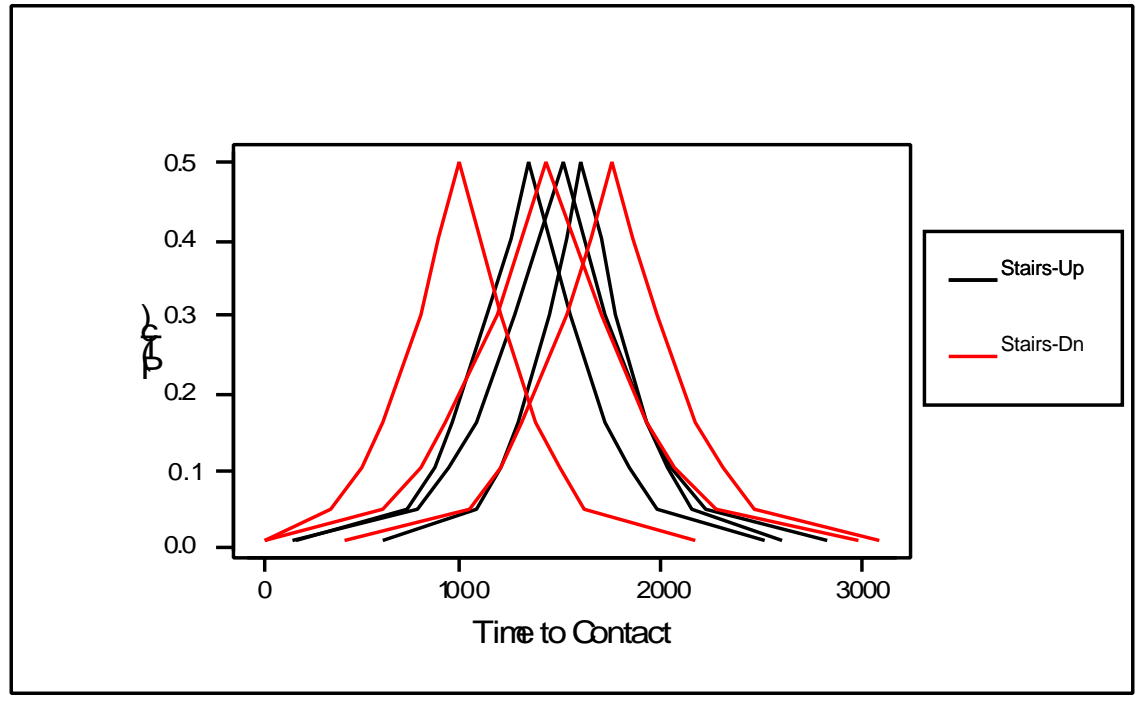

Figure 18: Dispersion of means across Stairs-Up and Stairs-Down conditions. Three curves in each color represent Day, Twilight, and Night Lighting conditions, respectively.

It is interesting to observe that Stairs-Up was clustered closely together, which demonstrates the lack of statistical difference among lighting levels at that location. The Stairs-Down location shows more dispersion in means and variance. That location did have statistical differences among lighting levels 


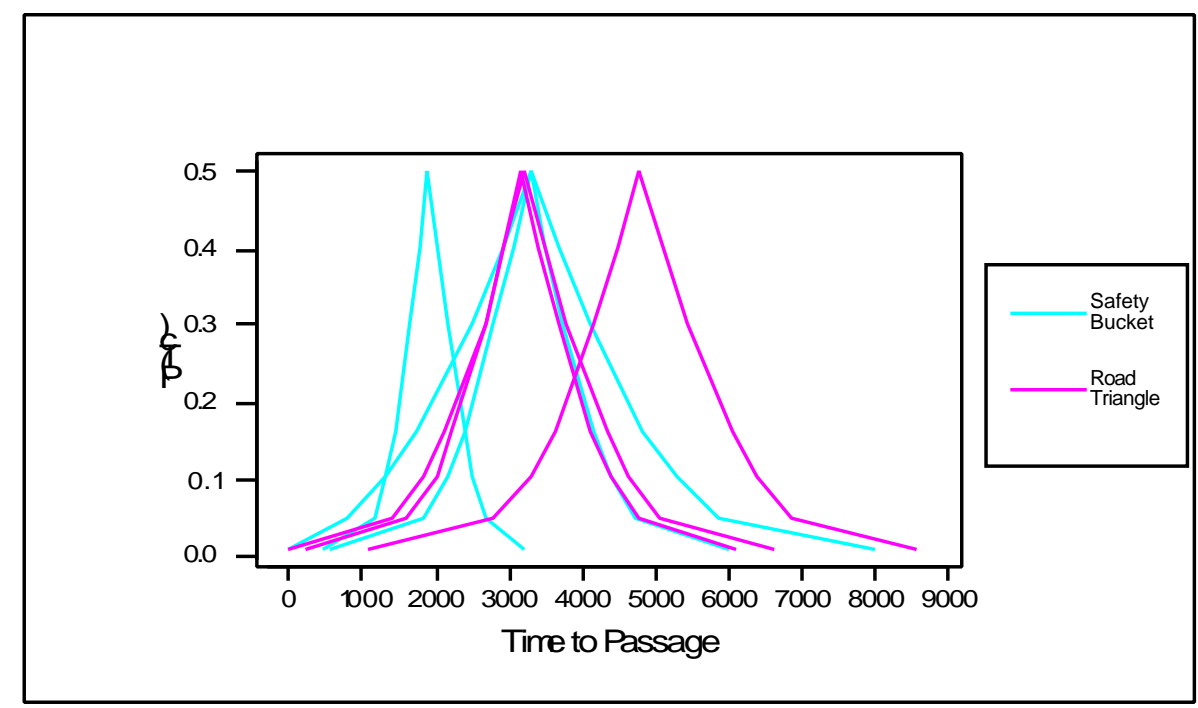

Figure 19: Dispersion of means across Safety Bucket Hazard and Road Triangle Hazard conditions. Three curves in each color represent Day, Twilight, and Night lighting conditions, respectively.

The Safety Bucket Hazard and Road Triangle Hazard locations both shows dispersion in means and variance. These locations did have statistical differences among lighting levels. 


\section{DISCUSSION}

\section{Fine Navigation Time-to-Contact.}

The results of Experiment 1: Fine Navigation Time-to-Contact indicate that, assuming normal walking speeds, humans switch from a gross navigation strategy to a fine navigation strategy farther away from a navigation hazard under night ambient lighting conditions than under day lighting conditions. There is no consistently notable difference in Tc when comparing day to twilight or twilight to night conditions.

Any differences noted within a particular hazard type could be a function of the type of hazard, but could be influenced also by shadows cast by the local vegetation. Since shadows were not experimentally controlled, they do function as a confounding factor for this experiment. However, since they are naturally occurring, even indoors, engineers must recognize that they play a factor in the design of walkways.

It is interesting to note that many of the means observed, regardless of the hazard type, lighting condition, or presence of shadows still fall close to the common Tc's observed of about 1500 ms for laboratory experiments where participants were walking, jogging, or running (Bardy, et al., 1991; Wann, et al., 1993).

While it is tempting to statistically compare results between navigation hazard types and draw conclusions, doing this would not yield truly meaningful results. The specific location dimensions of the different hazard types varied widely. As an example, it would not be meaningful to compare the Stairs-Down $x$ Day Lighting condition, where the path was $3.65 \mathrm{~m}$ wide, was level, and had 6 stairs, to the Hill with Step $x$ Night Lighting condition, where the path was 1.52 $\mathrm{m}$ wide, was inclined at two different angles, and had one step. The physical 
locations, surrounding vegetation, area utilization (walking path vs. building access), and specific navigation hazards presented are different. Even for the stairs-up and stairs-down locations, which used the same staircase, there were differences. Those two conditions had differences in path length and path dynamics (curved versus straight) leading to the navigation hazard. This study did not examine whether the brain would interpret the navigation hazards presented in a similar fashion. For that reason, no statistically-based cross hazard comparisons will be made.

\section{Fine Navigation Time-to-Passage.}

In the safety bucket results, the mean Tp for the night condition was considerably lower than the mean $\mathrm{Tp}$ for the road triangle. There are a number of reasons why this mean could be so different. The ambient night lighting level was lower at the safety bucket location ( 0.85 lux versus 2.32 lux at the road triangle), although both levels do qualify as night conditions, with ambient lighting of less that 5 lux. The lower light could have prevented participants from spotting the bucket until they were much closer. It could also have prevented the experimenter from catching very subtle body cues until the participant was closer to the safety bucket, thus cueing time start. Also, while the safety bucket's stripes are designed to be highly visible, the bucket still has a more muted coloration scheme (yellow, black and almond) than the road triangle, which is fluorescent orange and has red reflectors. Participants may have been able to see the triangle better at a distance, cueing navigation changes farther in advance of the navigation hazard, as compared to the safety bucket.

The results of Condition 2: Road Triangle indicate that, assuming normal walking speeds, humans switch from a gross navigation strategy to a fine navigation strategy farther away from the hazard under night lighting 
conditions than under day lighting conditions. There is also a notable difference in Tp when comparing twilight to night conditions.

For both hazards, the safety bucket and the road triangle, any differences noted are likely to be a function of the type of hazard. For these particular hazard locations, there was no large vegetation, nor were there any other large, non-uniform shadow casting structures.

Once again, it is tempting, but not meaningful, to compare results between navigation hazard types and draw conclusions. While the specific dimensions for locations of the different hazard types were fairly uniform, and shadows were not a confound, the hazard types were different in their comparative visibility (safety bucket's yellow, black and almond colors versus road triangle's fluorescent orange and red reflectors) and were on sidewalks of differing slopes. This study did not examine whether the individual would interpret those two color schemes similarly or whether the slope differences would have an impact on visual interpretation of the scene. For that reason, no cross hazard comparisons will be made.

\section{Comparison of Results to Prior Studies.}

Bardy et al. (1991) conducted a study that required participants to walk at $1.5 \mathrm{~m} / \mathrm{s}$ and place their noses on a face high target, creating a Tc condition. Their experimental results ranged from 1.14 to 1.41 seconds (1140 to 1410 $\mathrm{ms}$ ), depending on single or dual task methodology and size of target. Their ambient lighting conditions were at indoor levels, which is usually above 200 lux. Comparably, daylight Tc numbers from this study are $1333.4 \mathrm{~ms}$ for StairsUp, $977.8 \mathrm{~ms}$ for Stairs-Down, $1493 \mathrm{~ms}$ for $90^{\circ}$ Turn, and $1282.2 \mathrm{~ms}$ for Hill with Step. This compares fairly favorably. 
The Tp results for day and twilight lighting conditions are similar to those observed by Cutting, et al. (1992) in their experiment of walking past an obstacle. For a forward velocity of $1.9 \mathrm{~m} / \mathrm{s}$, Cutting, et al. (1992) observed a reaction time of 3.08 seconds, or $3080 \mathrm{~ms}$. Cutting's forward velocity of $1.9 \mathrm{~m} / \mathrm{s}$ is a faster walking pace than the pace this experiment observed. The experiment also was more controlled that this experiment. Nevertheless, Experiment 2 yielded means of $3289 \mathrm{~ms}$ (safety bucket) and $3198 \mathrm{~ms}$ (road triangle) under day lighting and $3318 \mathrm{~ms}$ (safety bucket) and $3242 \mathrm{~ms}$ (road triangle) under twilight lighting conditions.

Unfortunately, results could not be correlated with the original long jump studies to see if Tc does change with speed. Lee et al. (1982) and Hay (1988) both reported results in terms of stride length standard deviations, not mean distances before the take-off board. These results could not be changed to Tc numbers with the information provided in the reports.

\section{Age-Related Issues}

While there was no upper age restriction on study participants, a majority of the study's participants were younger adults, under the age of 40 . This is not unexpected, considering that the locations used were either on a university campus or in the area immediately surrounding the university. Observed individuals were excluded if they had observable difficulty walking or walked at a pace much slower than other observed individuals. This would preclude many elderly individuals. Without extensive study of the walking characteristics of older individuals and correlation with similar characteristics of younger individuals and the criteria presented here, this study's results should not be generalized to older populations.

\section{Engineering Applications and Guideline Development.}

While cross hazard comparisons are not made in this study, engineers can still use the information gathered as a start point for visibility guidelines for 
walkways. Prior research outlined in the background section indicates that, conceptually, Tc or Tp is the same for a specific task regardless of approach speed. Theoretically the same Tc or Tp numbers should apply if the individual is walking, running, or approaching at an in-between speed.

In human factors engineering, the common standard is to accommodate the $5^{\text {th }}$ to $95^{\text {th }}$ percentiles of humans in an environment. However, the study's results show a high level of variance in the numbers. Ninety-fifth percentile numbers would lead to exceedingly large areas that must be clear around navigation hazards. Additionally, all individuals observed during the videotaping of the locations successfully navigated the hazard. No one was observed tripping or falling over a navigation hazard. Information on navigational miscues would be valuable in deciding precisely where guidelines should be set.

From an engineering perspective, a balance must be reached between accommodating the widest range of individuals and providing the best utilization of valuable space. Considering that no one observed had trouble navigating the hazards and that no information regarding the Tc's or Tp's for unsuccessful navigation attempts is available, a design strategy of "designing for the average (Sanders and McCormick, 1987)" may be the best place to start.

When utilizing the results from this study, and any studies that may follow, the engineer or facility designer should bear a few ideas in mind. While Tc or Tp may not change with forward velocity, the amount of ground covered in that time is certainly speed dependent. A reasonable attempt should be made to fully define the uses of the facility under consideration. In most commercial, industrial, governmental, academic, and residential areas, a "walking speed" may be a safe presumption. In locomotor literature, walking speed has been described as $1.5 \mathrm{~m} / \mathrm{s}$ (Bardy et al., 1991) to $1.9 \mathrm{~m} / \mathrm{s}$ (Cutting et. al, 1992). Athletic facilities should be designed anticipating a faster locomotor velocity, 
thus accommodating jogging and running trails and tracks. Warren et al. (1986) simulated cross country running at $4 \mathrm{~m} / \mathrm{s}$. Typical world class athletes run at $9 \mathrm{~m} / \mathrm{s}$ (Hay, 1988). With a range between $1.5 \mathrm{~m} / \mathrm{s}$ and $9 \mathrm{~m} / \mathrm{s}$, there is a substantial difference in clear visible area required depending on the appropriate locomotor speed selection.

Another concept to consider is the specific layout of the locations detailed here. For instance, the staircase was $3.66 \mathrm{~m}$ wide, wider than most indoor staircases are. It is also 6 stair treads high, which is not unusual for outdoor applications. However, most indoor staircases are used to change floors, and are at least 12 stair treads per half story. Supplemental research should be done to determine if Tc's and Tp's vary within similar conditions (like different height and width staircases). Any guidelines developed should be tightly constrained and used only for matching conditions.

Ultimately, a large amount of supplemental research should be performed before any Tc or Tp numbers can be used to formulate code-quality guidelines. The wide variability in times exhibited here can be refined with much larger sample sizes. Examination of quantities of similar types of hazards, like multiples of similar types of staircases, would show if times are generalizable across different surface contrast levels, surface materials, and overall dimensions.

After extensive research, a goal of solid design guidelines should be attainable. The guidelines could look like the examples provided in Table 16 and 17. The speeds were chosen based upon researchers reports of walking speeds (Bardy, et al., 1991; Wann, et al., 1993) and running speeds (Warren et al., 1986, Lee, et al., 1982; Hay 1988). $1.8 \mathrm{~m} / \mathrm{s}$ is considered a brisk walking speed. $4 \mathrm{~m} / \mathrm{s}$ is an estimated jogging or cross country running speed. $7 \mathrm{~m} / \mathrm{s}$ is a road running speed. $9 \mathrm{~m} / \mathrm{s}$ is a world class athlete's running speed. 
Table 14: Sample Design Guidelines for Safe Pedestrian Navigation of Contact Type Hazards for a Variety of Locomotor Speeds.

\begin{tabular}{|c|c|c|c|c|c|}
\hline Contact Type & & \multicolumn{4}{|c|}{ Distance Traveled } \\
\hline Navigation Hazard & $\begin{array}{l}\text { Mean } \\
\text { Time }\end{array}$ & $1.8 \mathrm{~m} / \mathrm{s}$ & $4 \mathrm{~m} / \mathrm{s}$ & $7 \mathrm{~m} / \mathrm{s}$ & $9 \mathrm{~m} / \mathrm{s}$ \\
\hline $\begin{array}{l}\text { Stairs-traveling up: poured } \\
\text { concrete, } 6 \text { treads: } 5 / 12 \\
\text { pitch, } \\
3.66 \mathrm{~m} \text { wide } \times 0.66 \mathrm{~m} \text { high }\end{array}$ & $1.60 \mathrm{~s}$ & $2.88 \mathrm{~m}$ & $6.4 \mathrm{~m}$ & $11.2 \mathrm{~m}$ & $25.6 \mathrm{~m}$ \\
\hline $\begin{array}{l}\text { Stairs-traveling down : } \\
\text { poured concrete, } 6 \text { treads: } \\
5 / 12 \text { pitch, } \\
3.66 \mathrm{~m} \text { wide } \times 0.66 \mathrm{~m} \text { high }\end{array}$ & $1.74 \mathrm{~s}$ & $3.1 \mathrm{~m}$ & $7.0 \mathrm{~m}$ & $12.2 \mathrm{~m}$ & $15.7 \mathrm{~m}$ \\
\hline $\begin{array}{l}90^{\circ} \text { Turn: plaza setting } \\
\text { poured concrete, } 3.66 \mathrm{~m} \text { wide } \\
\text { pathway }\end{array}$ & $2.42 \mathrm{~s}$ & $4.4 \mathrm{~m}$ & $9.7 \mathrm{~m}$ & $17.0 \mathrm{~m}$ & $21.8 \mathrm{~m}$ \\
\hline $\begin{array}{l}\text { Inclined Sidewalk with Step: } \\
\text { poured concrete, } 3.66 \mathrm{~m} \\
\text { wide, } 1 \text { step: } 6 / 12 \text { pitch, } \\
\text { Slope } 5.06^{\circ} \text { to } 8.73^{\circ} .\end{array}$ & $1.95 \mathrm{~s}$ & $3.5 \mathrm{~m}$ & $7.8 \mathrm{~m}$ & $13.7 \mathrm{~m}$ & $17.6 \mathrm{~m}$ \\
\hline
\end{tabular}


Table 15: Sample Design Guidelines for Safe Pedestrian Navigation of Passage Type Hazards for a Variety of Locomotor Speeds.

\begin{tabular}{|l|c|c|c|c|c|}
\hline \multicolumn{1}{|c|}{$\begin{array}{l}\text { Types of Navigation Hazard } \\
\text { That Are Passed }\end{array}$} & $\begin{array}{c}95 \% \\
\text { Time }\end{array}$ & $1.8 \mathrm{~m} / \mathrm{s}$ & $4 \mathrm{~m} / \mathrm{s}$ & $7 \mathrm{~m} / \mathrm{s}$ & $9 \mathrm{~m} / \mathrm{s}$ \\
\hline $\begin{array}{l}\text { Neutral Colored, Marked } \\
\text { Navigation Hazard: } \\
24 \mathrm{~cm} \text { high x } 26 \mathrm{~cm} \text { wide } \times 26 \\
\mathrm{~cm} \text { deep } \\
\begin{array}{l}\text { Placed on poured concrete, } \\
\text { level sidewalk }\end{array}\end{array}$ & $3.32 \mathrm{~s}$ & $6.0 \mathrm{~m}$ & $13.3 \mathrm{~m}$ & $23.2 \mathrm{~m}$ & $29.9 \mathrm{~m}$ \\
$\begin{array}{l}\text { Reflective Red/Orange } \\
\text { Hazard Marker: } \\
43.18 \mathrm{~cm} \text { high } \mathrm{x} 42 \mathrm{~cm} \text { wide, } \\
\text { placed on } \\
\text { poured concrete sidewalk, } \\
\text { slight incline. }\end{array}$ & $4.83 \mathrm{~s}$ & $8.7 \mathrm{~m}$ & $19.3 \mathrm{~m}$ & $33.8 \mathrm{~m}$ & $43.5 \mathrm{~m}$ \\
\hline
\end{tabular}




\section{CONCLUSIONS / IMPACT}

The results collected in this study help to clarify the heuristic model of walking proposed earlier. These results help most in clarifying the switching between the gross navigation and the fine navigation stages

\section{Review of Metamodel of Walking.}

\section{Gross Navigation.}

Gross Navigation takes place when individuals are moving from one navigational landmark to another. Navigational landmarks are those landmarks that form hazards to locomotion (e.g., staircases, curbs) or indicate that direction must be changed (e.g., intersections). Some characteristics of gross navigation that are impacted by this study's results are:

1. Gross navigation takes into account observed gross impediments (construction, obstructions, safety issues observed during locomotion).

2. Affordances of support (Gibson, 1979) are taken into consideration.

\section{Fine Navigation.}

Fine Navigation takes place when individuals are maneuvering around or across those hazards to navigation encountered in the environment. Fine Navigation requires more attention than gross navigation, because the individual is moving through an area that has potential safety hazards or areas that, if not recognized, could lead to navigational mistakes. Some characteristics of fine navigation that are impacted by this study's results are:

1. Fine Navigation guides the individual through transitions in locomotor strategy or methodology. 
2. Fine Navigation usually is limited to areas where there are Gibson's (1979) "preventers of locomotion:...obstacles, barriers, water margins, and brinks."

3. Affordances of support (Gibson, 1979) are under continual reevaluation.

\section{Model in Action.}

When the individual reaches the first navigational landmark, navigation strategy switches from gross navigation to fine navigation until the landmark is safely negotiated. Then the individual switches back to gross navigation. Gross and fine navigation can switch in rapid succession if there is a series of landmarks in close proximity. Under normal circumstances, the walker cycles between stages 2 and 3 continually until the walker reaches the destination. The walker is not normally aware of the switches in navigation strategy

This model is a rapid response model. Changes in navigation stages are automatic and are responsive to warranted circumstances. Anything less than a rapid response and navigation switch would leave the individual more vulnerable to injury than is currently seen.

\section{New Insights Gained.}

The study's results help refine the understanding of the transition between gross navigation and fine navigation as the individual approaches a navigational landmark or hazard.

Humans navigate differently if they are coming in contact with the hazard (a Contact situation) than if they are passing the hazard without ever needing to touch it (a Passage situation). Because humans navigate these situations differently, the timing of the transition from gross to fine navigation is different. 
Passage situations evidently require more fine navigation skills to assure the hazard is successfully passed, with no contact between individual and hazard.

Humans require more time to evaluate a navigation hazard before reaching it if lighting levels are low, assuming they can recognize that a hazard exists early enough. Under every condition except one (Stairs-Up), individuals walking under Night Lighting conditions required significantly longer amounts of time using their fine navigation skills before they contacted or passed by the hazard. This translates into additional viewing space being required over the daytime or twilight conditions, since the individuals are moving as they are utilizing their navigation abilities.

\section{Additional Research Opportunities.}

At this point, navigation hazards should not be universally given a Tc or Tp value. Visual recognition of hazards is dependent upon the area over which the hazard is situated. Tc and Tp may be influenced by such things as surface material, width and depth of viewing area, weather and precipitation, hazard surface contrast, shadows cast by surroundings, slope of walking surface, and a host of other influences that were not considered in depth in this study. Tc and Tp may also be influenced on knowledge of the locomotion area.

An individual who travels across an area frequently has some knowledge of upcoming hazards, whereas strangers do not. The individual who is a stranger to an area may pick up on unexpected hazards sooner than the familiar individual. This could impact Tc and Tp values. Information in this area would be valuable for designers of areas that have large concentrations of "strangers" to the surroundings, such as airports, railway stations, and tourist attractions. 
Further research to develop, expand, and confirm a database of basic Tc and $T p$ values would benefit the engineering, architecture, landscaping, and interior design professions, as well as anyone else who must evaluate the trip and fall potential of a specific navigation hazard area.

\section{Human Factors Engineering and Design Impact.}

For the human factors engineer, this study introduces an overall way of looking at locomotion, specifically walking, through the heuristic model of walking. It confirms the idea that design of walkways cannot be performed by strictly looking at distances, because the human brain does not judge navigational decisions based on spatial (distance) estimation. The human uses temporal (time) estimation to make navigational decisions. Navigational decision making involves more than just deciding to go from one point to another. The brain continually changes navigation modes, from gross navigation strategy to fine navigation strategy, to help insure safety as the individual is locomotoring. It is possible that miscues of this navigational change are responsible, in part, for trip, and fall injuries.

Practical applications principally are in the facilities planning and safety design fields. If the human factors engineer is supplied with enough information (such as hazard type, characteristics of hazard approach, ranges of ambient light, normal Tc and Tp data for the hazard type, and predicted mean approach speeds) the engineer can create an optimized design for walkway construction. This will help in planning or redesigning facilities, maximizing usable floor space while providing enough visual information for safe, effective locomotion. Human factors engineers also could evaluate existing walkway layouts to see if there is a mismatch between the human's needs and the environment's affordances. Recommendations for changes to improve the safety of the individual can then be made. 
By adopting a perceptual view of walking, and, specifically, examining the visual requirements for safe and effective locomotion, the human factors engineer could interact knowledgeably with other professionals responsible for the design of walking spaces, helping to assure that the paths humans must take are designed to meet the human's requirements. 


\section{REFERENCES}

Bardy, B.G., and Laurent, M. (1989). Use of Peripheral Vision in the Decision to Brake. Perceptual and Motor Skills, 69, 163-166.

Bardy, B.G., and Laurent, M. (1991). Visual Cues and Attention Demand in Locomotor Positioning. Perceptual and Motor Skills, 72, 915-926.

Beyer, W.H. (Ed.). (1988). CRC Handbook of Tables for Probability and Statistics. Boca Raton, FL: CRC Press.

Cohen, H.H., and Cohen, D.M. (1992). Walking Requires Your Attention: a Human Factors Analysis of Slip and Fall Accidents. Forensic Reports, 5, 273-282.

Cohen, H.H., and Cohen, D.M. (1994). Perception of Walking Surface Slipperiness Under Realistic Conditions Utilizing a Slipperiness Rating Scale. Journal of Safety Research, 25(1), 27-31.

Cohen, H.H., Templer, J., and Archea, J. (1985). Analysis of Occupational Stair Accidents. Journal of Safety Research, 16, 171-181.

Cutting, J.E. (1996). Wayfinding From Multiple Sources of Local Information in Retinal Flow. Journal of Experimental Psychology: Human Perception and Performance, 22, 1299-1313.

Cutting, J.E., Springer, K., Braren, P.A., and Johnson, S.H. (1992). Wayfinding on Foot From Information in Retinal, Not Optical, Flow. Journal of Experimental Psychology: General, 121, 41-72. 
Flach, J.M. (1995). Situation Awareness: Proceed with Caution. Human Factors, 37(1), 149-157.

Gibson, J.J., (1950). The Perception of the Visual World. Boston: HoughtonMifflin.

Gibson, J.J., (1958). Visually Controlled Locomotion and Visual Orientation in Animals. British Journal of Psychology, 49, 182-194.

Gibson, J.J., (1979). The Ecological Approach to Visual Perception. Boston: Houghton Mifflin.

Gibson, J.J., (1994). The Visual Perception of Objective Motion and Subjective Movement. (Reprint of original work in Psychological Review, 61, 304314). Psychological Review, 101, 318-323.

Hay, J.G. (1988). Approach Strategies in the Long Jump. International Journal of Sport Biomechanics, 4, 114-129.

Hollands, M.A., Marple-Horvat, D.E., Henkes, S., and Rowan, A.K. (1995). Human Eye Movement During Visually Guided Stepping. Journal of Motor Behavior, 27, 155-163.

Kaiser, M.K., and Hecht, H. (1995). Time to Passage Judgments in Nonconstant Optical Flow Fields. Perception and Psychophysics, 57(6), 817-825.

Kaufman, J.E., and Christensen, J.F. (Eds.). (1972). IES Lighting Handbook: The Standard Lighting Guide: Fifth Edition. New York: Illuminating Engineering Society of North America. 
Kaufman, J.E., and Christensen, J.F. (Eds.). (1984). IES Lighting Handbook: 1984 Reference Volume. New York: Illuminating Engineering Society of North America.

Kim, N.G., Turvey, M.T., and Growney, R. (1996). Wayfinding and the Sampling of Optical Flow By Eye Movements. Journal of Experimental Psychology: Human Perception and Performance, 22, 1314-1319.

Konczak, J. (1994). Effects of Optic Flow on the Kinematics of Human Gait: A Comparison of Young and Older Adults. Journal of Motor Behavior, 26, 225-236.

Laurent, M. and Thomson, J.A. (1991). Anticipation and Control in VisuallyGuided Locomotion. International Journal of Sport Psychology, 22, 251270.

Lee, D.N. (1974). Visual Information During Locomotion. In R. MacLeod and H. Pick (Eds.), Perception: Essays in Honor of James J. Gibson (pp. 250267). Ithaca, NY: Cornell University Press.

Lee, D.N., Lishman, J.R., and Thomson, J.A. (1982). Regulation of Gait in Long Jumping. Journal of Experimental Psychology: Human Perception and Performance, 8, 448-459.

Lee, D.N. and Thomson, J.A. (1982). Vision in Action: The Control of Locomotion. In D.J. Ingle, M. Jeannerod, and D.N. Lee (Eds.), Analysis of Visual Behavior (pp. 411-433). Cambridge: MIT Press. 
McFayden, B.J., Magnan, G.A., and Boucher, J.P. (1993). Anticipatory Locomotor Adjustments for Avoiding Visible, Fixed Hazards of Varying Proximity. Human Movement Science, 12, 259-272.

Minitab, Inc. (1995). Minitab: Release 10Xtra Windows/Macintosh. State College, PA: Author.

National Safety Council. (1996). Accident Facts. 1996 Edition. Itasca, IL: Author.

Niebel, B.W. (1988). Motion and Time Study, Eighth Edition. Homewood, IL: Irwin, Inc.

Patla, A.E. (1989). In Search of Laws for the Visual Control of Locomotion: Some Observations. Journal of Experimental Psychology: Human Perception and Performance, 15, 624-628.

Patla, A.E., Prentice, S.D., Robinson, C., and Neufield, J. (1991). Visual Control of Locomotion: Strategies for Changing Direction and for Going Over Hazards. Journal of Experimental Psychology: Human Perception and Performance, 17, 603-634.

Sanders, M.S., and McCormick, E.J. (1993). Human Factors in Engineering and Design. New York: McGraw-Hill.

Smyth, M.M., and Wing, A.M. (1984). The Psychology of Human Movement. London: Academic Press.

Strandberg, L., and Lanshammar, H. (1981). The Dynamics of Slipping Accidents. Journal of Occupational Accidents, 3, 153-162. 
Swensen, E.E., Purswell, J.L., and Schlegel, R.E. (1992). Coefficient of Friction and Subjective Assessment of Slippery Work Surfaces. Human Factors, 34(1), 67-77.

Tisserand, M. (1985). Progress in the Prevention of Falls Caused By Slipping. Ergonomics, 28(7), 1027-1042.

Wann, J.P., Edgar, P., and Blair, D. (1993). Time-To-Contact Judgment in the Locomotion of Adults and Preschool Children. Journal of Experimental Psychology: Human Perception and Performance, 19, 1053-1065.

Warren, W.H., Young, D.S., Lee, D.N. (1986). Visual Control of Step Length During Running Over Irregular Terrain. Journal of Experimental Psychology: Human Perception and Performance, 12, 259-266.

Wickens, C.D., (1984). Engineering Psychology and Human Performance. Columbus: Charles E. Merrill Publishing.

Winer, B.J., Brown, D.R., and Michels, K.M. (1991). Statistical Principles in Experimental Design. New York: McGraw-Hill.

Zohar, D. (1978). Why Do We Bump Into Things While Walking. Human Factors, 20, 671-679. 


\section{APPENDIX A}

\section{IRB APPROVAL- EXEMPTION}




\section{Virginia}

[IIII) Tech

VIRGINIA POLYTECHNIC INSTITUTE

AND STATE UNIVERSITY

Office of Sponsored Programs

301 Burruss Hall

Blecksburg. Virginia 24061-0249

(540) 231.5013 Fax: (540) 231.4822

\section{MEMORANDUM}

TO:

Christi J. Adams, Robert J. Beaton

Industrial and Systems Engineering

FROM: H. T. Hurd

Director

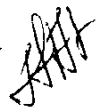

DATE: October 1, 1996

SUBJECT: IRB APPROVAL-EXEMPTION/"Evaluation of Variability in Optical Flow Time to Contact as a Function of Navigation

Hazard and Environmental Lighting Conditions" -

IRB \#96-243

I have reviewed your request to the IRB for exemption for the above referenced project. I concur that the research falls within the exempt status.

Best wishes.

$\mathrm{HTH} / \mathrm{pli}$

A Land-Grant University-The Commonwealth Is Our Campus

An Equal Opporninity/ Affirmative Acrion Institution 
Investigators): Choust I Adams; Robert I Beaton PhD

Departmentis: Trdustrial and Systems Engineering

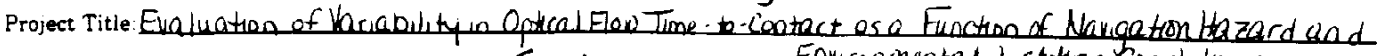
Source of Support: Departmental Research D' Sponsored Research J Enyironinental Lighting Conditions

1. The criteria for "exemption" from review by the IRB for a project involving the use of huma $96-243$ subject is listed below. Please initial all appiicable conditions and provide the substantjangg statement of protosol.

a. The research will be conducted in estabilished or commonly established educational settings. involving normal education practices. For example:

1) Research on regular and special education instructional strategies:

2) Research on effectiveness of instructional techniques. curricula or classroom management techniques.

$\square$ b. The research involves use of education tests ( - cognitive, _ diagnostic, _ aptitude, _achievement). and the subject cannot be identified directly or through identifiers with the information.

c. The research involves survey or interview procedures, in which:

$\square$ 1) Subjects cannot be identified directly or through identifiers with the information;

2) Subject's responses, if known, will not place the subject at risk of criminal or civil liability or be damaging to the subject's financial standing or employability;

3) The research does not deal with sensitive aspects of subject's own behavior (illegal conduct, drug use, sexual behavior on alcohol use);

4) The research involves survey or interview procedures with elected or appointed public officials. or candidaces for public office.

$\nabla$ d. The research involves the observation of public behavior, in which:

$C_{1} \square_{1}$ The subjects cannot be identified directly or through identifiers:

(f) $\Xi$ 2) The observations recorded about an individuai could not put the subject at risk of criminal or civil liability or be damaging to the subject's financial standing or employability;

(y) 3 3 ) The research does not deal with sensitive aspects of the subject's behavior (illegal conduct, drug use, sexual behavior or use of alcohol). e. The resenrch involves collection or study of existing date, documents, recording pathological specimens or diagnostic
specimens, of which:

\section{1) The sources are publicly available: or}

2) The information is recorded such that the subject cannot be identified directly or indirectly through identifiers.

2. I further certify that the project will not be changed to increase the risk or exceed exempt condition(s) without filing an additional certification or aplication for use by the Human Subjects Review Board.

Note: If children are in any way at risk while this project is underway, the chairman of IRB should be notified immediately in

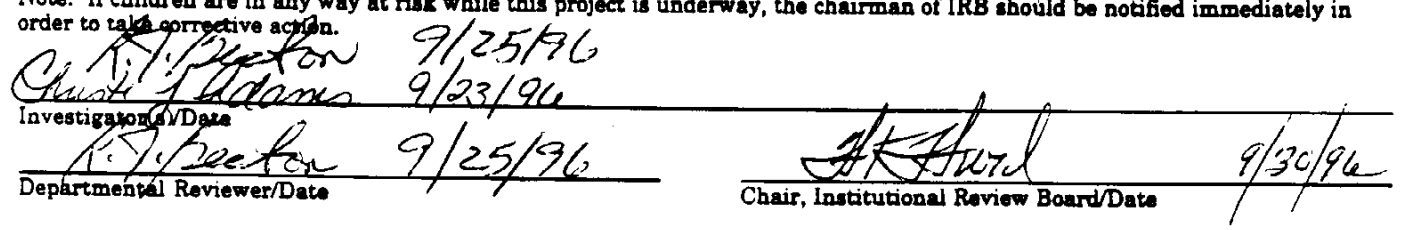




\section{APPENDIX B}

\section{LOCATION SPECIFIC DATASHEETS}


Table 16: Raw Data: Stairs-Up Hazard, Day Condition

Stairs-Up: Day Condition

\begin{tabular}{|c|c|c|c|c|c|c|c|}
\hline Tape \# & Subj & Group & \#Gr. & Start & Stop & $\begin{array}{c}\stackrel{\#}{ } \\
\text { Frames } \\
\end{array}$ & Time \\
\hline 1 & 1 & $\mathrm{~N}$ & & $3: 37: 00$ & $3: 38: 01$ & 32 & 1066.67 \\
\hline 1 & 2 & $\mathrm{~N}$ & & $4: 14: 16$ & $4: 16: 08$ & 53 & 1766.67 \\
\hline 1 & 3 & $N$ & & $4: 25: 23$ & $4: 26: 25$ & 33 & 1100.00 \\
\hline 1 & 4 & $N$ & & $6: 22: 05$ & $6: 24: 01$ & 57 & 1900.00 \\
\hline 1 & 5 & $\mathrm{~N}$ & & $7: 15: 17$ & $7: 16: 20$ & 34 & 1133.33 \\
\hline 1 & 6 & $\mathrm{~N}$ & & $9: 41: 29$ & $9: 42: 25$ & 27 & 900.00 \\
\hline 1 & 7 & $N$ & & $10: 04: 07$ & $10: 04: 29$ & 23 & 766.66 \\
\hline 1 & 8 & $Y$ & $\mathrm{R}$ & $18: 26: 20$ & $18: 27: 25$ & 36 & 1200.00 \\
\hline 1 & 9 & $N$ & & $20: 46: 01$ & $20: 47: 01$ & 31 & 1033.33 \\
\hline 1 & 10 & Y & $\mathrm{R}$ & $22: 48: 16$ & $22: 49: 20$ & 35 & 1166.67 \\
\hline 4 & 11 & $N$ & & $4: 13: 02$ & $4: 14: 12$ & 41 & 1366.67 \\
\hline 4 & 12 & $N$ & & $4: 21: 29$ & $4: 23: 11$ & 41 & 1366.67 \\
\hline 4 & 13 & $N$ & & $5: 01: 08$ & $5: 03: 02$ & 55 & 1833.33 \\
\hline 4 & 14 & $N$ & & $7: 43: 21$ & $7: 45: 01$ & 41 & 1366.67 \\
\hline 4 & 15 & $\mathrm{~N}$ & & $8: 37: 26$ & $8: 39: 26$ & 61 & 2033.33 \\
\hline
\end{tabular}


Table 17: Raw Data: Stairs-Up Hazard, Twilight Condition

Stairs-Up: Twilight Condition

\begin{tabular}{|c|c|c|c|c|c|c|c|}
\hline$\underline{\text { Tape \# }}$ & Subj & Group & \#Gr. & Start & Stop & $\begin{array}{c}\stackrel{\#}{ } \\
\text { Frames } \\
\end{array}$ & Time \\
\hline 1 & 1 & $\mathrm{~N}$ & & $26: 07: 17$ & 26:09:05 & 50 & 1666.67 \\
\hline 1 & 2 & $\mathrm{~N}$ & & $26: 33: 15$ & $26: 34: 22$ & 68 & 2066.67 \\
\hline 1 & 3 & $N$ & & $28: 45: 15$ & $28: 47: 05$ & 50 & 1666.67 \\
\hline 4 & 4 & $\mathrm{~N}$ & & $2: 07: 02$ & 2:08:01 & 30 & 1000.00 \\
\hline 4 & 5 & $\mathrm{~N}$ & & $3: 16: 00$ & $3: 16: 28$ & 29 & 966.67 \\
\hline 4 & 6 & Y & $\mathrm{R}$ & $6: 10: 07$ & $6: 12: 10$ & 64 & 2133.33 \\
\hline 4 & 7 & Y & $\mathrm{L}$ & $6: 11: 01$ & $6: 12: 10$ & 40 & 1333.33 \\
\hline 4 & 8 & Y & $\mathrm{L}$ & $6: 58: 19$ & 7:00:01 & 43 & 1433.33 \\
\hline 4 & 9 & Y & Ctr & $6: 58: 24$ & 7:00:02 & 39 & 1300.00 \\
\hline 4 & 10 & $N$ & & $10: 17: 25$ & $10: 19: 00$ & 36 & 1200.00 \\
\hline 4 & 11 & $N$ & & $10: 30: 07$ & $10: 31: 02$ & 26 & 866.67 \\
\hline 4 & 12 & $N$ & & $10: 44: 16$ & $10: 46: 17$ & 62 & 2066.67 \\
\hline 4 & 13 & $\mathrm{~N}$ & & $10: 57: 22$ & $10: 58: 28$ & 37 & 1233.33 \\
\hline 4 & 14 & $N$ & & $11: 09: 12$ & $11: 10: 23$ & 42 & 1400.00 \\
\hline 4 & 15 & $N$ & & $11: 48: 00$ & $11: 49: 25$ & 56 & 1866.67 \\
\hline
\end{tabular}


Table 18: Raw Data: Stairs-Up Hazard, Night Condition

Stairs-Up: Night Condition

\begin{tabular}{rrr} 
Subj & \multicolumn{1}{r}{ Clock Time $(\mathbf{s e c})$} & Time $(\mathbf{m s})$ \\
\cline { 2 - 3 } 1 & 1.97 & 1970 \\
2 & 1.33 & 1330 \\
3 & 1.51 & 1510 \\
4 & 2.08 & 2080 \\
5 & 2.01 & 2010 \\
6 & 1.42 & 1420 \\
7 & 1.53 & 1530 \\
8 & 1.35 & 1350 \\
9 & 1.06 & 1060 \\
10 & 1.18 & 1180 \\
11 & 1.69 & 1690 \\
12 & 1.41 & 1410 \\
13 & 1.70 & 1700 \\
14 & 1.69 & 1690 \\
15 & 2.08 & 2080
\end{tabular}


Table 19: Raw Data: Stairs-Down Hazard, Day Condition

Stairs-Down: Day Condition

\begin{tabular}{|c|c|c|c|c|c|c|c|}
\hline Tape \# & Subj & Group & \#Gr. & Start & Stop & $\begin{array}{c}\text { \# } \\
\text { Frames }\end{array}$ & Time \\
\hline 1 & 1 & Y & $\mathrm{L}$ & $0: 45: 14$ & $0: 46: 07$ & 25 & 833.33 \\
\hline 1 & 2 & Y & $\mathrm{R}$ & $0: 45: 27$ & $0: 46: 13$ & 17 & 566.67 \\
\hline 3 & 3 & Y & L & $30: 38: 07$ & $30: 39: 07$ & 31 & 1033.33 \\
\hline 3 & 4 & Y & $R$ & $30: 38: 07$ & $30: 39: 07$ & 33 & 1100.00 \\
\hline 3 & 5 & Y & Center & $30: 38: 18$ & $30: 39: 14$ & 27 & 900.00 \\
\hline 3 & 6 & $N$ & & $30: 52: 05$ & $30: 52: 19$ & 15 & 500.00 \\
\hline 3 & 7 & $N$ & & $31: 00: 26$ & $31: 01: 23$ & 28 & 933.33 \\
\hline 3 & 8 & Y & Center & $31: 15: 16$ & $31: 17: 09$ & 55 & 1833.33 \\
\hline 3 & 9 & Y & L & $31: 16: 06$ & $31: 17: 00$ & 25 & 833.33 \\
\hline 3 & 10 & Y & $\mathrm{L}$ & $31: 41: 25$ & $31: 42: 14$ & 20 & 666.67 \\
\hline 3 & 11 & $N$ & & $31: 55: 03$ & $31: 56: 15$ & 43 & 1433.33 \\
\hline 3 & 12 & Y & $R$ & $32: 19: 21$ & $32: 20: 12$ & 22 & 733.33 \\
\hline 3 & 13 & Y & L & $32: 19: 18$ & $32: 20: 04$ & 17 & 566.66 \\
\hline 3 & 14 & $N$ & & $32: 31: 06$ & $32: 32: 10$ & 35 & 1166.67 \\
\hline 3 & 15 & Y & $\mathrm{L}$ & $33: 02: 20$ & $33: 04: 07$ & 48 & 1600.00 \\
\hline
\end{tabular}


Table 20: Raw Data: Stairs-Down Hazard, Twilight Condition.

Stairs-Down: Twilight Condition

\begin{tabular}{|c|c|c|c|c|c|c|c|}
\hline Tape \# & Subj & Group & \#Gr. & $\underline{\text { Start }}$ & Stop & $\begin{array}{c}\stackrel{\#}{ } \\
\text { Frames } \\
\end{array}$ & Time \\
\hline 1 & 1 & $\mathrm{~N}$ & & $2: 28: 29$ & $2: 29: 29$ & 31 & 1033.33 \\
\hline 1 & 2 & $\mathrm{~N}$ & & $40: 14: 02$ & $40: 15: 16$ & 45 & 1500.00 \\
\hline 1 & 3 & $\mathrm{~N}$ & & & $41: 22: 10$ & 39 & 1300.00 \\
\hline & & & & $41: 21: 02$ & & & \\
\hline 1 & 4 & $\mathrm{~N}$ & & $50: 48: 04$ & $50: 49: 08$ & 35 & 1166.67 \\
\hline 1 & 5 & Y & L-Wht Hat & $51: 01: 05$ & $51: 02: 20$ & 46 & 1533.33 \\
\hline 1 & 6 & Y & $\mathrm{RC}$ & $51: 00: 20$ & $51: 03: 03$ & 74 & 2466.67 \\
\hline 1 & 7 & $\mathrm{~N}$ & & $52: 23: 08$ & $52: 24: 11$ & 34 & 1133.33 \\
\hline 1 & 8 & Y & LL & $52: 58: 02$ & $52: 59: 02$ & 31 & 1033.33 \\
\hline 1 & 9 & Y & LC & $52: 57: 09$ & $52: 59: 09$ & 61 & 2033.33 \\
\hline 1 & 10 & $\mathrm{~N}$ & & $53: 09: 15$ & $53: 09: 28$ & 14 & 466.67 \\
\hline 3 & 11 & $\mathrm{~N}$ & & $33: 57: 05$ & $33: 58: 07$ & 33 & 1100.00 \\
\hline 3 & 12 & Y & Blu/Wht Rugby & $34: 16: 03$ & $34: 18: 04$ & 62 & 2066.67 \\
\hline 3 & 13 & Y & $\mathrm{L}$ & $34: 40: 14$ & $34: 41: 24$ & 41 & 1366.66 \\
\hline 3 & 14 & Y & Sousaphone & $34: 16: 28$ & $34: 18: 07$ & 40 & 1333.33 \\
\hline 4 & 15 & $\mathrm{~N}$ & & $0: 58: 21$ & $1: 00: 16$ & 56 & 1866.67 \\
\hline
\end{tabular}


Table 21: Raw Data: Stairs-Down Hazard, Night Condition.

Stairs-Down: Night Condition

$\underline{\text { Tape Method }}$

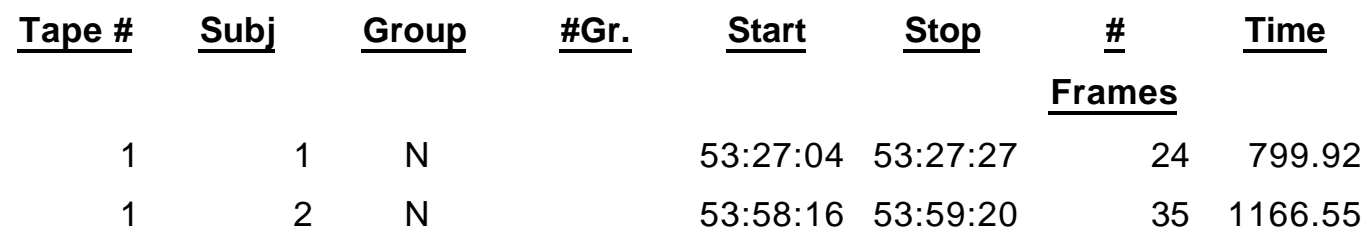

Stopwatch Method

\begin{tabular}{|c|c|c|}
\hline Subj & Clock Time (sec) & Time (ms) \\
\hline 3 & 2.10 & 2100 \\
\hline 4 & 1.94 & 1940 \\
\hline 5 & 2.21 & 2210 \\
\hline 6 & 2.00 & 2000 \\
\hline 7 & 1.73 & 1730 \\
\hline 8 & 2.06 & 2060 \\
\hline 9 & 2.44 & 2440 \\
\hline 10 & 1.87 & 1870 \\
\hline 11 & 1.41 & 1410 \\
\hline 12 & 1.76 & 1760 \\
\hline 13 & 1.23 & 1230 \\
\hline 14 & 1.75 & 1750 \\
\hline 15 & 1.60 & 1600 \\
\hline
\end{tabular}


Table 22: Raw Data: $90^{\circ}$ Turn Hazard, Day Condition.

$\underline{90}^{\circ}$ Turn: Day Condition

\begin{tabular}{|c|c|c|c|c|c|c|c|}
\hline$\underline{\text { Tape \# }}$ & Subj & Group & \#Gr. & Start & Stop & $\begin{array}{c}\text { \# } \\
\text { Frames }\end{array}$ & Time \\
\hline 2 & 1 & $\mathrm{~N}$ & & $9: 42: 27$ & $9: 43: 22$ & 26 & 866.67 \\
\hline 2 & 2 & $\mathrm{~N}$ & & $12: 07: 05$ & $12: 07: 27$ & 23 & 766.67 \\
\hline 2 & 3 & $\mathrm{~N}$ & & 13:29:18 & $13: 30: 03$ & 16 & 533.33 \\
\hline 2 & 4 & $Y$ & Blonde & $16: 50: 00$ & $16: 50: 19$ & 20 & 666.67 \\
\hline 3 & 5 & $\mathrm{~N}$ & & $18: 18: 14$ & $18: 20: 10$ & 57 & 1899.81 \\
\hline 3 & 6 & $\mathrm{~N}$ & & $19: 09: 26$ & $19: 12: 08$ & 73 & 2433.33 \\
\hline 3 & 7 & $\mathrm{Y}$ & Ctr & $19: 36: 27$ & 19:38:07 & 41 & 1366.67 \\
\hline 3 & 8 & Y & $\mathrm{R}$ & $19: 53: 13$ & 19:54:09 & 27 & 900.00 \\
\hline 3 & 9 & $\mathrm{~N}$ & & $20: 12: 29$ & $20: 15: 12$ & 74 & 2466.67 \\
\hline 3 & 10 & Y & L & $20: 27: 24$ & $20: 29: 14$ & 51 & 1700.00 \\
\hline 3 & 11 & Y & $\mathrm{R}$ & $20: 26: 17$ & $20: 29: 27$ & 101 & 3366.33 \\
\hline 3 & 12 & $Y$ & $\begin{array}{c}\text { Wht.Sht/Dk } \\
\text { Oversht }\end{array}$ & $22: 31: 00$ & $22: 32: 04$ & 35 & 1166.67 \\
\hline 3 & 13 & $\mathrm{~N}$ & Ctr of Screen & $22: 44: 03$ & $22: 45: 03$ & 31 & 1033.33 \\
\hline 3 & 14 & Y & $\begin{array}{c}\text { Left: Dk Sht. } \\
\text { Jeans }\end{array}$ & $23: 47: 01$ & $23: 48: 05$ & 35 & 1166.67 \\
\hline 3 & 15 & $N$ & & $24: 20: 04$ & $24: 22: 05$ & 62 & 2066.67 \\
\hline
\end{tabular}


Table 23: Raw Data: $90^{\circ}$ Turn Hazard, Twilight Condition.

$\underline{90}^{\circ}$ Turn: Twilight Condition

\begin{tabular}{|c|c|c|c|c|c|c|c|}
\hline$\underline{\text { Tape \# }}$ & Subj & Group & \#Gr. & Start & Stop & $\begin{array}{c}\text { \# } \\
\text { Frames }\end{array}$ & Time \\
\hline 2 & 1 & Y & $\mathrm{R}$ & $22: 37: 05$ & $22: 38: 01$ & 27 & 900.00 \\
\hline 2 & 2 & $\mathrm{~N}$ & & $22: 55: 23$ & $22: 56: 17$ & 25 & 833.33 \\
\hline 2 & 3 & $\mathrm{~N}$ & & $23: 06: 21$ & 23:07:16 & 26 & 866.67 \\
\hline 2 & 4 & Y & $\mathrm{R}$ & $49: 09: 13$ & $49: 10: 17$ & 35 & 1166.67 \\
\hline 5 & 5 & Y & $\mathrm{R}$ & $7: 48: 16$ & $7: 51: 05$ & 50 & 1666.67 \\
\hline 5 & 6 & Y & $\mathrm{L}$ & $7: 49: 00$ & $7: 51: 02$ & 63 & 2100.00 \\
\hline 5 & 7 & $\mathrm{~N}$ & & $8: 06: 03$ & 8:09:01 & 89 & 2966.67 \\
\hline 5 & 8 & $\mathrm{~N}$ & & $8: 13: 13$ & $8: 15: 08$ & 56 & 1866.67 \\
\hline 5 & 9 & $\mathrm{~N}$ & & $8: 17: 15$ & $8: 19: 20$ & 66 & 2200.00 \\
\hline 5 & 10 & $\mathrm{~N}$ & & $8: 20: 10$ & 8:22:09 & 60 & 2000.00 \\
\hline 5 & 11 & Y & $\mathrm{R}$ & $8: 28: 25$ & $8: 31: 23$ & 89 & 2966.67 \\
\hline 5 & 12 & Y & L & $8: 30: 27$ & $8: 32: 26$ & 60 & 2000.00 \\
\hline 5 & 13 & $\mathrm{~N}$ & & $16: 20: 12$ & $16: 22: 05$ & 55 & 1866.67 \\
\hline 5 & 14 & $\mathrm{~N}$ & & $16: 31: 07$ & $16: 32: 18$ & 42 & 1400.00 \\
\hline 5 & 15 & $\mathrm{~N}$ & & $16: 57: 19$ & $16: 58: 24$ & 36 & 1200.00 \\
\hline
\end{tabular}


Table 24: Raw Data: $90^{\circ}$ Turn Hazard, Night Condition

$90^{\circ}$ Turn: Night Condition

\begin{tabular}{rrr} 
Subj & Clock Time $(\mathbf{s e c})$ & Time $(\mathbf{m s})$ \\
\cline { 2 - 3 } 1 & 1.79 & 1790 \\
2 & 2.24 & 2240 \\
3 & 2.50 & 2500 \\
4 & 1.76 & 1760 \\
5 & 3.17 & 3170 \\
6 & 3.52 & 3520 \\
7 & 1.98 & 1980 \\
8 & 3.31 & 3310 \\
9 & 1.43 & 1430 \\
10 & 2.85 & 2850 \\
11 & 2.57 & 2570 \\
12 & 2.25 & 2250 \\
13 & 2.55 & 2550 \\
14 & 2.25 & 2250 \\
15 & 2.17 & 2170
\end{tabular}


Table 25: Raw Data: Hill with Step Hazard, Day Condition

Down Grade w/ Step: Day Condition

\begin{tabular}{|c|c|c|c|c|c|c|c|}
\hline Tape \# & Subj & Group & \#Gr. & Start & Stop & $\begin{array}{c}\stackrel{\#}{ } \\
\text { Frames } \\
\end{array}$ & Time \\
\hline 2 & 1 & $\mathrm{~N}$ & & $8: 59: 27$ & $9: 00: 27$ & 31 & 1033.33 \\
\hline 4 & 2 & $\mathrm{~N}$ & & 13:09:13 & $13: 10: 10$ & 28 & 933.33 \\
\hline 4 & 3 & $Y$ & $L$ & $13: 49: 03$ & $13: 50: 10$ & 38 & 1266.67 \\
\hline 4 & 4 & $\mathrm{~N}$ & & $14: 18: 17$ & $14: 19: 21$ & 35 & 1166.67 \\
\hline 4 & 5 & $Y$ & $L$ & $16: 14: 16$ & $16: 16: 11$ & 56 & 1866.67 \\
\hline 4 & 6 & $Y$ & $\mathrm{~L}$ & $17: 57: 15$ & $17: 58: 18$ & 34 & 1133.33 \\
\hline 4 & 7 & $\mathrm{~N}$ & & $17: 46: 12$ & $17: 47: 13$ & 32 & 1066.67 \\
\hline 4 & 8 & $Y$ & $\mathrm{R}$ & $17: 57: 19$ & $17: 58: 15$ & 27 & 900.00 \\
\hline 4 & 9 & $Y$ & $\mathrm{R}$ & $18: 42: 01$ & $18: 43: 02$ & 32 & 1066.67 \\
\hline 4 & 10 & $\mathrm{~N}$ & & $19: 56: 27$ & $19: 57: 13$ & 17 & 566.67 \\
\hline 4 & 11 & $\mathrm{Y}$ & 1st Dn & $21: 35: 20$ & $21: 37: 00$ & 50 & 1666.67 \\
\hline 4 & 12 & $Y$ & 2nd Dn & $21: 37: 21$ & $21: 38: 11$ & 21 & 700.00 \\
\hline 4 & 13 & $Y$ & $\mathrm{R}$ & $24: 31: 00$ & $24: 33: 04$ & 64 & 2166.67 \\
\hline 4 & 14 & $Y$ & L & $24: 31: 24$ & $24: 33: 27$ & 64 & 2133.33 \\
\hline 4 & 15 & $Y$ & $\mathrm{~L}$ & $24: 50: 21$ & $24: 52: 07$ & 47 & 1566.67 \\
\hline
\end{tabular}


Table 26: Raw Data: Hill with Step Hazard, Twilight Condition

Down Grade w/ Step: Twilight Condition

\begin{tabular}{|c|c|c|c|c|c|c|c|}
\hline Tape \# & Subj & Group & \#Gr. & Start & Stop & $\begin{array}{c}\text { \# } \\
\text { Frames }\end{array}$ & Time \\
\hline 4 & 1 & $\mathrm{~N}$ & & $19: 25: 12$ & $19: 26: 05$ & 24 & 800.00 \\
\hline 4 & 2 & $Y$ & $\mathrm{~L}$ & $19: 36: 09$ & $19: 37: 11$ & 33 & 1100.00 \\
\hline 4 & 3 & $Y$ & $\mathrm{R}$ & $19: 36: 06$ & $19: 37: 20$ & 45 & 1500.00 \\
\hline 4 & 4 & $Y$ & $\mathrm{R}$ & 23:03:09 & $23: 05: 13$ & 65 & 2166.67 \\
\hline 6 & 5 & $\mathrm{~N}$ & & $2: 06: 11$ & $2: 08: 19$ & 69 & 2300.00 \\
\hline 6 & 6 & $\mathrm{~N}$ & & $2: 22: 18$ & $2: 23: 22$ & 35 & 1166.67 \\
\hline 6 & 7 & $Y$ & L & $2: 45: 17$ & $2: 48: 02$ & 76 & 2533.33 \\
\hline 6 & 8 & $Y$ & $\mathrm{R}$ & $2: 46: 26$ & $2: 47: 20$ & 25 & 833.33 \\
\hline 6 & 9 & $Y$ & Ctr & $2: 46: 28$ & $2: 47: 20$ & 23 & 766.67 \\
\hline 6 & 10 & Y & $\mathrm{L}$ & $3: 12: 22$ & $3: 13: 23$ & 32 & 1066.67 \\
\hline 6 & 11 & $\mathrm{Y}$ & $\mathrm{R}$ & $3: 13: 23$ & $3: 14: 08$ & 16 & 533.33 \\
\hline 6 & 12 & $\mathrm{~N}$ & & $3: 16: 08$ & $3: 17: 27$ & 51 & 1700.00 \\
\hline 6 & 13 & $Y$ & Wht Shrt & $3: 17: 25$ & $3: 19: 27$ & 63 & 2100.00 \\
\hline 6 & 14 & $Y$ & $\mathrm{~L}$ & $3: 43: 26$ & $3: 45: 14$ & 49 & 1633.33 \\
\hline 6 & 15 & $\mathrm{~N}$ & & $4: 02: 23$ & $4: 03: 20$ & 28 & 933.33 \\
\hline
\end{tabular}


Table 27: Raw Data: Hill with Step Hazard, Night Condition

Down Grade w/ Step: Night Condition

\begin{tabular}{|c|c|c|}
\hline Subj & $\frac{\text { Clock Time }}{\underline{(\mathrm{sec})}}$ & Time (ms) \\
\hline 1 & 2.18 & 2180 \\
\hline 2 & 1.01 & 1010 \\
\hline 3 & 0.99 & 990 \\
\hline 4 & 2.66 & 2660 \\
\hline 5 & 1.32 & 1320 \\
\hline 6 & 3.57 & 3570 \\
\hline 7 & 3.49 & 3490 \\
\hline 8 & 2.03 & 2030 \\
\hline 9 & 1.51 & 1510 \\
\hline 10 & 1.68 & 1680 \\
\hline 11 & 1.24 & 1240 \\
\hline 12 & 1.89 & 1890 \\
\hline 13 & 1.76 & 1760 \\
\hline 14 & 1.88 & 1880 \\
\hline 15 & 2.05 & 2050 \\
\hline
\end{tabular}


Table 28: Raw Data: Safety Bucket Hazard, Day Condition

Safety Bucket Hazard: Day Condition

\begin{tabular}{|c|c|c|c|c|c|c|c|}
\hline Tape \# & Subj & Group & \#Gr. & Start & Stop & $\begin{array}{c}\# \\
\text { Frames } \\
\end{array}$ & Time \\
\hline 5 & 1 & $\mathrm{~N}$ & & $0: 07: 17$ & $0: 09: 26$ & 70 & 2333.333 \\
\hline 5 & 2 & $\mathrm{~N}$ & & $0: 47: 15$ & $0: 50: 05$ & 81 & 2700.000 \\
\hline 5 & 3 & $\mathrm{~N}$ & & 1:15:07 & $1: 18: 16$ & 100 & 3333.333 \\
\hline 5 & 4 & $\mathrm{~N}$ & & $1: 31: 16$ & 1:33:22 & 67 & 2233.333 \\
\hline 5 & 5 & $\mathrm{~N}$ & & $1: 56: 10$ & $2: 00: 13$ & 124 & 4133.333 \\
\hline 5 & 6 & $\mathrm{~N}$ & & $2: 11: 23$ & $2: 16: 25$ & 153 & 5100.000 \\
\hline 5 & 7 & $\mathrm{~N}$ & & $3: 21: 13$ & $3: 25: 00$ & 108 & 3600.000 \\
\hline 5 & 8 & $\mathrm{~N}$ & & $3: 49: 22$ & $3: 51: 22$ & 61 & 2033.333 \\
\hline 5 & 9 & $\mathrm{~N}$ & & 4:10:29 & $4: 15: 04$ & 126 & 4200.000 \\
\hline 5 & 10 & $\mathrm{~N}$ & & $5: 03: 10$ & $5: 06: 19$ & 100 & 3333.333 \\
\hline 5 & 11 & $Y$ & L & 5:44:06 & $5: 47: 26$ & 111 & 3700.000 \\
\hline 5 & 12 & $Y$ & $\mathrm{R}$ & 6:08:08 & $6: 11: 00$ & 83 & 2766.667 \\
\hline 5 & 13 & $Y$ & L & $6: 36: 02$ & $6: 39: 08$ & 97 & 3233.333 \\
\hline 5 & 14 & $Y$ & $\mathrm{R}$ & $6: 37: 29$ & $6: 40: 11$ & 73 & 2433.333 \\
\hline 5 & 15 & $N$ & & 7:14:09 & $7: 18: 14$ & 126 & 4200.000 \\
\hline
\end{tabular}


Table 29: Raw Data: Safety Bucket Hazard, Twilight Condition

Safety Bucket Hazard: Twilight Condition

\begin{tabular}{|c|c|c|c|c|c|c|c|}
\hline Tape \# & Subj & Group & \#Gr. & Start & Stop & $\begin{array}{c}\stackrel{\#}{ } \\
\text { Frames }\end{array}$ & Time \\
\hline 5 & 1 & $\mathrm{~N}$ & & $14: 13: 05$ & $14: 20: 12$ & 218 & 7266.667 \\
\hline 5 & 2 & Y & L & $14: 33: 26$ & $14: 37: 27$ & 122 & 4066.667 \\
\hline 5 & 3 & Y & $\mathrm{R}$ & $14: 32: 19$ & $14: 33: 10$ & 22 & 733.333 \\
\hline 5 & 4 & $\mathrm{~N}$ & & $14: 53: 27$ & $14: 58: 05$ & 139 & 4633.333 \\
\hline 5 & 5 & $\mathrm{~N}$ & & $14: 58: 04$ & $15: 01: 13$ & 100 & 3333.333 \\
\hline 5 & 6 & $Y$ & L & $15: 10: 27$ & $15: 13: 20$ & 84 & 2800.000 \\
\hline 5 & 7 & $Y$ & $\mathrm{R}$ & $15: 11: 13$ & $15: 15: 02$ & 110 & 3666.667 \\
\hline 5 & 8 & $\mathrm{~N}$ & & $15: 20: 09$ & $15: 22: 26$ & 78 & 2600.000 \\
\hline 5 & 9 & $\mathrm{~N}$ & & $15: 47: 01$ & $15: 51: 19$ & 139 & 4633.333 \\
\hline 5 & 10 & $\mathrm{~N}$ & & $16: 01: 05$ & $16: 04: 22$ & 108 & 3600.000 \\
\hline 6 & 11 & $N$ & & $0: 13: 12$ & $0: 17: 04$ & 113 & 3766.667 \\
\hline 6 & 12 & $\mathrm{~N}$ & & $0: 41: 19$ & $0: 43: 12$ & 54 & 1800.000 \\
\hline 6 & 13 & $N$ & & $0: 56: 24$ & $0: 59: 10$ & 77 & 2566.667 \\
\hline 6 & 14 & Y & L & $5: 12: 20$ & $5: 14: 25$ & 66 & 2200.000 \\
\hline 6 & 15 & $\mathrm{~N}$ & & $5: 25: 17$ & $5: 27: 19$ & 63 & 2100.000 \\
\hline
\end{tabular}


Table 30: Raw Data: Safety Bucket Hazard, Night Condition

Safety Bucket Hazard: Night Condition

\begin{tabular}{|c|c|c|}
\hline Subj & $\frac{\text { Clock Time }}{\underline{(\mathrm{sec})}}$ & Time (ms) \\
\hline 1 & 2.22 & 2220 \\
\hline 2 & 2.29 & 2290 \\
\hline 3 & 1.48 & 1480 \\
\hline 4 & 1.30 & 1300 \\
\hline 5 & 3.00 & 3000 \\
\hline 6 & 1.89 & 1890 \\
\hline 7 & 2.02 & 2020 \\
\hline 8 & 2.52 & 2520 \\
\hline 9 & 2.15 & 2150 \\
\hline 10 & 2.03 & 2030 \\
\hline 11 & 1.64 & 1640 \\
\hline 12 & 1.71 & 1710 \\
\hline 13 & 1.54 & 1540 \\
\hline 14 & 1.67 & 1670 \\
\hline 15 & 1.36 & 1360 \\
\hline
\end{tabular}


Table 31: Raw Data: Road Triangle Hazard, Day Condition

$\underline{\text { Road Triangle Hazard: Day Condition }}$

\begin{tabular}{|c|c|c|c|c|c|c|c|}
\hline Tape \# & Subj & Group & \#Gr. & Start & Stop & $\begin{array}{c}\stackrel{\#}{ } \\
\text { Frames }\end{array}$ & Time \\
\hline 7 & 1 & $Y$ & $\mathrm{R}$ & 1:10:01 & $1: 13: 26$ & 116 & 3866.667 \\
\hline 7 & 2 & $Y$ & $\mathrm{~L}$ & $1: 12: 04$ & $1: 14: 03$ & 60 & 2000.000 \\
\hline 7 & 3 & $\mathrm{~N}$ & & $1: 28: 08$ & $1: 30: 21$ & 74 & 2466.667 \\
\hline 7 & 4 & $Y$ & Ctr & 2:08:09 & $2: 12: 11$ & 123 & 4100.000 \\
\hline 7 & 5 & $Y$ & $\mathrm{R}$ & $2: 08: 14$ & $2: 10: 16$ & 63 & 2100.000 \\
\hline 7 & 6 & $Y$ & $\mathrm{R}$ & $2: 38: 20$ & $2: 42: 27$ & 128 & 4266.667 \\
\hline 7 & 7 & $Y$ & L & $2: 40: 25$ & $2: 42: 28$ & 64 & 2133.333 \\
\hline 7 & 8 & $\mathrm{~N}$ & & $2: 57: 23$ & $3: 00: 08$ & 76 & 2533.333 \\
\hline 7 & 9 & $Y$ & $\mathrm{R}$ & $3: 17: 09$ & $3: 20: 24$ & 106 & 3533.333 \\
\hline 7 & 10 & $Y$ & L & $3: 38: 25$ & $3: 43: 01$ & 127 & 4233.333 \\
\hline 7 & 11 & $\mathrm{~N}$ & & $4: 21: 25$ & $4: 24: 11$ & 77 & 2566.667 \\
\hline 7 & 12 & $\mathrm{~N}$ & & $4: 34: 29$ & $4: 37: 02$ & 64 & 2133.333 \\
\hline 7 & 13 & $\mathrm{~N}$ & & $7: 54: 27$ & 7:58:08 & 102 & 3400.000 \\
\hline 7 & 14 & $\mathrm{~N}$ & & $8: 11: 21$ & $8: 15: 18$ & 118 & 3933.333 \\
\hline 7 & 15 & $Y$ & L & $9: 13: 22$ & $9: 18: 12$ & 141 & 4700.000 \\
\hline
\end{tabular}


Table 32: Raw Data: Road Triangle Hazard, Twilight Condition

$\underline{\text { Road Triangle Hazard: Twilight Condition }}$

\begin{tabular}{|c|c|c|c|c|c|c|c|}
\hline Tape \# & Subj & Group & \#Gr. & Start & Stop & $\begin{array}{c}\stackrel{\#}{ } \\
\text { Frames }\end{array}$ & Time \\
\hline 7 & 1 & $\mathrm{~N}$ & & 0:09:15 & $0: 12: 08$ & 84 & 2800.000 \\
\hline 7 & 2 & $\mathrm{~N}$ & & $0: 52: 16$ & $0: 55: 07$ & 82 & 2733.333 \\
\hline 7 & 3 & $\mathrm{~N}$ & & $5: 26: 18$ & $5: 30: 04$ & 107 & 3566.667 \\
\hline 7 & 4 & $\mathrm{~N}$ & & $5: 41: 16$ & $5: 45: 00$ & 105 & 3500.000 \\
\hline 7 & 5 & $Y$ & Wht Swtr & $6: 25: 00$ & $6: 28: 06$ & 97 & 3233.333 \\
\hline 7 & 6 & $Y$ & Blue Swtr & $6: 26: 03$ & $6: 28: 19$ & 77 & 2566.667 \\
\hline 7 & 7 & $\mathrm{~N}$ & & $10: 31: 13$ & $10: 34: 14$ & 92 & 3066.667 \\
\hline 7 & 8 & $\mathrm{~N}$ & & $10: 53: 29$ & $10: 55: 27$ & 59 & 1966.667 \\
\hline 7 & 9 & $Y$ & $\begin{array}{c}\text { Blue on } \\
\text { Blue }\end{array}$ & $11: 43: 17$ & $11: 49: 00$ & 164 & 5466.667 \\
\hline 7 & 10 & $Y$ & $\begin{array}{c}\text { Wht } \\
\text { Jacket }\end{array}$ & $11: 49: 05$ & $11: 49: 01$ & 147 & 4900.000 \\
\hline 7 & 11 & $Y$ & Rt Ctr & $11: 46: 12$ & $11: 51: 15$ & 152 & 5066.667 \\
\hline 7 & 12 & $Y$ & $\mathrm{R}$ & $12: 14: 10$ & $12: 16: 28$ & 79 & 2633.333 \\
\hline 7 & 13 & $Y$ & $\mathrm{~L}$ & $12: 15: 06$ & $12: 16: 27$ & 52 & 1733.333 \\
\hline 7 & 14 & $\mathrm{~N}$ & & $13: 32: 28$ & $13: 35: 17$ & 80 & 2666.667 \\
\hline 7 & 15 & $\mathrm{~N}$ & & $13: 48: 14$ & $13: 51: 05$ & 82 & 2733.333 \\
\hline
\end{tabular}


Table 33: Raw Data: Road Triangle Hazard, Night Condition

$\underline{\text { Road Triangle Hazard: Night Condition }}$

\begin{tabular}{|c|c|c|}
\hline Subj & $\frac{\text { Clock Time }}{\underline{\text { (sec) }}}$ & $\frac{\text { Time }}{\text { (ms) }}$ \\
\hline 1 & $10: 48$ & 5450 \\
\hline 2 & $4: 19$ & 6180 \\
\hline 3 & $4: 19$ & 4180 \\
\hline 4 & 4.73 & 4730 \\
\hline 5 & 5.69 & 5690 \\
\hline 6 & 6.39 & 6390 \\
\hline 7 & 4.58 & 4580 \\
\hline 8 & 2.73 & 2730 \\
\hline 9 & 5.00 & 5000 \\
\hline 10 & 6.82 & 6820 \\
\hline 11 & 3.84 & 3840 \\
\hline 12 & 5.18 & 5180 \\
\hline 13 & 4.35 & 4350 \\
\hline 14 & 4.87 & 4870 \\
\hline 15 & 2.47 & 2470 \\
\hline
\end{tabular}




\section{APPENDIX C}

\section{SPECIFIC LIGHTING DATA}


Table 34: Specific Lighting During Data Recording - Stairs-Down Location.

\begin{tabular}{|c|c|c|c|c|c|c|c|}
\hline Date & $\begin{array}{l}\text { Start/ } \\
\text { End }\end{array}$ & Time & Lighting & $\begin{array}{l}\text { Illum } \\
\text { (lux) }\end{array}$ & $\begin{array}{c}\text { Lum } \\
\left(\mathrm{cd} / \mathrm{m}^{2}\right)\end{array}$ & CIE 1 & $\begin{array}{c}\text { CIE } \\
2\end{array}$ \\
\hline \multirow[t]{2}{*}{$11-15$} & $\bar{S}$ & $16: 55$ & Day & 901 & 99.5 & .312 & .323 \\
\hline & $E$ & $17: 23$ & “ & 265 & 28.3 & $\mathrm{~N} / \mathrm{A}$ & $\mathrm{N} / \mathrm{A}$ \\
\hline \multirow[t]{2}{*}{$11-20$} & $S$ & $12: 10$ & Day & 55800 & 6260 & .365 & .367 \\
\hline & E & $12: 20$ & " & 55600 & 5930 & .367 & .367 \\
\hline \multirow[t]{2}{*}{$2-20$} & $S$ & $15: 48$ & Day & 11000 & 1150 & .355 & .357 \\
\hline & $E$ & $17: 32$ & " & 2140 & 223 & .334 & .339 \\
\hline \multirow[t]{2}{*}{$11-15$} & $S$ & $17: 47$ & Twilight & 98 & 11.6 & .282 & .291 \\
\hline & $E$ & $18: 12$ & “ & 10 & 1.12 & $N / A$ & $\mathrm{~N} / \mathrm{A}$ \\
\hline \multirow[t]{2}{*}{$2-20$} & $S$ & $18: 12$ & Twilight & 100 & 11.2 & .324 & .318 \\
\hline & $E$ & $18: 24$ & " & 10.7 & 1.14 & .299 & .298 \\
\hline \multirow[t]{2}{*}{$4-29$} & $S$ & $20: 14$ & Twilight & 100 & 11.4 & .280 & .296 \\
\hline & $E$ & $20: 17$ & " & 78.3 & 9.00 & .282 & .300 \\
\hline \multirow[t]{2}{*}{$2-20$} & $S$ & $18: 26$ & Night & 4.78 & 0.63 & .298 & .288 \\
\hline & E & $19: 26$ & “ & 0.20 & 0.15 & .400 & .257 \\
\hline \multirow[t]{2}{*}{$4-29$} & $S$ & $20: 35$ & Night & 1.44 & 0.29 & .261 & .257 \\
\hline & $E$ & $21: 40$ & “ & 0.17 & 0.13 & .086 & .374 \\
\hline \multirow[t]{2}{*}{$4-30$} & $S$ & $20: 32$ & Night & 4.67 & 0.69 & .244 & .273 \\
\hline & $E$ & $21: 25$ & " & 0.17 & 0.05 & .427 & .189 \\
\hline
\end{tabular}


Table 35: Specific Lighting During Data Recording - Stairs-Up Location.

\begin{tabular}{|c|c|c|c|c|c|c|c|}
\hline Date & $\begin{array}{l}\text { Start/ } \\
\text { End }\end{array}$ & Time & Lighting & $\begin{array}{l}\text { Illum } \\
\text { (lux) }\end{array}$ & $\begin{array}{c}\text { Lum } \\
\left(\mathrm{cd} / \mathrm{m}^{2}\right)\end{array}$ & CIE 1 & $\begin{array}{c}\text { CIE } \\
2\end{array}$ \\
\hline \multirow[t]{2}{*}{$11-20$} & $\bar{S}$ & $12: 22$ & Day & 43300 & 7660 & .367 & .367 \\
\hline & $E$ & $13: 45$ & “ & 40900 & 4590 & .369 & .365 \\
\hline \multirow[t]{2}{*}{$12-4$} & $S$ & $11: 18$ & Day & 28900 & 1920 & .350 & .352 \\
\hline & $E$ & $11: 40$ & " & 67100 & 2030 & .349 & .352 \\
\hline \multirow[t]{2}{*}{$12-4$} & $S$ & $15: 51$ & Day & 6240 & 466 & .325 & .332 \\
\hline & $E$ & $16: 30$ & " & 1970 & 230 & .309 & .322 \\
\hline \multirow[t]{2}{*}{$4-30$} & $S$ & 20:02 & Day & 643 & 85.0 & .327 & .344 \\
\hline & $E$ & $20: 15$ & " & 202 & 24.7 & .350 & .344 \\
\hline \multirow[t]{2}{*}{$5-1$} & $S$ & $19: 25$ & Day & 1480 & 184 & .278 & .307 \\
\hline & $E$ & $19: 51$ & “ & 831 & 96.7 & .258 & .313 \\
\hline \multirow[t]{2}{*}{$12-4$} & $S$ & $17: 01$ & Twilight & 100 & 12.7 & .312 & .318 \\
\hline & $E$ & $17: 19$ & “ & 11.8 & 1.87 & .301 & .304 \\
\hline \multirow[t]{2}{*}{$4-29$} & $S$ & $20: 17$ & Twilight & 56.4 & 6.99 & .279 & .297 \\
\hline & $E$ & $20: 27$ & “ & 11.8 & 1.46 & .278 & .257 \\
\hline \multirow[t]{2}{*}{$4-30$} & $S$ & $20: 17$ & Twilight & 99 & 11.3 & .324 & .320 \\
\hline & E & $20: 27$ & “ & 12.0 & 1.42 & .260 & .280 \\
\hline \multirow[t]{2}{*}{$5-1$} & $S$ & $20: 16$ & Twilight & 100 & 12.3 & .280 & .299 \\
\hline & $E$ & $20: 26$ & " & 13.1 & 1.56 & .241 & .267 \\
\hline \multirow[t]{2}{*}{$2-19$} & $S$ & $19: 20$ & Night & 0.25 & 0.20 & .454 & .272 \\
\hline & $E$ & $21: 41$ & “ & 0.34 & 0.15 & .357 & .214 \\
\hline \multirow[t]{2}{*}{$4-22$} & $S$ & $20: 48$ & Night & 0.26 & 0.25 & .335 & .208 \\
\hline & $E$ & $22: 11$ & “ & 0.24 & 0.13 & .486 & .278 \\
\hline \multirow[t]{2}{*}{$4-24$} & $S$ & $20: 46$ & Night & 0.10 & 0.06 & .091 & .338 \\
\hline & $E$ & $22: 23$ & “ & 0.15 & 0.13 & .411 & .219 \\
\hline \multirow[t]{2}{*}{$4-29$} & $S$ & 20:35 & Night & 0.99 & 0.16 & .242 & .250 \\
\hline & $E$ & $21: 40$ & “ & 0.08 & 0.07 & .444 & .157 \\
\hline \multirow[t]{2}{*}{$4-30$} & $S$ & $20: 35$ & Night & 2.30 & 0.37 & .290 & .255 \\
\hline & $E$ & 21:00 & “ & 0.26 & 0.17 & .383 & .272 \\
\hline
\end{tabular}


Table 36: Specific Lighting During Data Recording - $90^{\circ}$ Turn Location

\begin{tabular}{|c|c|c|c|c|c|c|c|}
\hline Date & $\begin{array}{l}\text { Start/ } \\
\text { End }\end{array}$ & Time & Lighting & $\begin{array}{l}\text { Illum } \\
\text { (lux) }\end{array}$ & $\begin{array}{c}\text { Lum } \\
\left(\mathrm{cd} / \mathrm{m}^{2}\right)\end{array}$ & CIE 1 & $\begin{array}{c}\text { CIE } \\
2\end{array}$ \\
\hline \multirow[t]{2}{*}{$2-11$} & 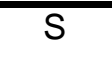 & $16: 53$ & Day & 5200 & 672 & .351 & .350 \\
\hline & $E$ & $17: 47$ & “ & 588 & 86.6 & .321 & .325 \\
\hline \multirow[t]{2}{*}{$2-20$} & $S$ & $9: 38$ & Day & 26700 & 3400 & .367 & .364 \\
\hline & $E$ & $11: 21$ & " & 46400 & 5270 & .371 & .364 \\
\hline \multirow[t]{2}{*}{$2-11$} & S & $18: 01$ & Twilight & 100 & 10.8 & .287 & .296 \\
\hline & $E$ & $18: 12$ & “ & 20.9 & 2.68 & .302 & .302 \\
\hline \multirow[t]{2}{*}{$2-12$} & $S$ & $17: 56$ & Twilight & 100 & 11.9 & .277 & .286 \\
\hline & $E$ & $18: 09$ & “ & 23.8 & 3.51 & .283 & .285 \\
\hline \multirow[t]{2}{*}{$5-5$} & $S$ & $20: 17$ & Twilight & 100 & 10.7 & .279 & .292 \\
\hline & $E$ & $20: 32$ & “ & 12.2 & 1.35 & .300 & .320 \\
\hline \multirow[t]{2}{*}{$5-7$} & $S$ & $20: 23$ & Twilight & 92.5 & 8.94 & .278 & .285 \\
\hline & $E$ & $20: 37$ & “ & 10.2 & 1.32 & .276 & .310 \\
\hline \multirow[t]{2}{*}{$2-11$} & S & $20: 43$ & Night & 3.89 & 0.55 & .433 & .366 \\
\hline & $E$ & $22: 15$ & “ & 3.66 & 0.44 & .486 & .416 \\
\hline \multirow[t]{2}{*}{$4-30$} & S & $21: 38$ & Night & 1.82 & 0.34 & .414 & .295 \\
\hline & $E$ & $22: 12$ & $“$ & 2.46 & 0.27 & .373 & .446 \\
\hline
\end{tabular}


Table 37: Specific Lighting During Data Recording - Hill with Step Location

\begin{tabular}{|c|c|c|c|c|c|c|c|}
\hline Date & $\begin{array}{l}\text { Start/ } \\
\text { End }\end{array}$ & Time & Lighting & $\begin{array}{l}\text { Illum } \\
\text { (lux) }\end{array}$ & $\begin{array}{c}\text { Lum } \\
\left(\mathrm{cd} / \mathrm{m}^{2}\right)\end{array}$ & CIE 1 & $\begin{array}{c}\text { CIE } \\
2\end{array}$ \\
\hline \multirow[t]{2}{*}{$2-7$} & $\bar{S}$ & $14: 23$ & Day & 11100 & 729 & .362 & .357 \\
\hline & $E$ & $15: 30$ & “ & 7210 & 627 & .363 & .360 \\
\hline \multirow[t]{2}{*}{$5-2$} & $S$ & $16: 45$ & Day & 11800 & 829 & .360 & .360 \\
\hline & $E$ & $20: 07$ & " & 299 & 18.4 & .304 & .315 \\
\hline \multirow[t]{2}{*}{$5-3$} & $S$ & $19: 36$ & Day & 1710 & 132 & .343 & .350 \\
\hline & $E$ & $20: 01$ & " & 500 & 30.2 & .295 & .311 \\
\hline \multirow[t]{2}{*}{$5-4$} & $S$ & $11: 30$ & Day & 10800 & 777 & .337 & .347 \\
\hline & $E$ & $13: 25$ & " & 98900 & 2240 & .359 & .364 \\
\hline \multirow[t]{2}{*}{$5-4$} & $S$ & $16: 43$ & Day & 12300 & 600 & .349 & .355 \\
\hline & $E$ & $19: 54$ & " & 1100 & 64.9 & .337 & .341 \\
\hline \multirow[t]{2}{*}{$5-6$} & $S$ & $18: 23$ & Day & 4500 & 255 & .315 & .338 \\
\hline & $E$ & $19: 14$ & " & 2860 & 162 & .319 & .337 \\
\hline \multirow[t]{2}{*}{$5-2$} & $S$ & $20: 15$ & Twilight & 99 & 6.74 & .277 & .287 \\
\hline & $E$ & $20: 25$ & “ & 15.2 & 1.14 & .282 & .260 \\
\hline \multirow[t]{2}{*}{$5-3$} & $S$ & $20: 16$ & Twilight & 96.2 & 5.71 & .296 & .304 \\
\hline & E & $20: 28$ & " & 1037 & 0.67 & .285 & .286 \\
\hline \multirow[t]{2}{*}{$5-4$} & $S$ & $20: 15$ & Twilight & 100 & 6.44 & .293 & .306 \\
\hline & E & $20: 32$ & “ & 11.5 & 0.85 & .270 & .275 \\
\hline \multirow[t]{2}{*}{$5-10$} & $S$ & $20: 24$ & Twilight & 100 & 6.2 & .296 & .302 \\
\hline & $E$ & $20: 37$ & “ & 10.7 & 0.82 & .291 & .271 \\
\hline \multirow[t]{2}{*}{$2-12$} & $\mathrm{~S}$ & $20: 00$ & Night & 0.66 & 0.31 & .345 & .494 \\
\hline & $E$ & $22: 30$ & “ & 0.68 & 0.16 & .454 & .335 \\
\hline \multirow[t]{2}{*}{$4-19$} & $S$ & $20: 21$ & Night & 4.57 & 0.51 & .287 & .262 \\
\hline & $E$ & $20: 52$ & " & 0.41 & 0.16 & .347 & .216 \\
\hline \multirow[t]{2}{*}{ 5-1 } & $S$ & $20: 43$ & Night & 1.00 & 0.14 & .088 & .356 \\
\hline & $E$ & $21: 54$ & " & 0.40 & 0.16 & .347 & .286 \\
\hline
\end{tabular}


Table 38: Specific Lighting During Data Recording - Safety Bucket Condition

\begin{tabular}{|c|c|c|c|c|c|c|c|}
\hline Date & $\begin{array}{l}\text { Start/ } \\
\text { End }\end{array}$ & Time & Lighting & $\begin{array}{l}\text { Illum } \\
\text { (lux) }\end{array}$ & $\begin{array}{c}\text { Lum } \\
\left(\mathrm{cd} / \mathrm{m}^{2}\right)\end{array}$ & CIE 1 & $\begin{array}{c}\text { CIE } \\
2\end{array}$ \\
\hline \multirow[t]{2}{*}{$5-5$} & $\bar{S}$ & $16: 11$ & Day & 68700 & 99700 & .352 & .356 \\
\hline & $E$ & $19: 13$ & “ & 6350 & 977 & .341 & .345 \\
\hline \multirow[t]{2}{*}{$5-6$} & $S$ & 7:45 & Day & 7380 & 644 & .342 & .346 \\
\hline & $E$ & $8: 40$ & “ & 12800 & 1320 &. .351 & .354 \\
\hline \multirow[t]{2}{*}{$5-6$} & $S$ & $16: 44$ & Day & 68400 & 10000 & .360 & .364 \\
\hline & $E$ & $18: 10$ & “ & 8100 & 1260 & .310 & .323 \\
\hline \multirow[t]{2}{*}{$5-6$} & $S$ & $20: 23$ & Twilight & 100 & 13.7 & .265 & .275 \\
\hline & $E$ & $20: 37$ & “ & 10.0 & 1.41 & .332 & .323 \\
\hline \multirow[t]{2}{*}{$5-9$} & $S$ & $20: 26$ & Twilight & 100 & 15.3 & .278 & .287 \\
\hline & $E$ & $20: 37$ & “ & 10.8 & 1.62 & .307 & .291 \\
\hline \multirow[t]{2}{*}{$5-11$} & $S$ & $20: 30$ & Twilight & 73.4 & 11.1 & .291 & .292 \\
\hline & $E$ & $20: 39$ & “ & 19.1 & 2.83 & .314 & .292 \\
\hline \multirow[t]{2}{*}{$5-5$} & $\mathrm{~S}$ & $21: 15$ & Night & 0.74 & 0.20 & .250 & .374 \\
\hline & $E$ & $21: 51$ & “ & 0.85 & 0.23 & .351 & .346 \\
\hline
\end{tabular}


Table 39: Specific Lighting During Data Recording - Road Triangle Condition

\begin{tabular}{|c|c|c|c|c|c|c|c|}
\hline Date & $\begin{array}{l}\text { Start/ } \\
\text { End }\end{array}$ & Time & Lighting & $\begin{array}{l}\text { Illum } \\
\text { (lux) }\end{array}$ & $\begin{array}{c}\text { Lum } \\
\left(\mathrm{cd} / \mathrm{m}^{2}\right)\end{array}$ & CIE 1 & $\begin{array}{c}\text { CIE } \\
2\end{array}$ \\
\hline \multirow[t]{2}{*}{$6-8$} & $\bar{S}$ & $19: 10$ & Day & 5850 & 376 & .341 & .347 \\
\hline & $E$ & $20: 31$ & “ & 395 & 26.4 & .304 & .315 \\
\hline \multirow[t]{2}{*}{$6-9$} & $S$ & $19: 30$ & Day & 4780 & 311 & .350 & .349 \\
\hline & $E$ & $20: 26$ & “ & 767 & 52.5 & .331 & .334 \\
\hline \multirow[t]{2}{*}{$6-7$} & $S$ & $20: 40$ & Twilight & 100 & 8.61 & .282 & .297 \\
\hline & $E$ & $20: 55$ & “ & 12.2 & 1.09 & .271 & .301 \\
\hline \multirow[t]{2}{*}{$6-8$} & $S$ & $20: 45$ & Twilight & 100 & 7.05 & .289 & .290 \\
\hline & $E$ & $20: 57$ & “ & 13.3 & 1.10 & .279 & .283 \\
\hline \multirow[t]{2}{*}{$6-9$} & $S$ & $20: 45$ & Twilight & 100 & 6.89 & .305 & .310 \\
\hline & $E$ & $21: 02$ & “ & 10.9 & 0.89 & .311 & .267 \\
\hline \multirow[t]{2}{*}{$6-10$} & $S$ & $20: 49$ & Twilight & 81.5 & 5.52 & .271 & .277 \\
\hline & $E$ & $21: 02$ & “ & 11.1 & 0.91 & .278 & .261 \\
\hline \multirow[t]{2}{*}{$6-7$} & $S$ & $21: 02$ & Night & 4.80 & 0.37 & .344 & .346 \\
\hline & $E$ & $22: 07$ & “ & 2.32 & 0.28 & .375 & .288 \\
\hline
\end{tabular}




\section{VITA}

\section{Christi J. Adams}

Christi J. Adams was born on May 30, 1967. She received a B.S. in Industrial Engineering and Operations Research from Virginia Polytechnic Institute and State University (Virginia Tech) in Blacksburg, VA in May 1989. While working as a Loss Control Engineer for a major insurance carrier, she gained a broad background in safety engineering principles. In her last years before returning to the university setting, she was involved in product design safety and worker safety consultation work for medium-sized accounts. She returned to Virginia Tech, entering the Industrial and Systems Engineering Department in the fall of 1995. At Virginia Tech, she conducted applied research in the Human Factors Center's Displays and Controls Laboratory. The research concerned an observational analysis of human walking behavior aimed at developing engineering design principles for reducing the likelihood of navigational errors resulting in injury. Christi completed her studies under the guidance of Robert J. Beaton and received her M.S. in the summer of 1997. 